Ampelis cedrorun, (Vriellot).

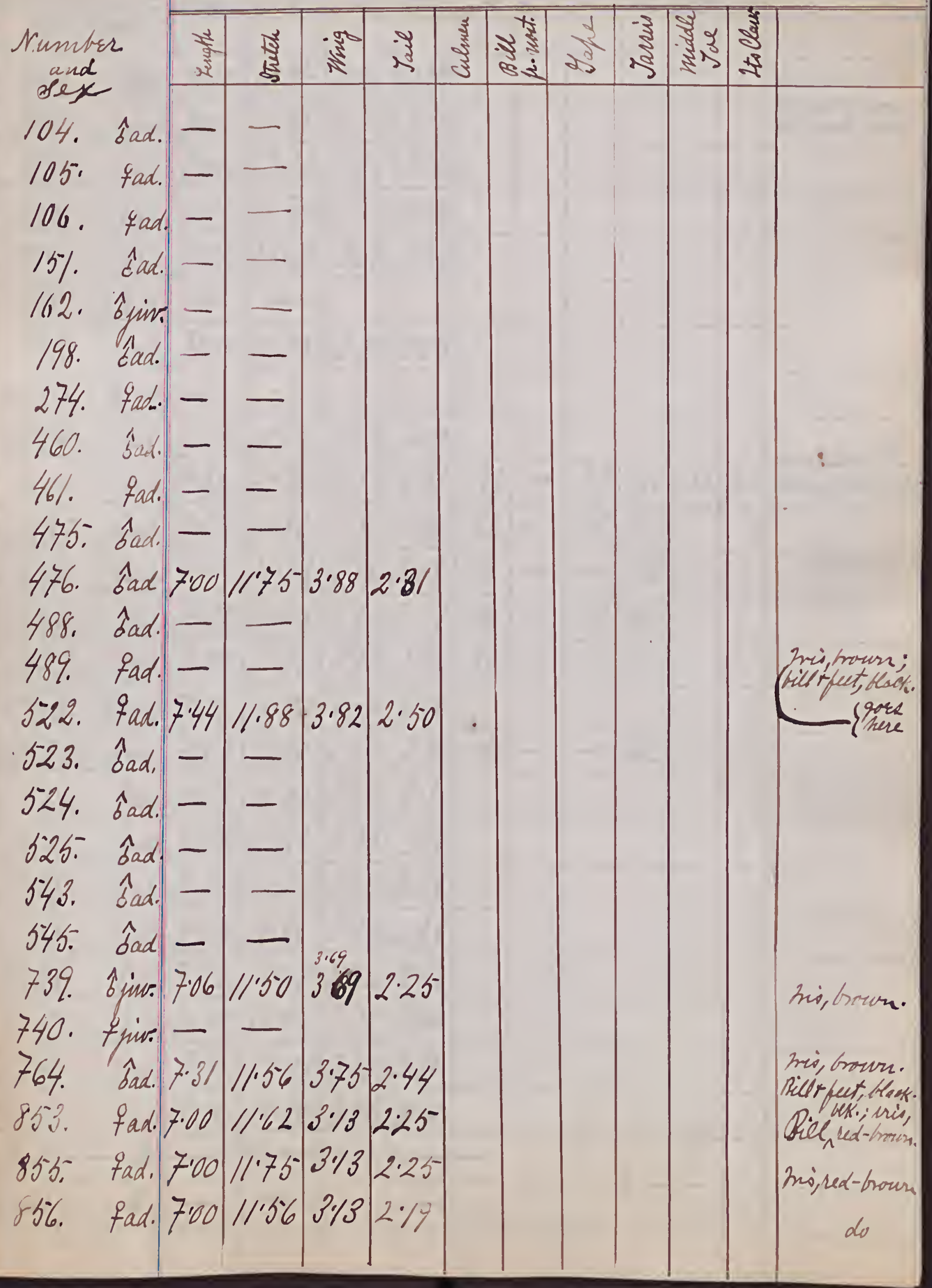


Ampelis cedrorum, (Vieillot). [2]

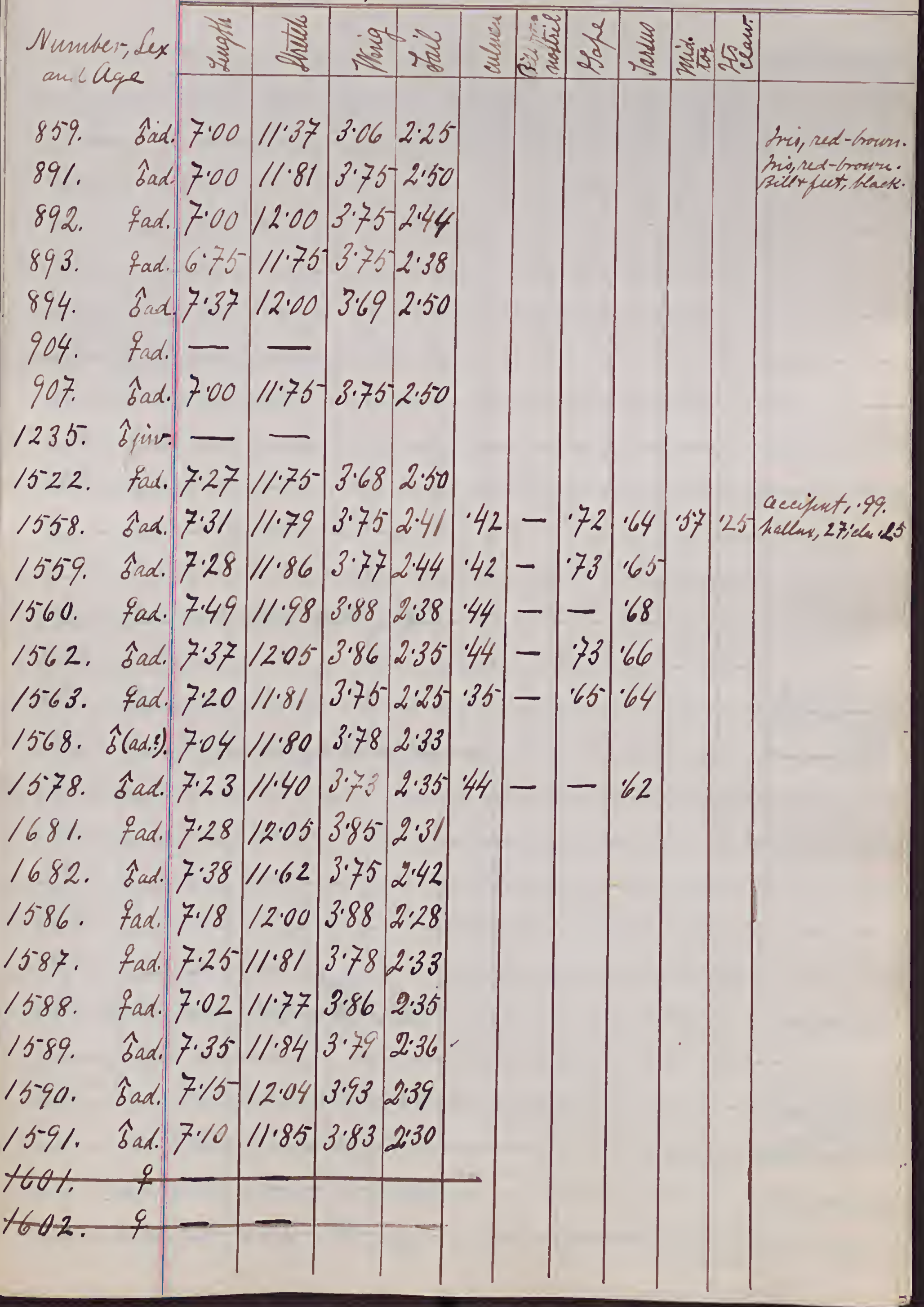


Ampelis cedromm, (Vreullot). [3]

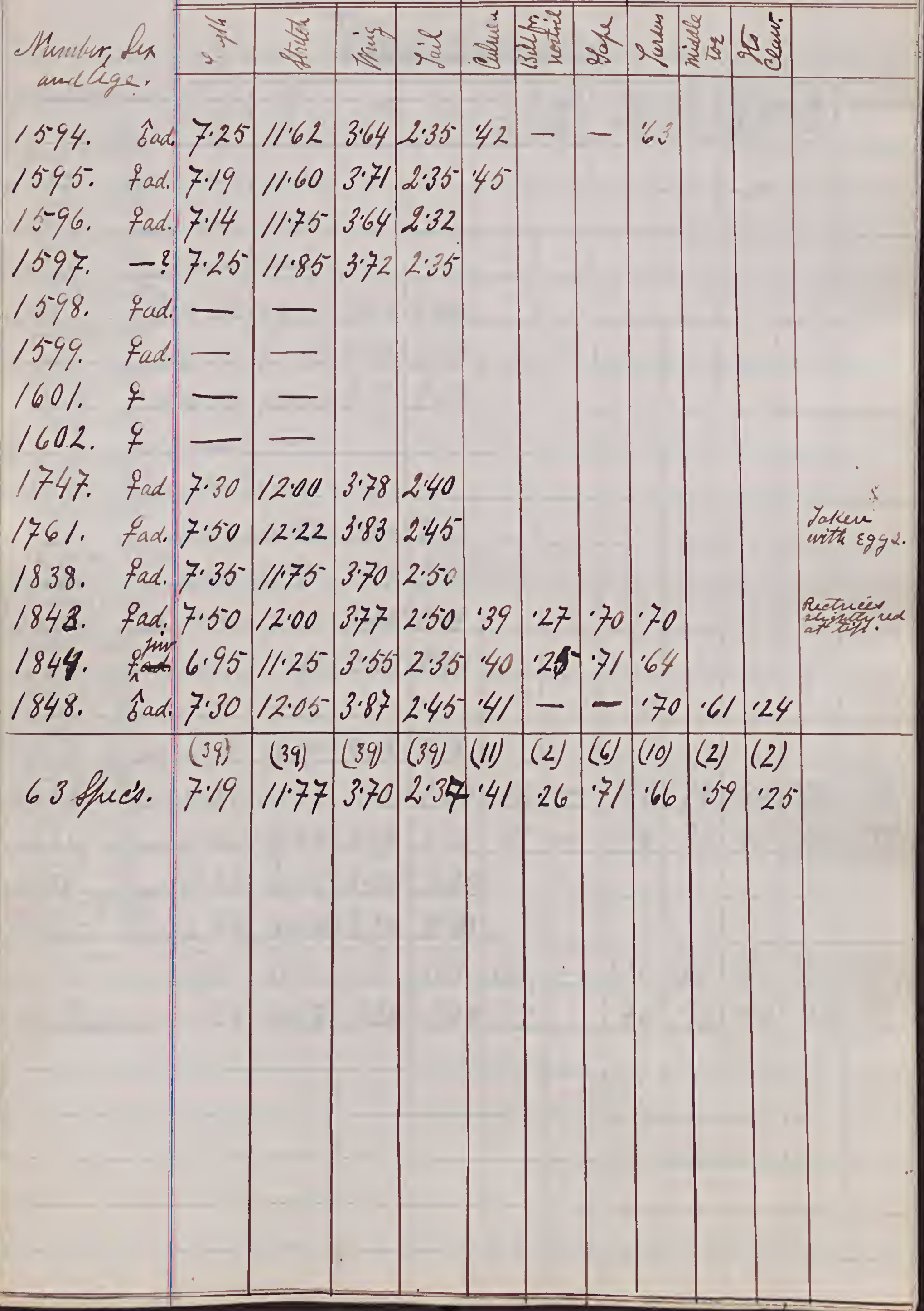


Viriv gilve.

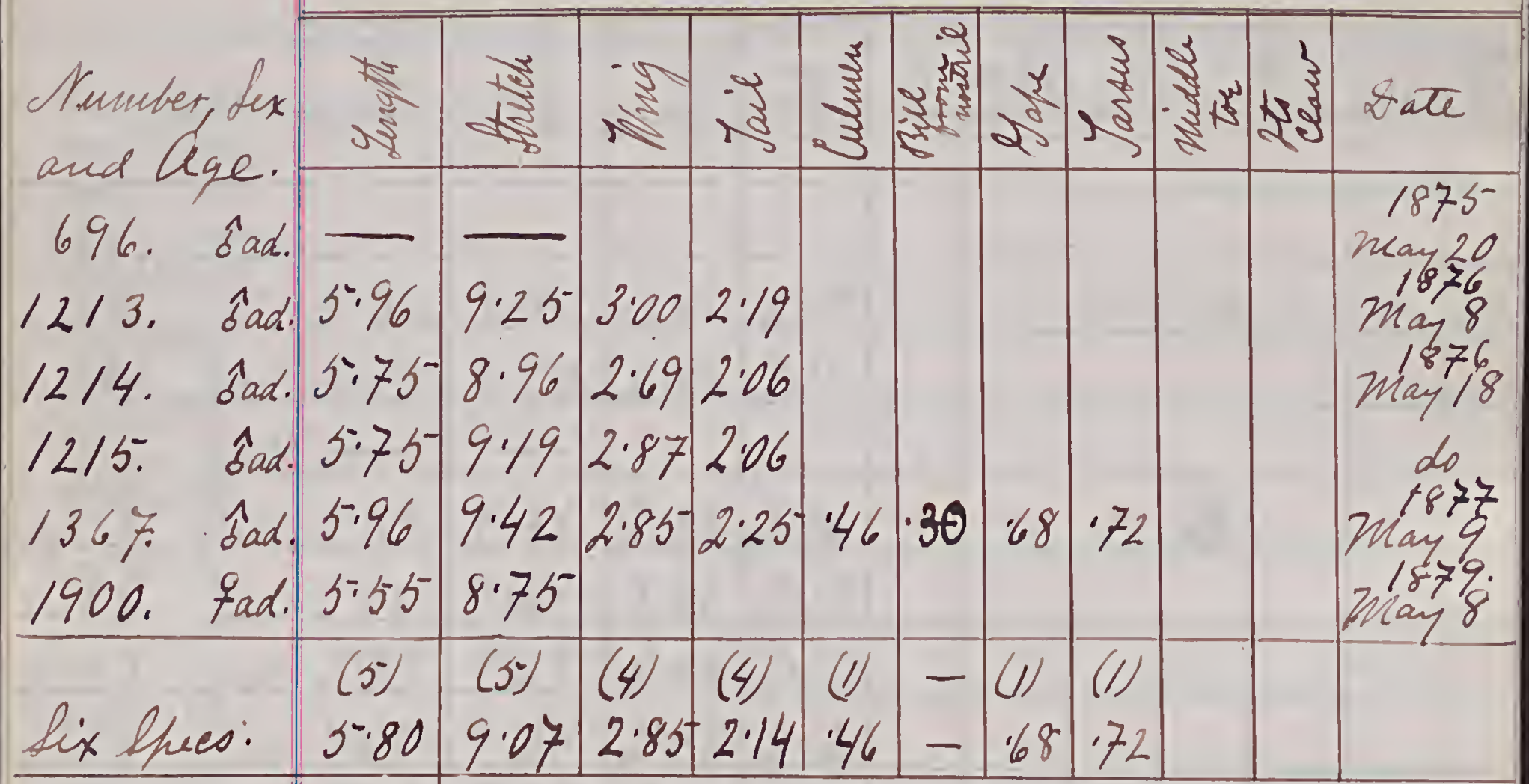

Vireo Alavitrous.

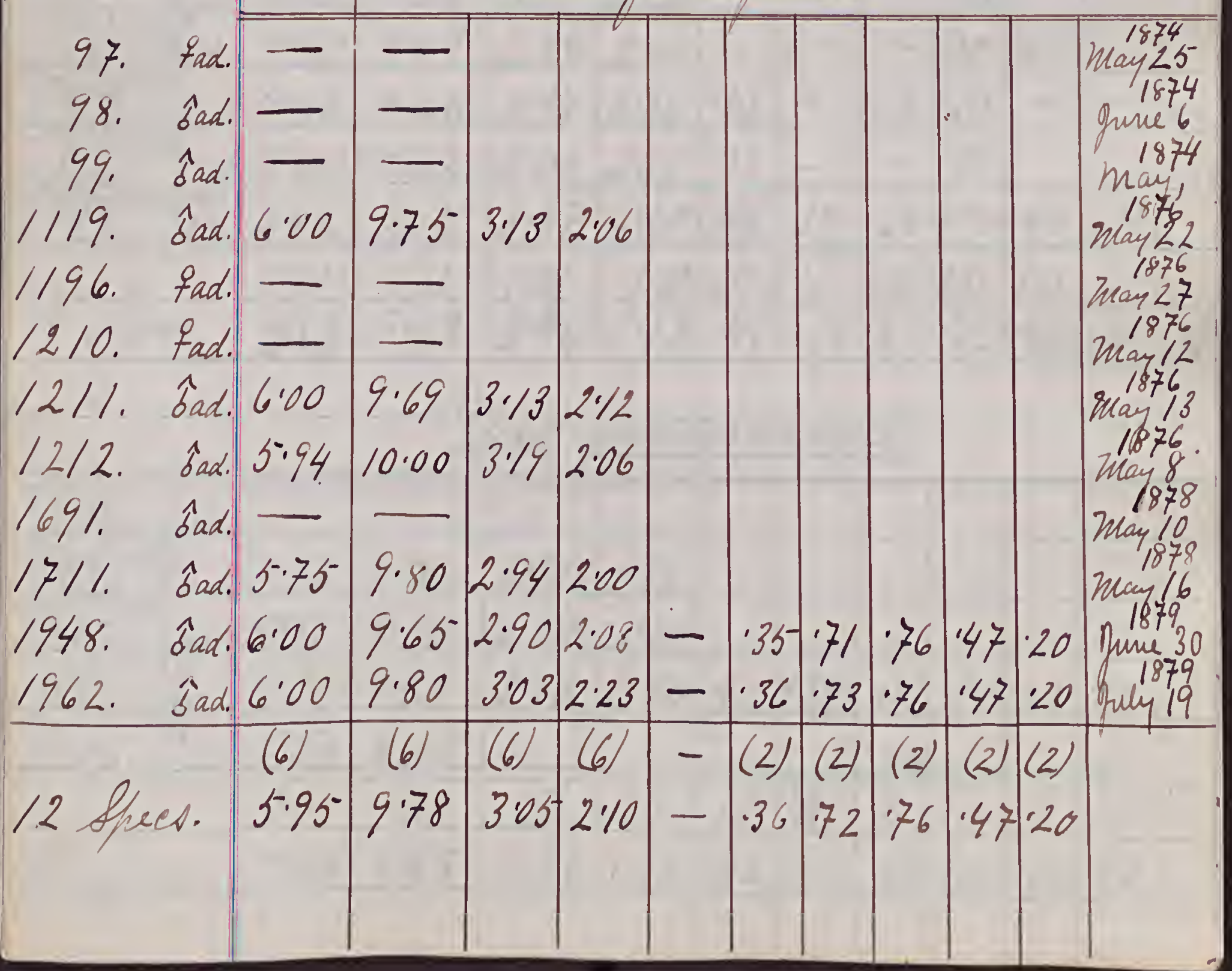


Ynio solitarius

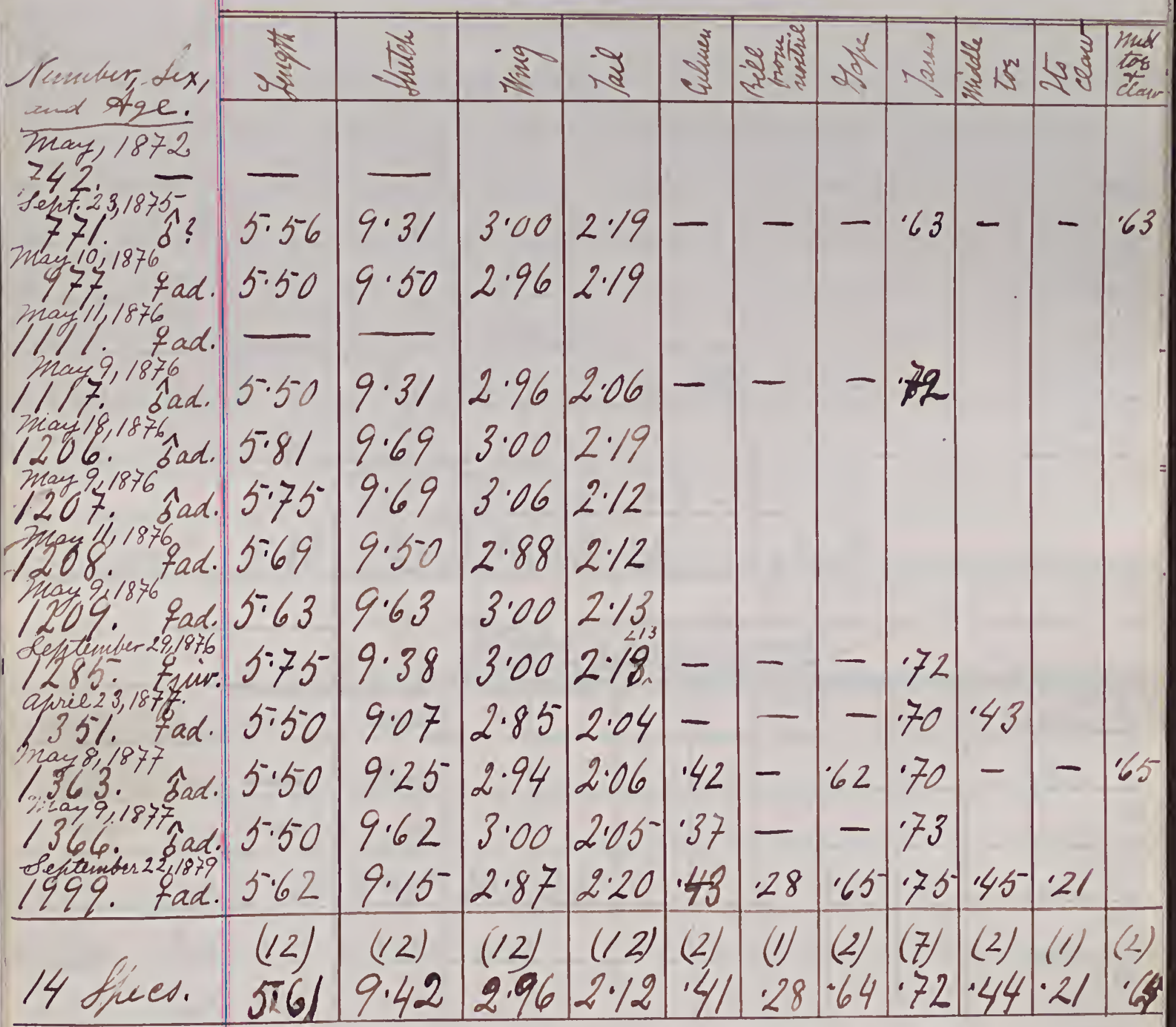

Merio novbovacenais.

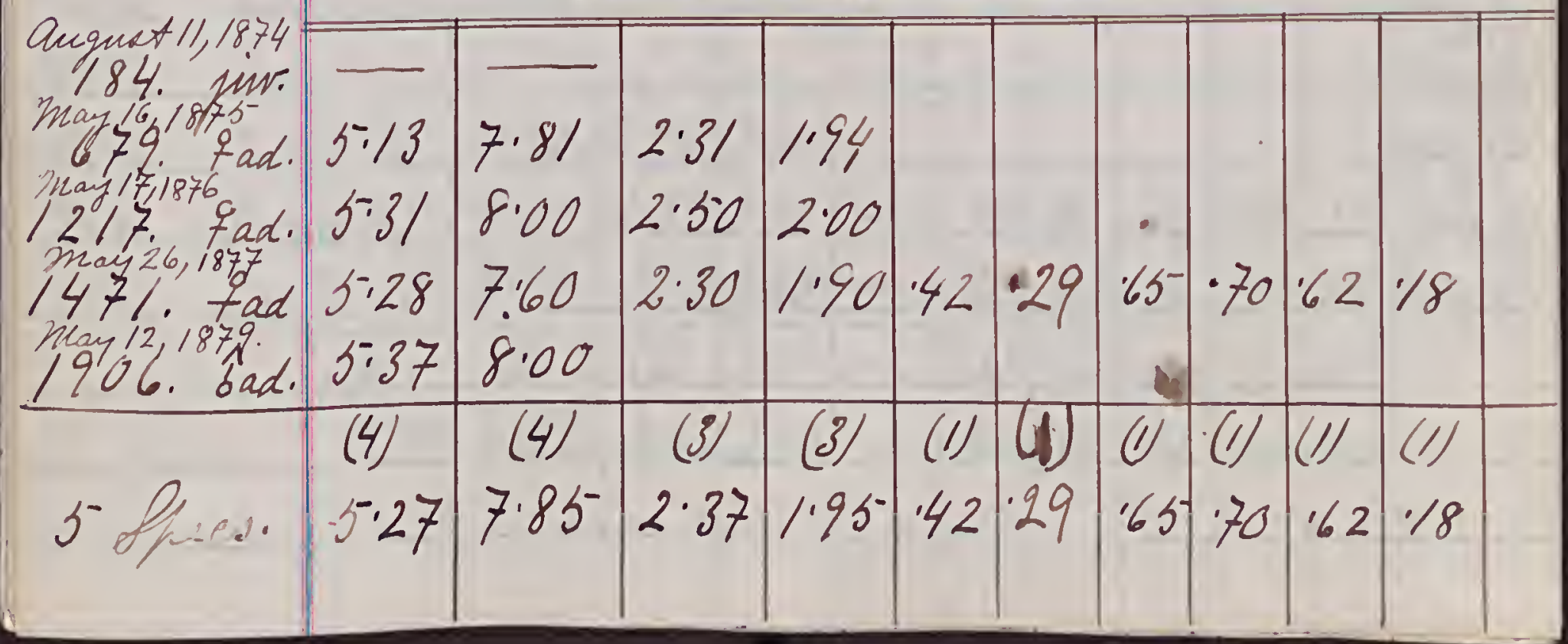


Lanius borealis.

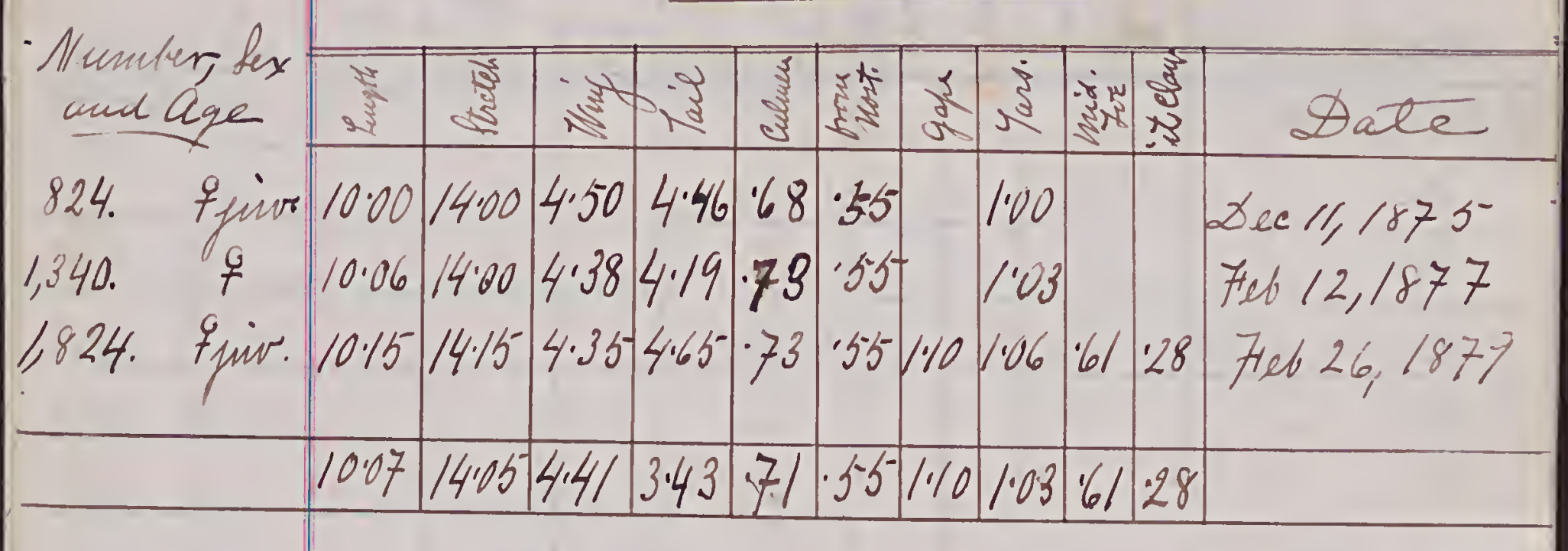

Pinicola enucleator.

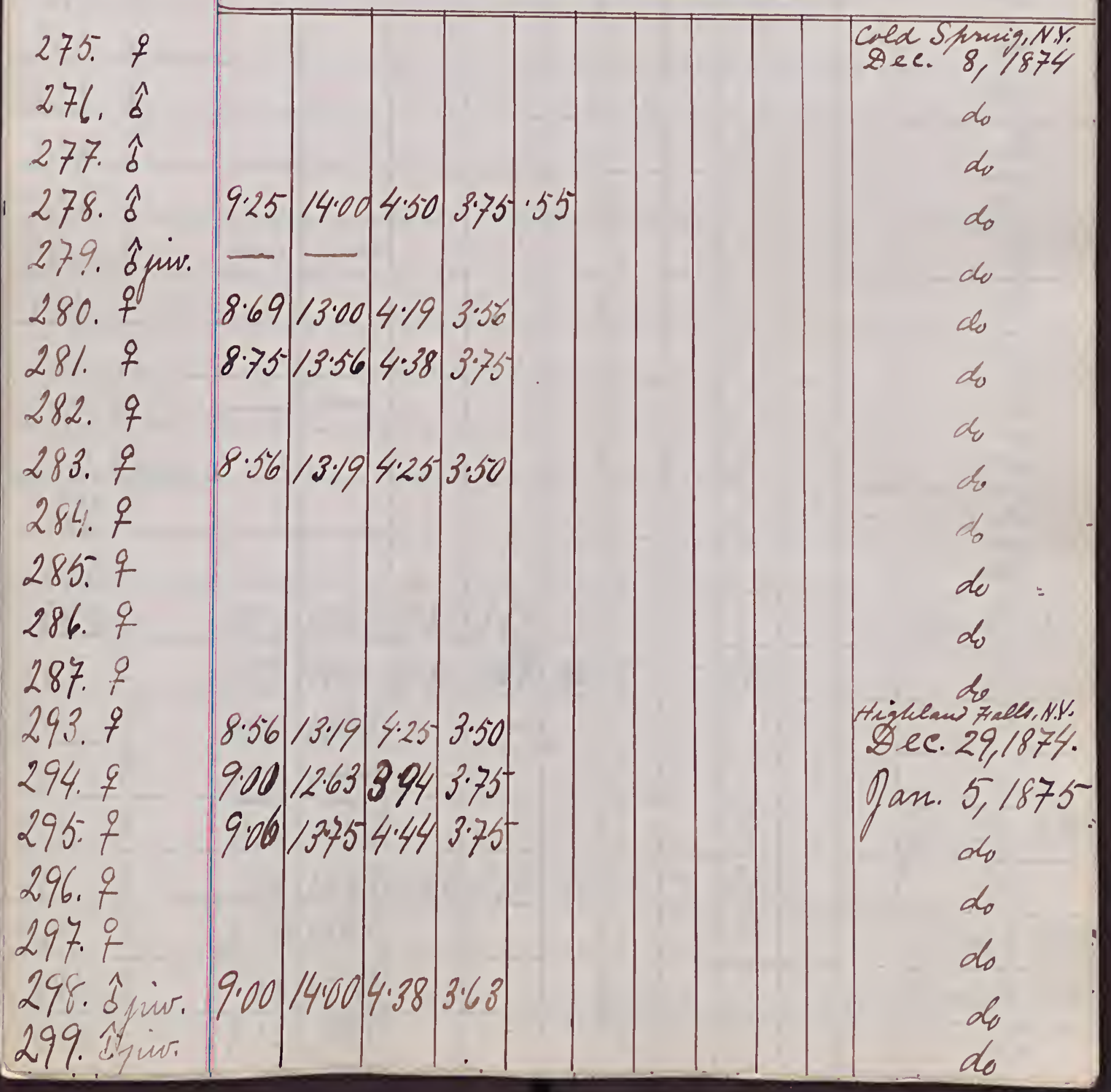


Pinicola enucleator:

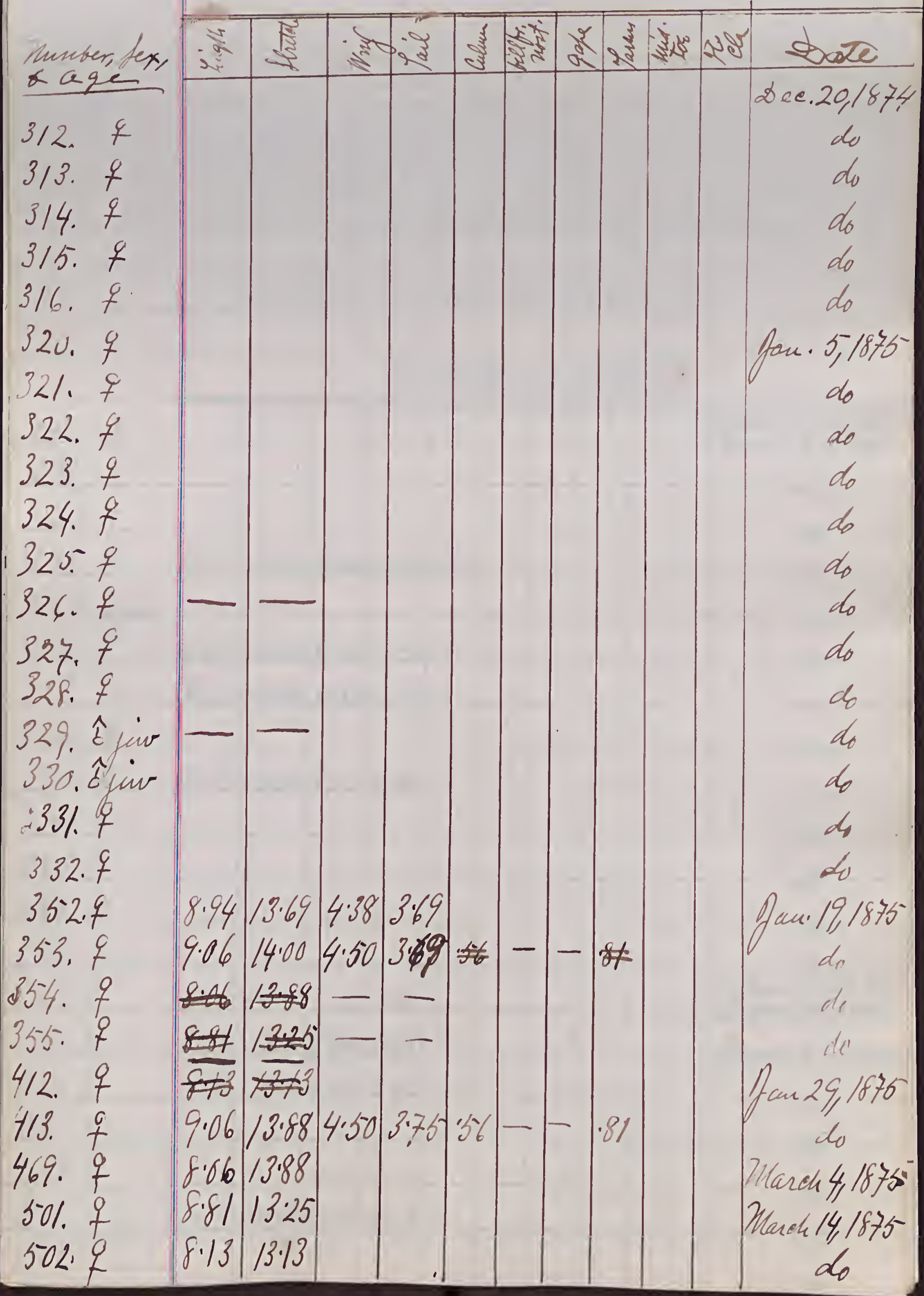


Pinicola enucleator.

(mrasurements:)

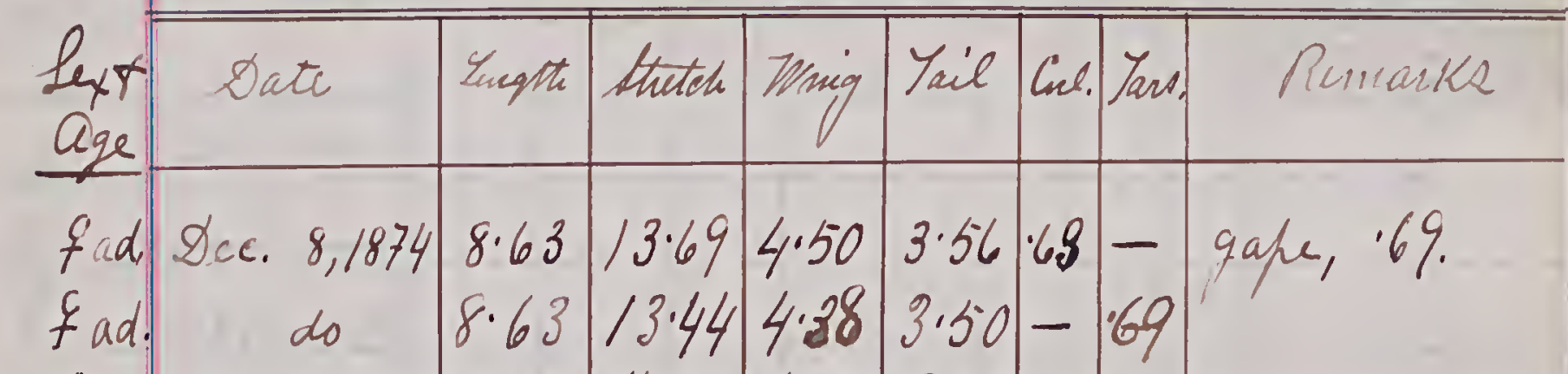

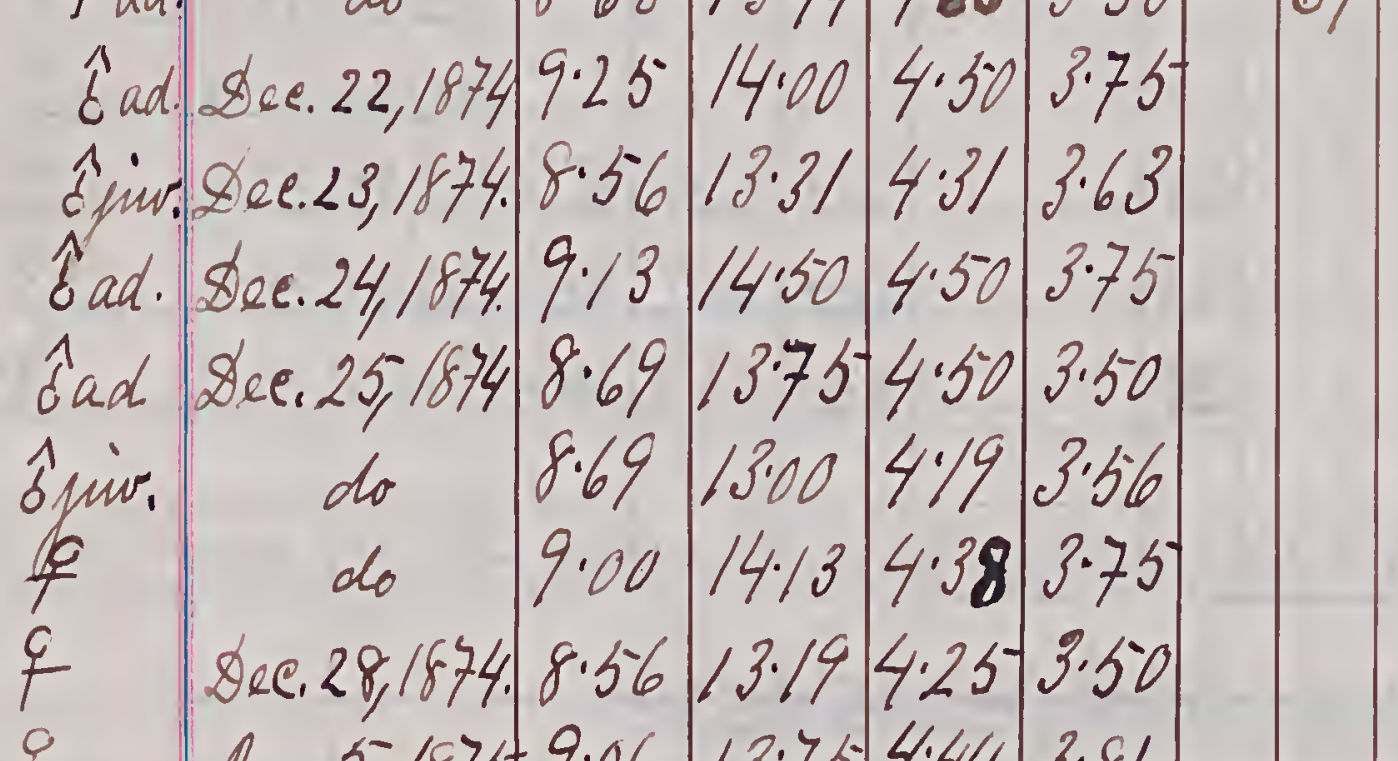

$7 \quad \tan .5,187599.06 \quad 13.754 .44 \quad 3.81$

$\begin{array}{lllllllll}q & d o & 9.00 & 12.63 & 3.94 & 3.75\end{array}$

ágir.

\begin{tabular}{ll|l|l|l|l|l|l|l|l|l|l|l} 
do & 9.00 & 14.00 & 4.38 & 3.63 \\
do & 8.63 & 13.44 & 4.25 & 3.63
\end{tabular}

do $\quad 8.75013 .06 \quad 4.2503 .56$

\begin{tabular}{l|l|l|l|l|l|l|} 
do & 9.13 & 13.50 & 4.31 & 3.63 \\
do & 9.19 & 13.50 & 4.31 & 3.63
\end{tabular}

do $\quad 8.94 / 3.7504 .503 .63$

\begin{tabular}{c|c|c|c|c|c|c|}
$q$ & Jan.19,1875 & 9.06 & 14.00 & 4.50 & 3.69 \\
$q$ & do & 8.94 & 13.69 & 4.38 & 3.69
\end{tabular}

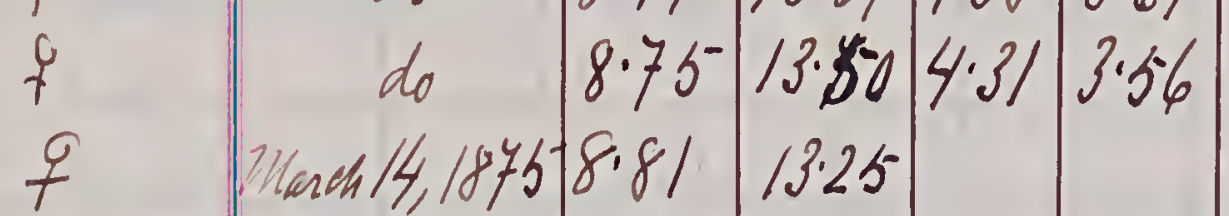

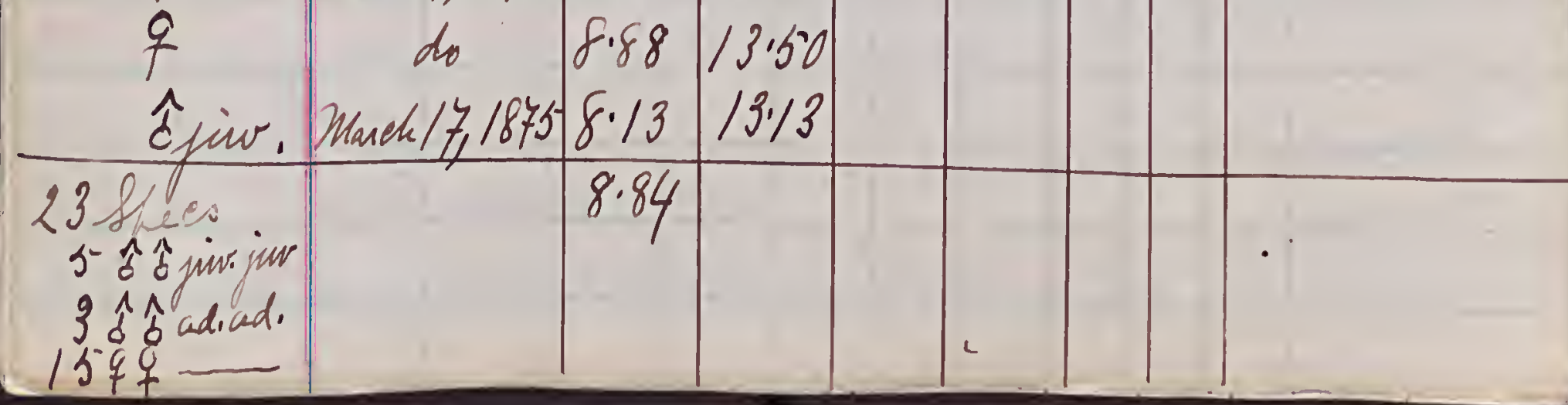


Pinicola snucleator.

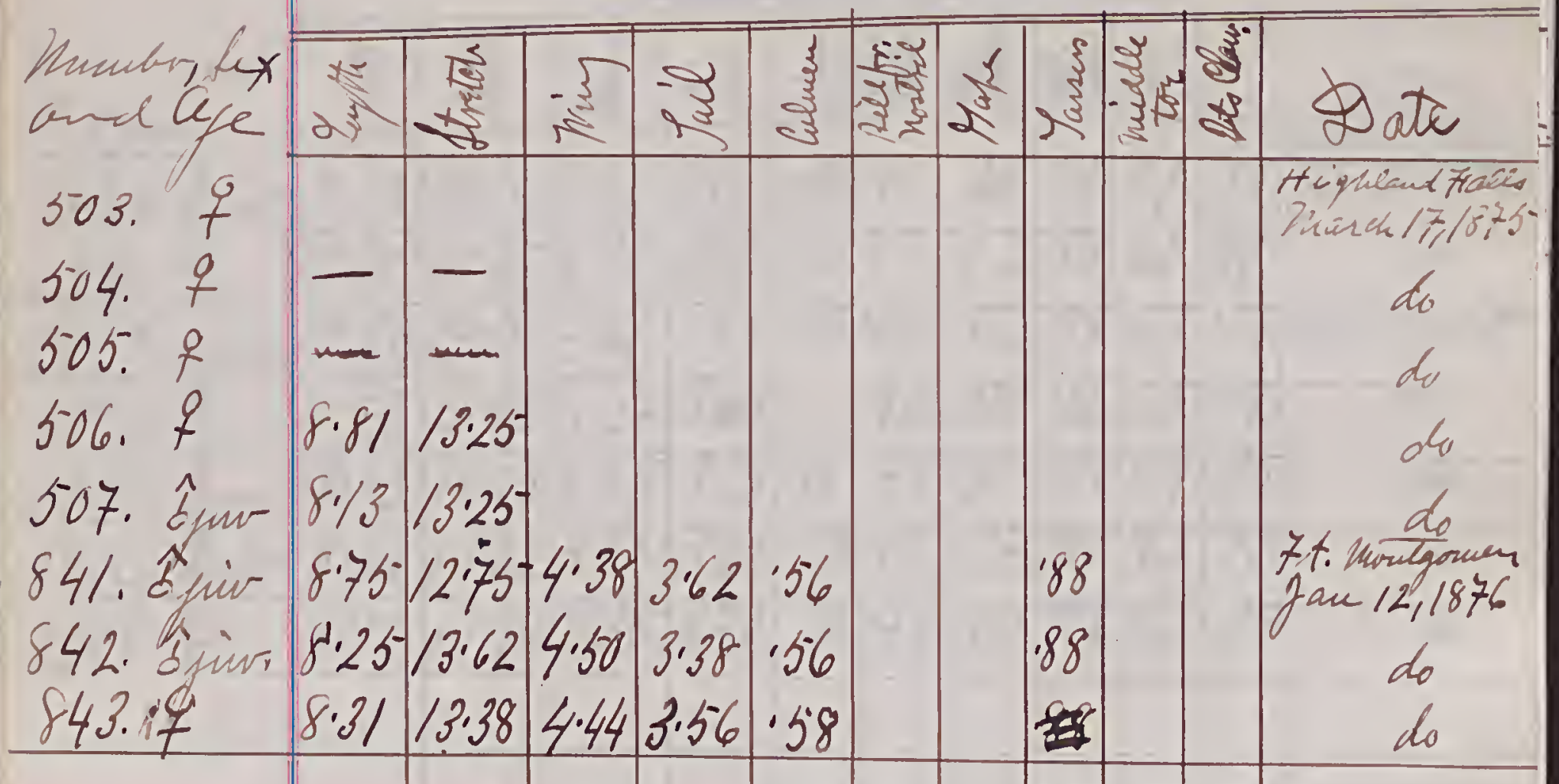

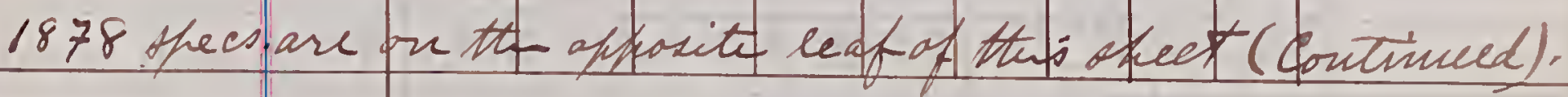

Carpodacus purpureus.

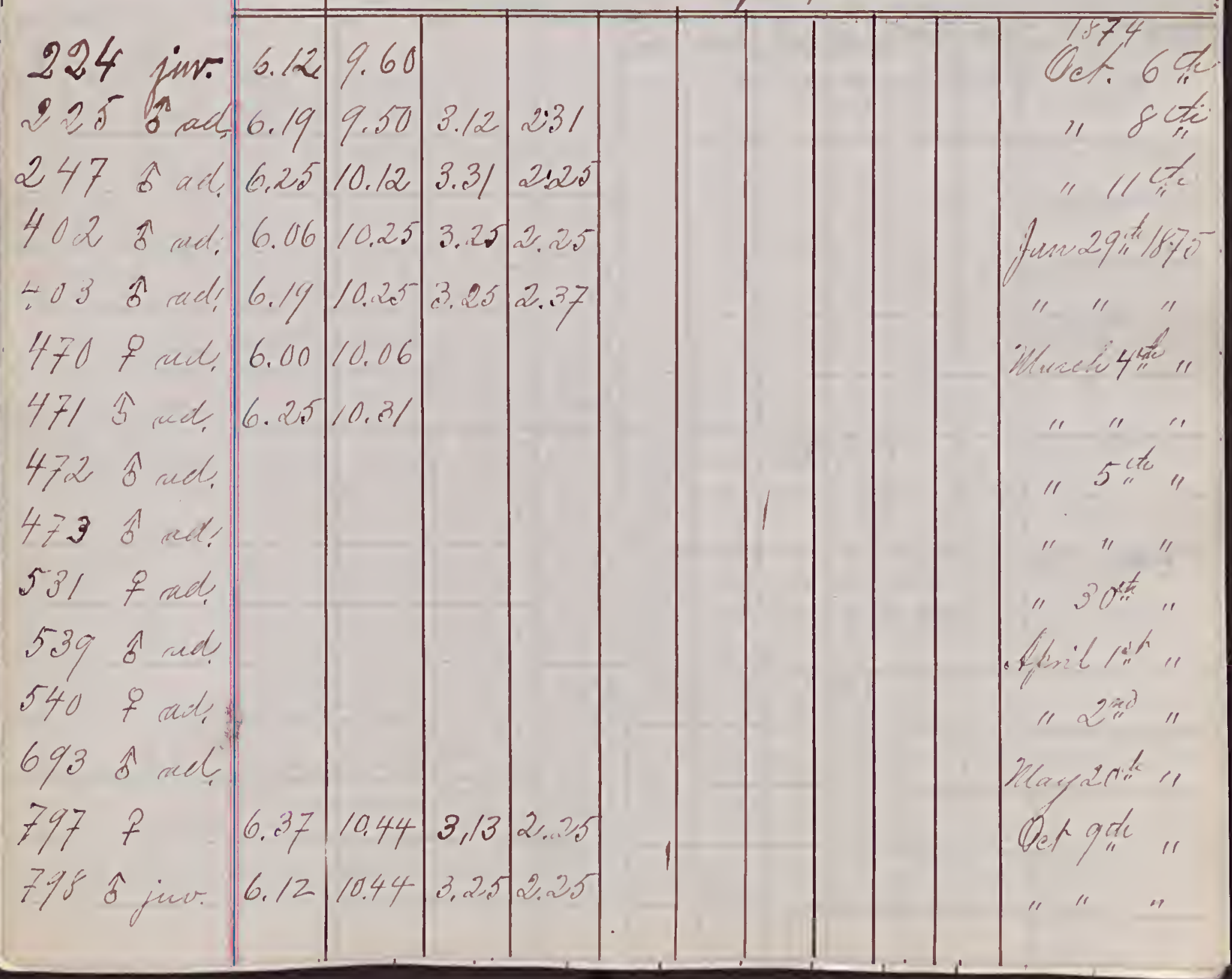




\section{Pinicola smicleator.}

thenture, tex

F ape

1,795:-3inu

1796.8

179\%.

1798.9

1799. $\hat{\text { byin }}$

1800 . sin

1801 \&

*

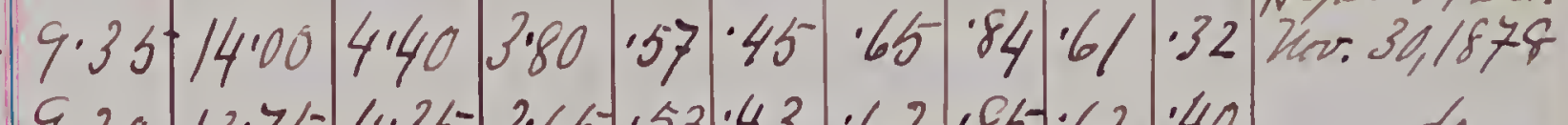
$9 \cdot 2013.7544 .35 \cdot 3.65 \cdot .53 \cdot 43 \cdot 62 \cdot 85 \cdot 62 \cdot 40$

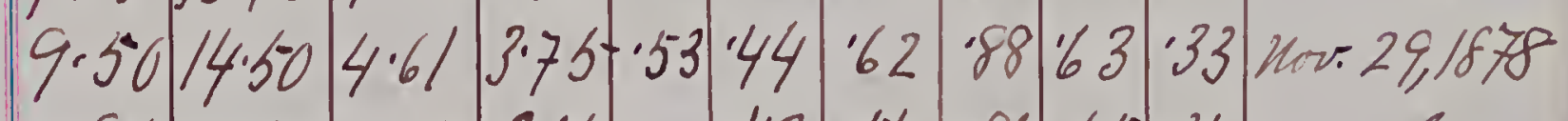

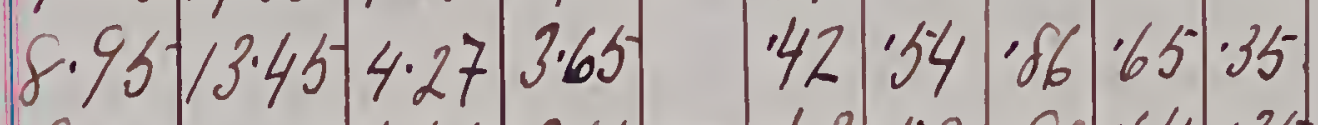
$9.0014 .054 .4533 .65 \cdot 54 \cdot 43 \cdot 58 \cdot 92164135$ do

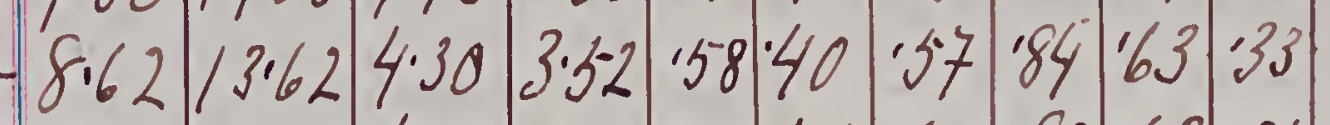
$8.90 / 3.904 .35 \quad 370 \cdot 50 \cdot 45 \cdot 60 \cdot 92 \cdot 63 \cdot 35$ do do

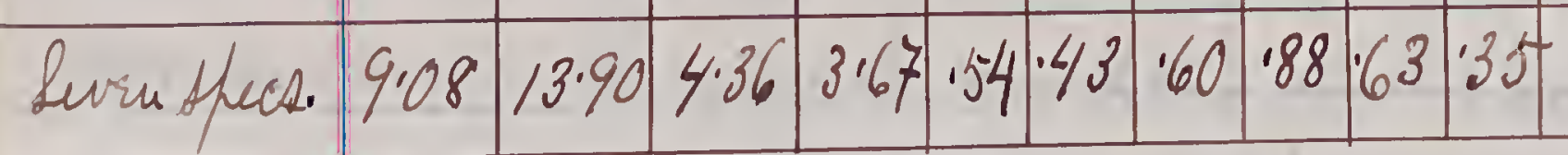

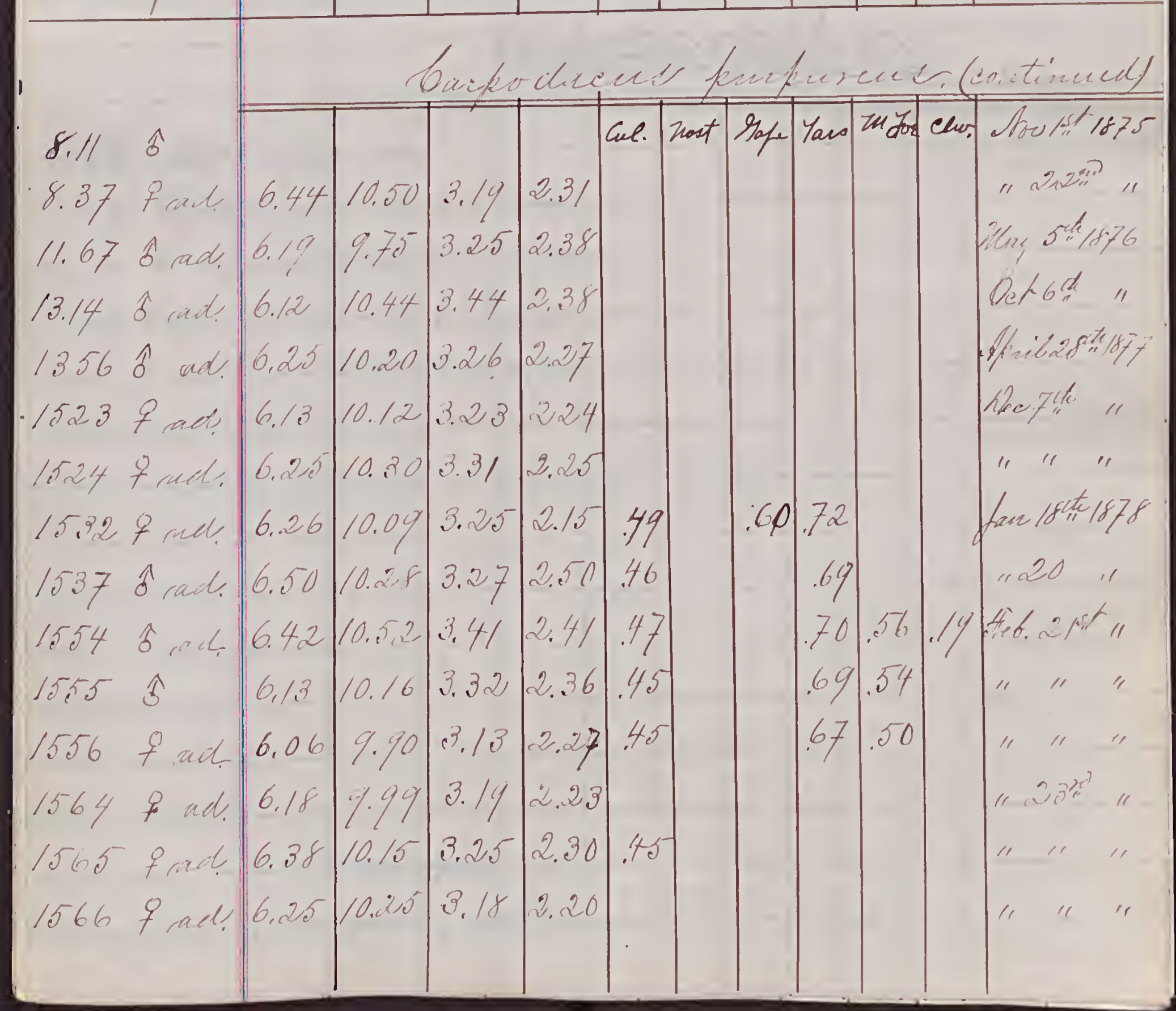




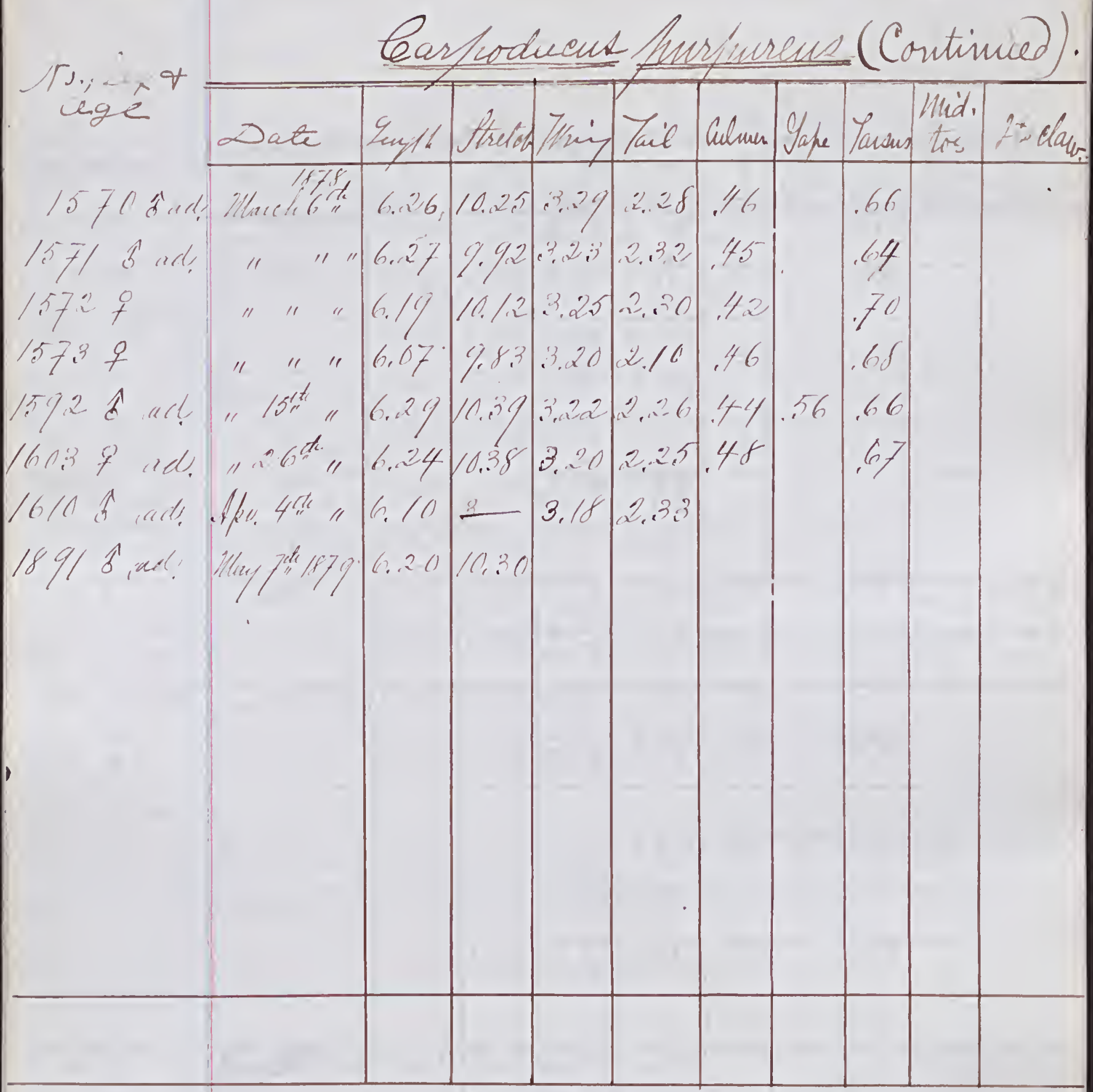

Chreomitrie trietis.

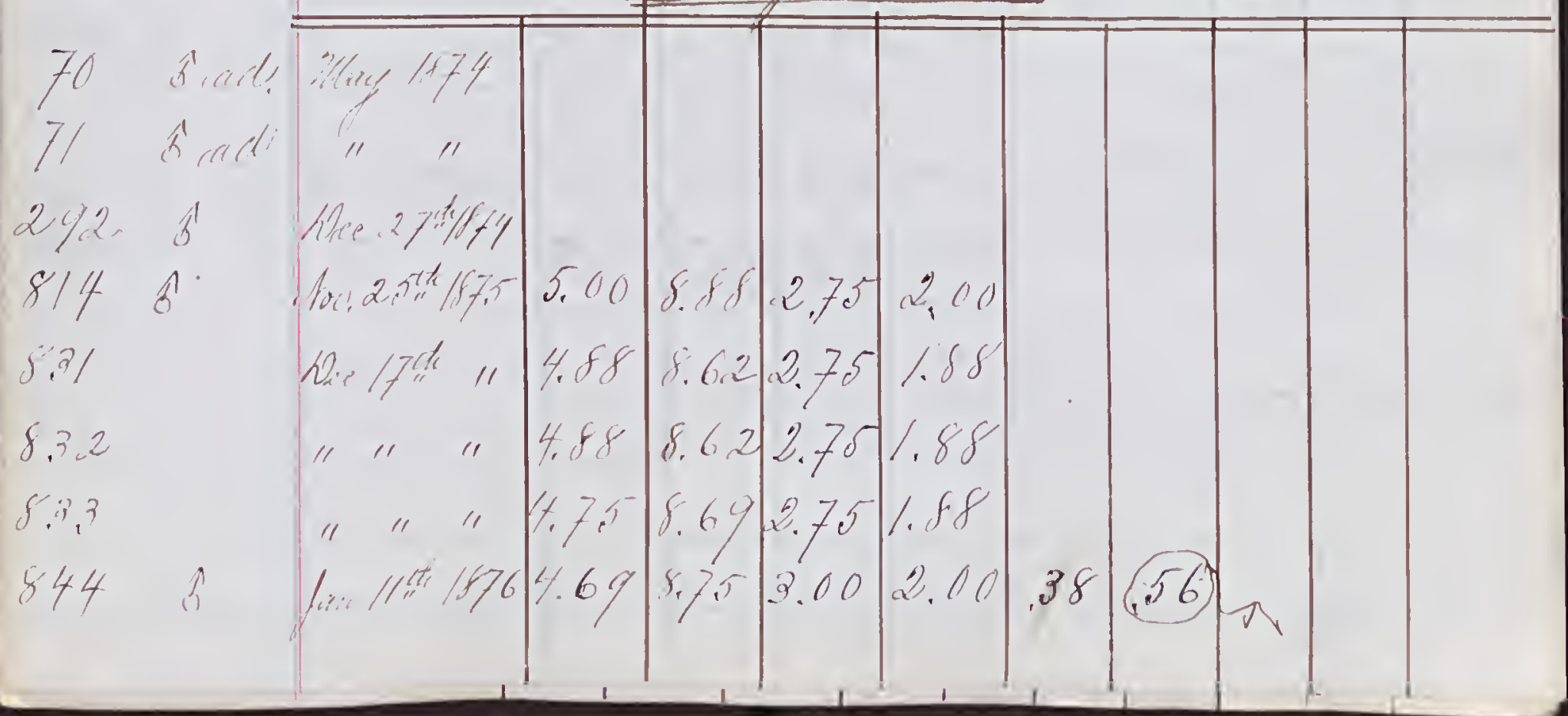




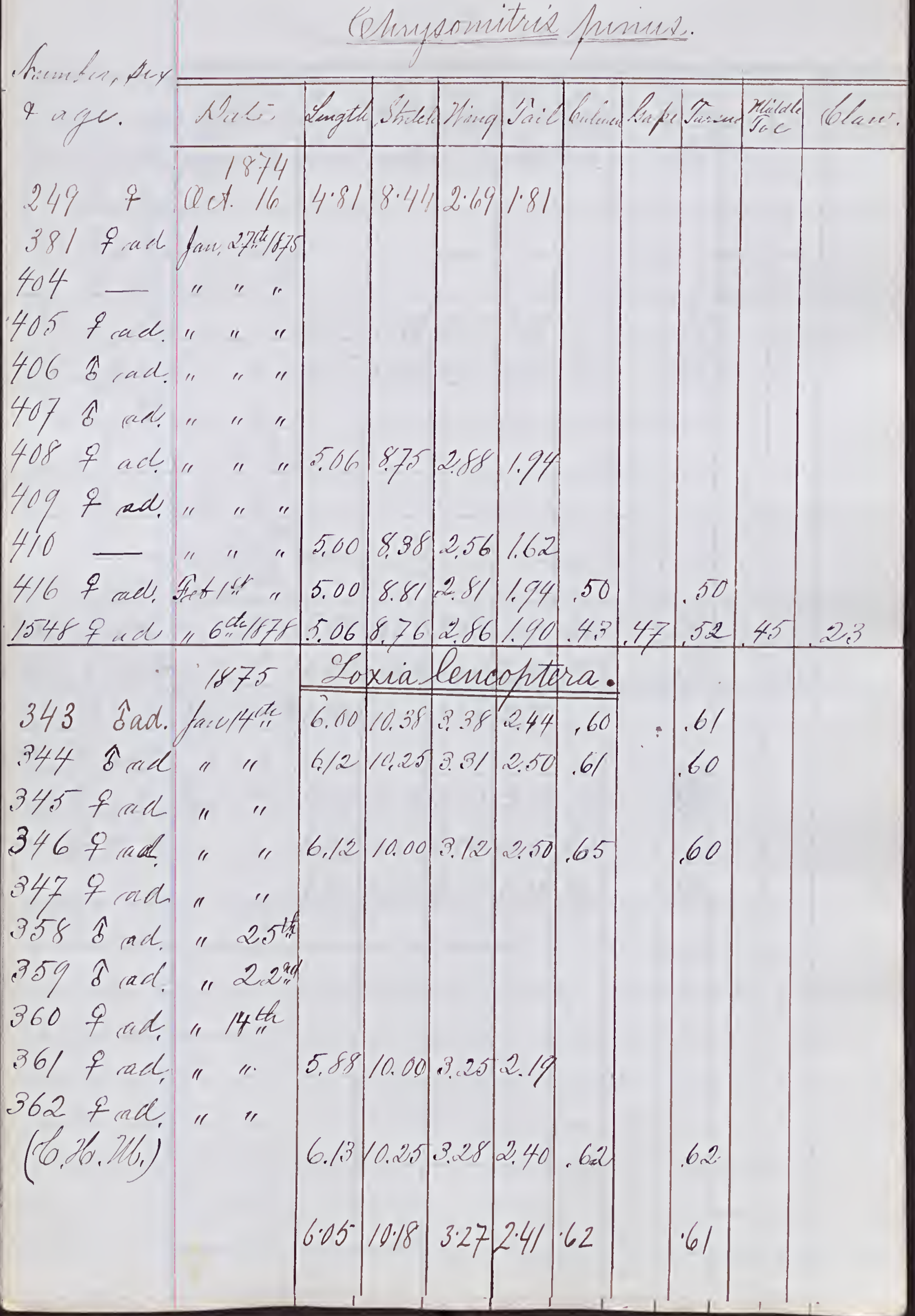


Loxia curvirostra americana.

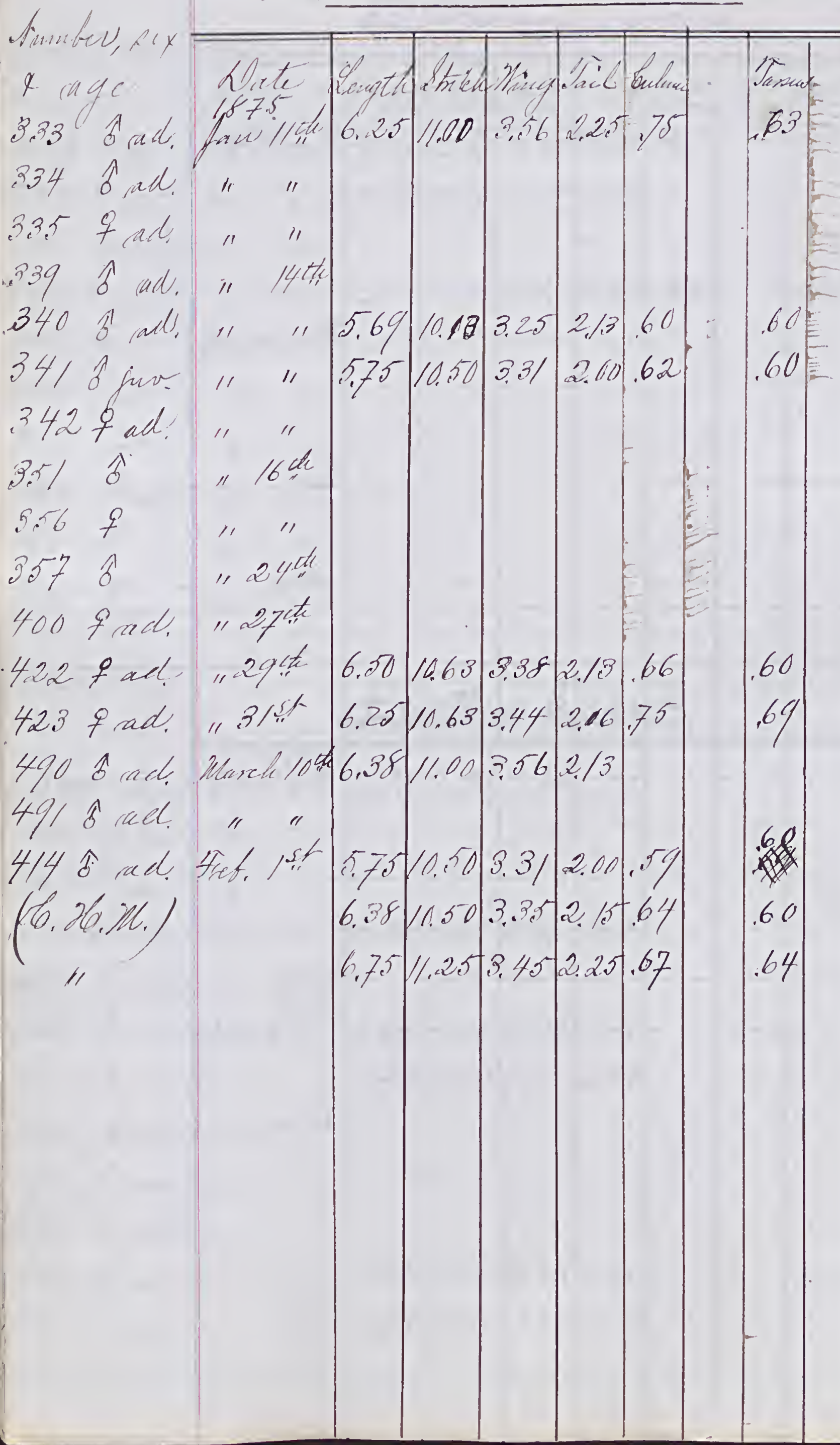


Aingoup puy

Plectrothanes mialis.

e $\pi q c$.

439 הind.

440 fad " "

$441+9 d$

$44: 2$ o racl.

481 \& Mruch sith

482

$483=11$

494 tad. " qut

496 व

500 ई

\begin{tabular}{|c|c|c|c|c|c|c|c|c|c|}
\hline hate & & & $\mathrm{H}_{1: 2}$ & & & & & & colos \\
\hline $07875 \mathrm{pgch}$ & 7.1 .3 & 12,81 & $4 / 3$ & 8.88 & .45 & & .8 & & \\
\hline
\end{tabular}

$6.6 .312 .13 \quad 4.1 .320 .56$ 


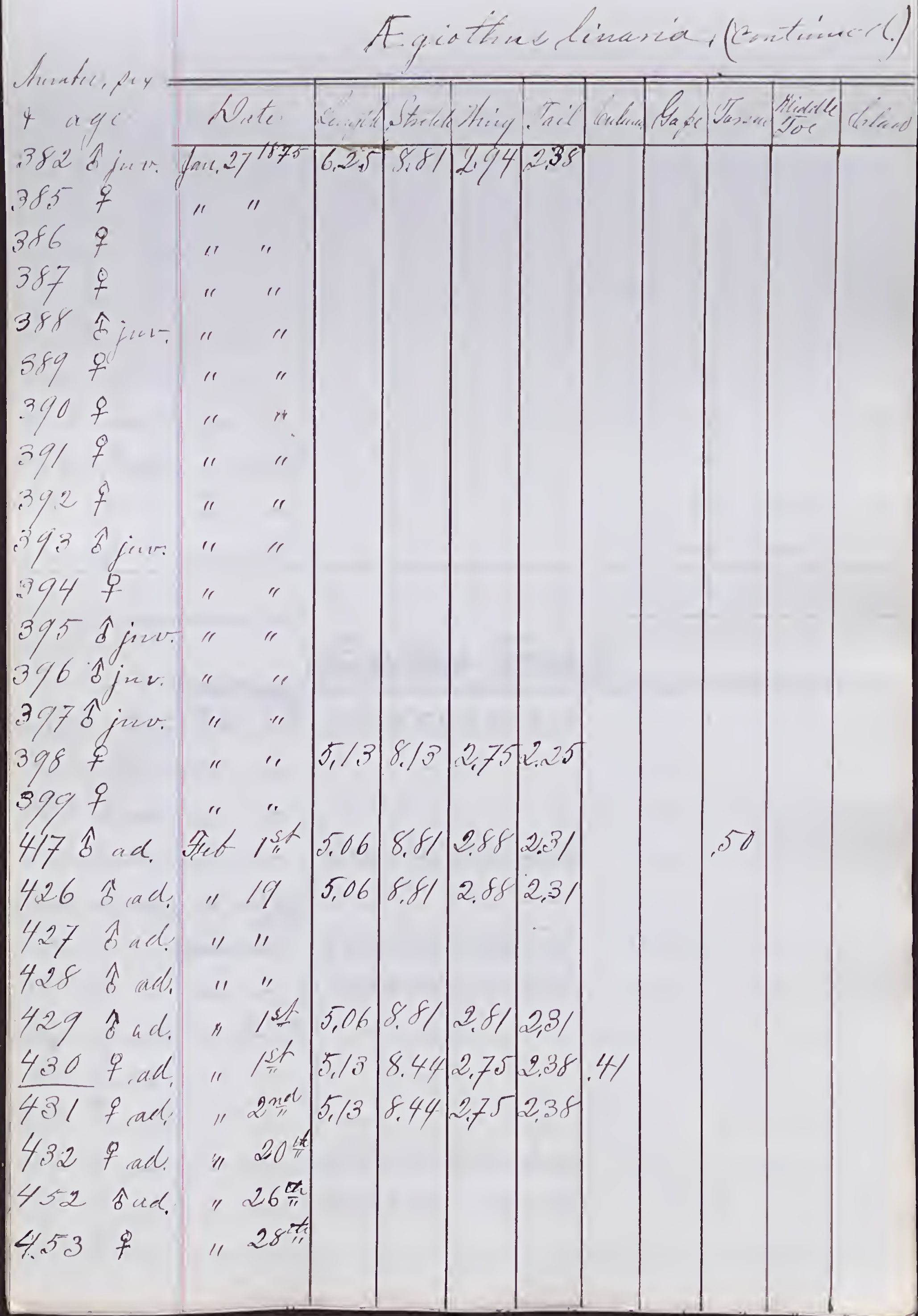




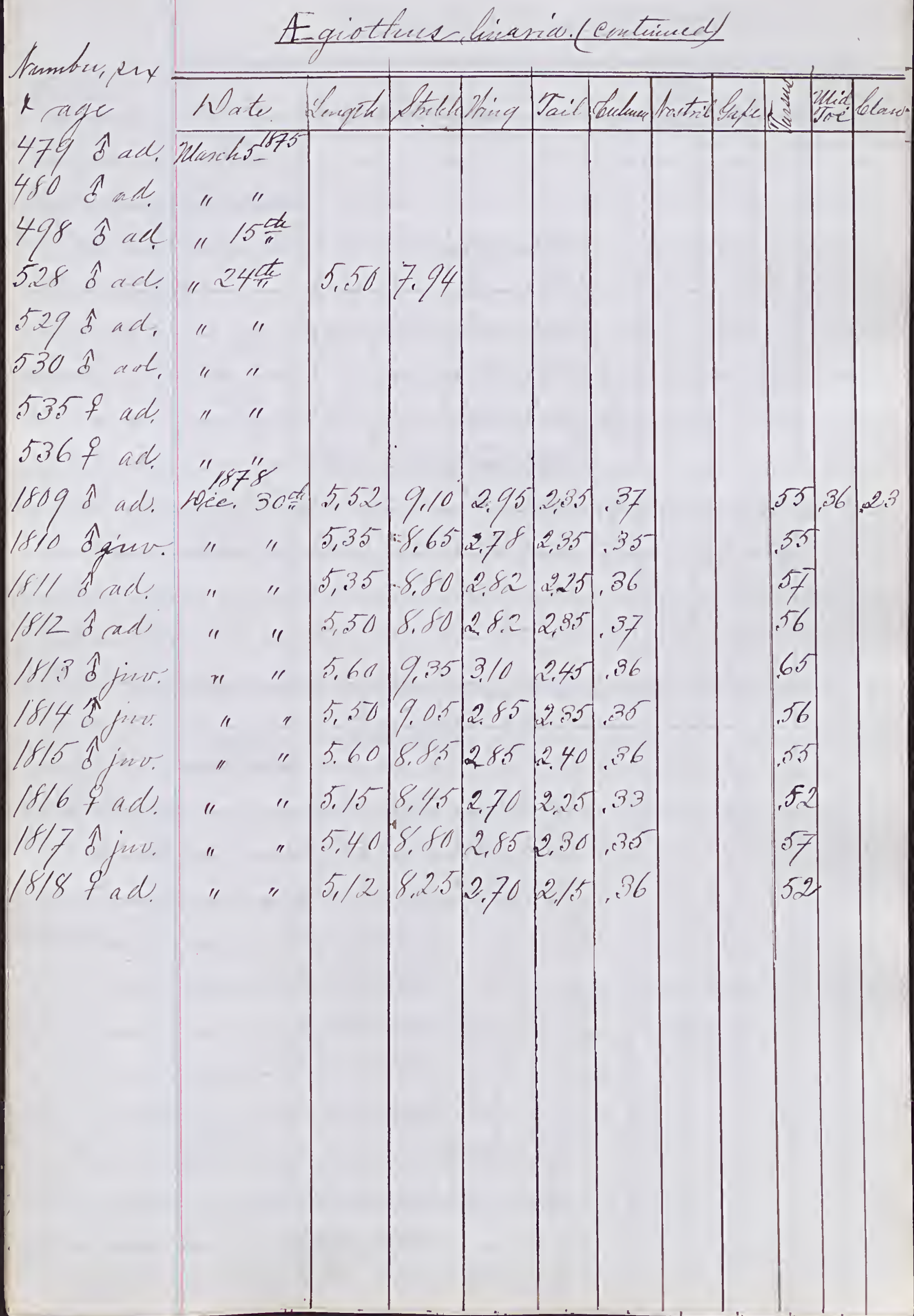


(1.)

Passerculus savamna.

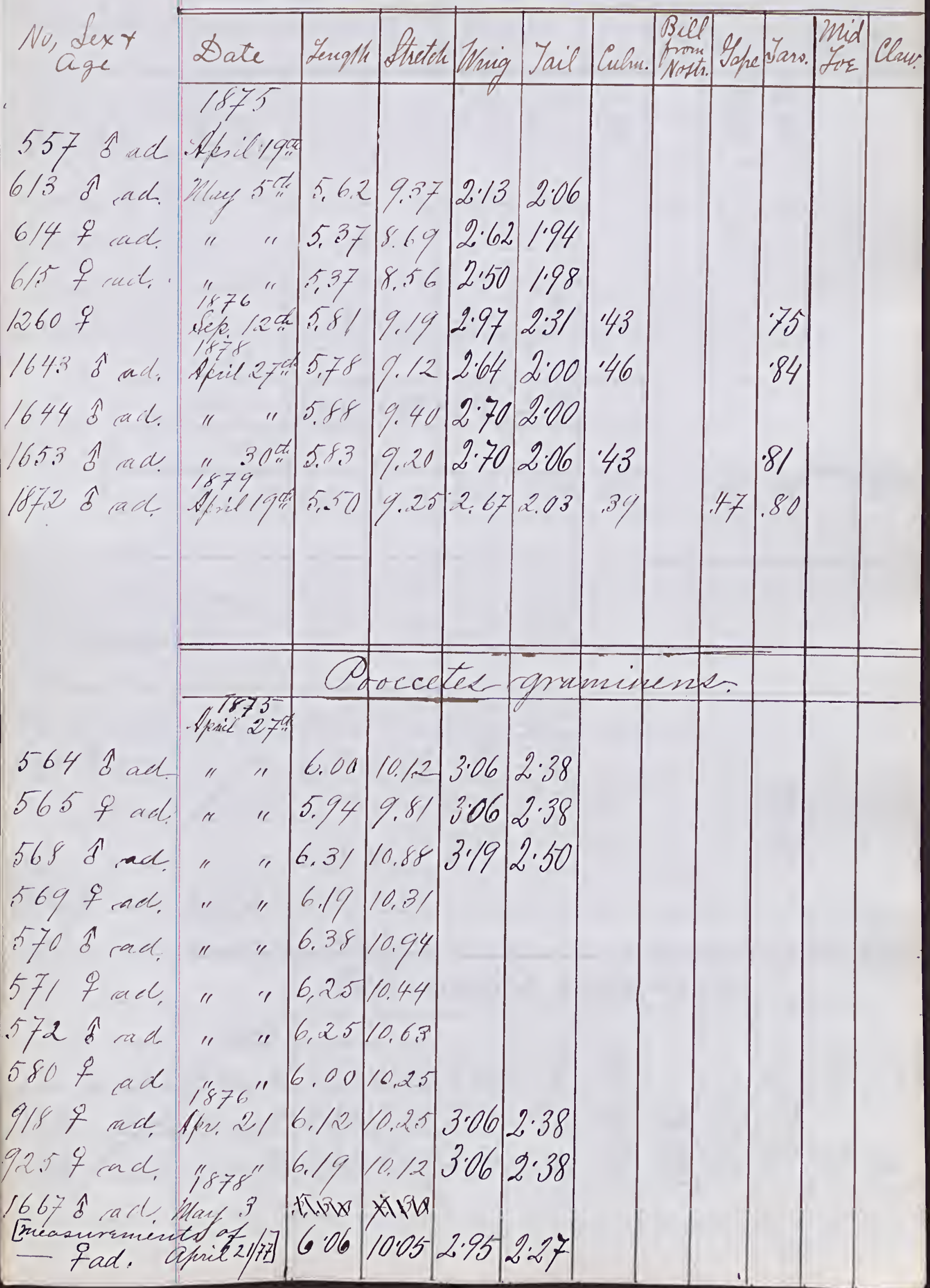


So, dey.tige

- Ammodronue caudarutuir.

246
1495979

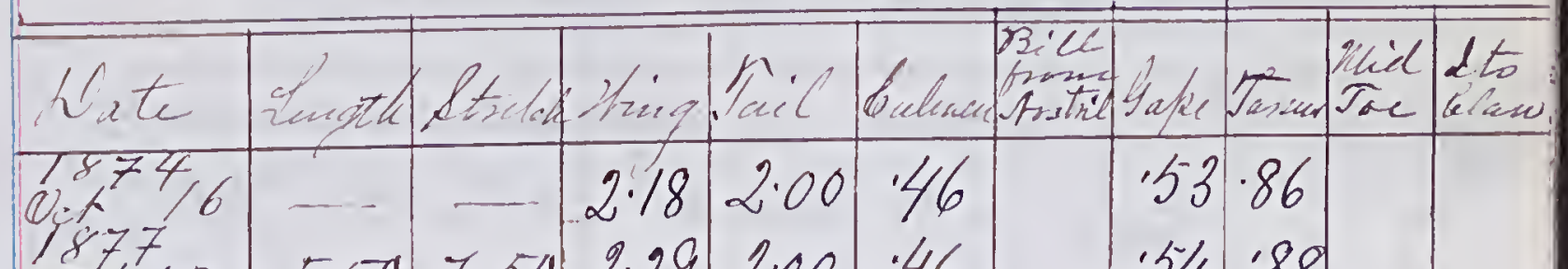

$245 q$

25251826

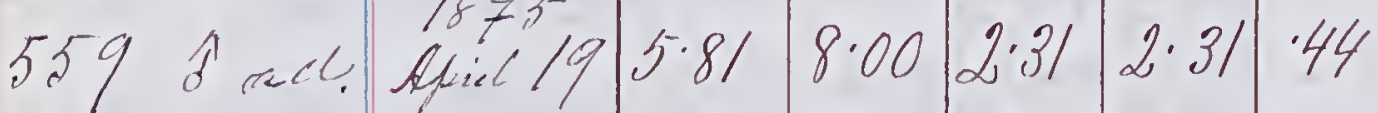

5600 ade.

561 ade.

917 o $\quad$ is 76 "

$956-125$

966.8 ad. 129

467 a ad

12937 jins.

1294 है jue.

$14.583 \mathrm{bad}$.

$16.51 \%$, ad

"

sep. 30

$5.56 \quad 7.69 \quad 2 \cdot 31 \quad 2 \cdot 31$

5.887 .942 .372 .25

"877" $6.067 .88 \quad 2 \cdot 19 \quad 2 \cdot 31 \cdot 49$

$6.06 \quad 8.312 .44 \quad 2.37$

$6.12 \quad 8.252 .44 \quad 2.37$

Nelospigat paluatsin.

1874

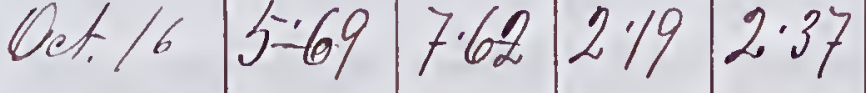

oet.12 $5.507 .502 .29200 \quad 46 \quad .54 \cdot 88$


Oonotrichia albcollien (Bmelii).

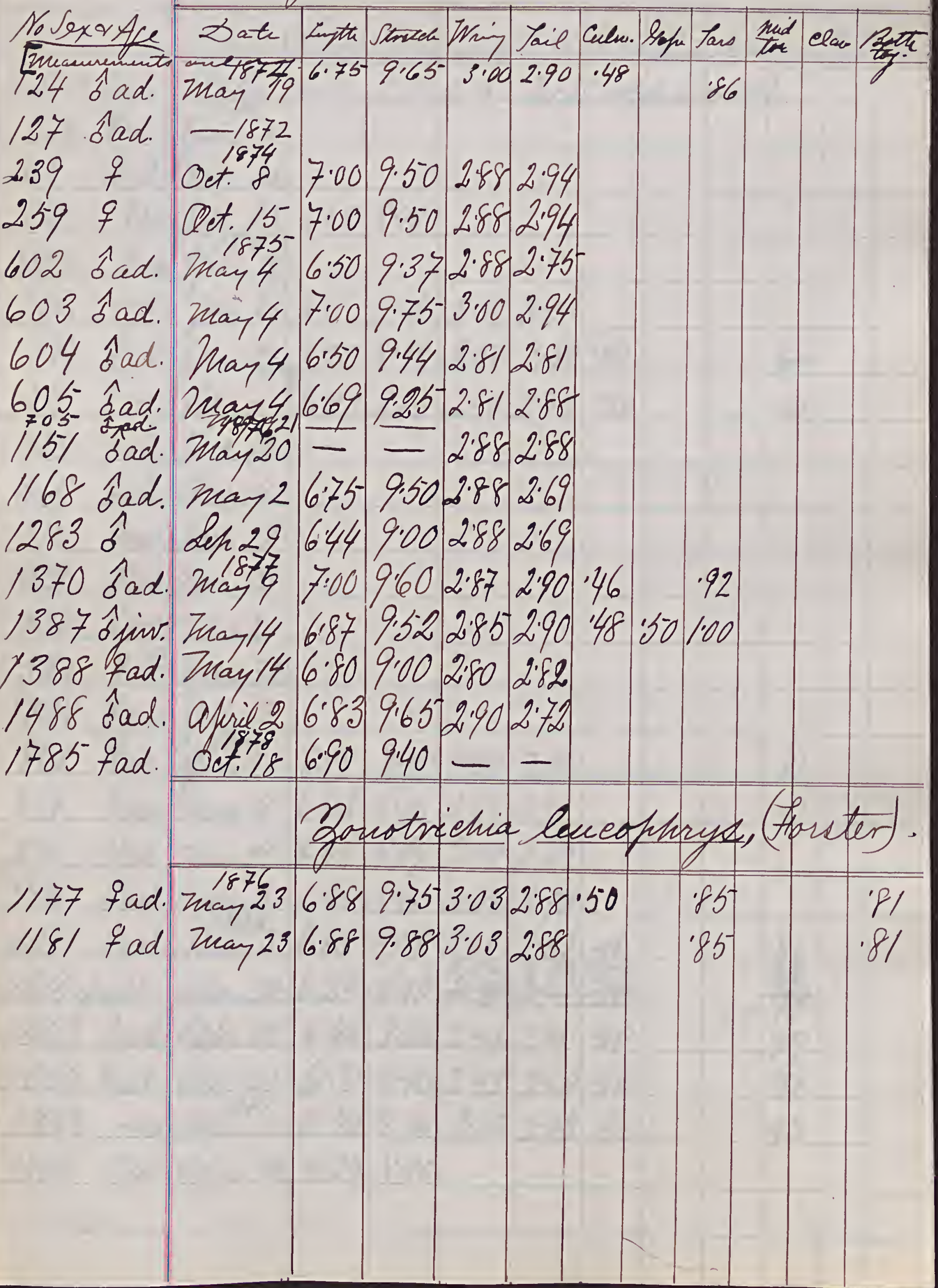


Melospiza fncladia.

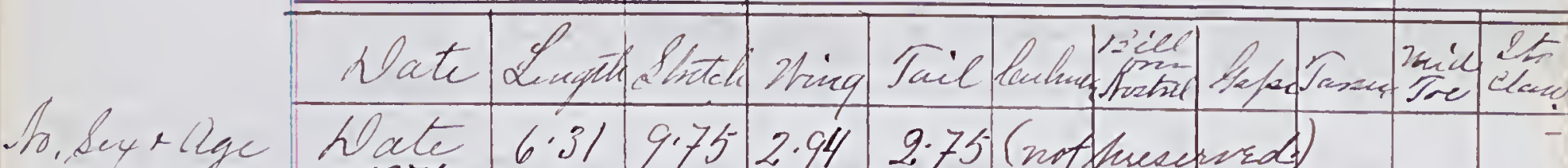

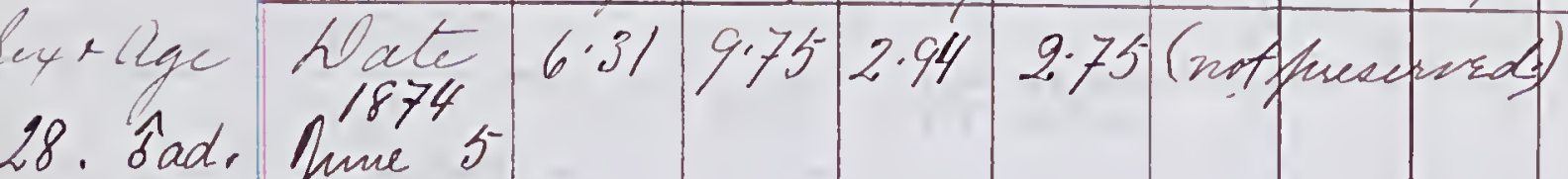

103.

210. Sad. Lepris75 2312848

349. Bade நan. 1875

\begin{tabular}{ll|l|l|l|l|l|l|l}
363. & $-? \tan 23$ & $6 \cdot 19$ & $8 \% 3$ & $2 \cdot 38$ & 2.50
\end{tabular}

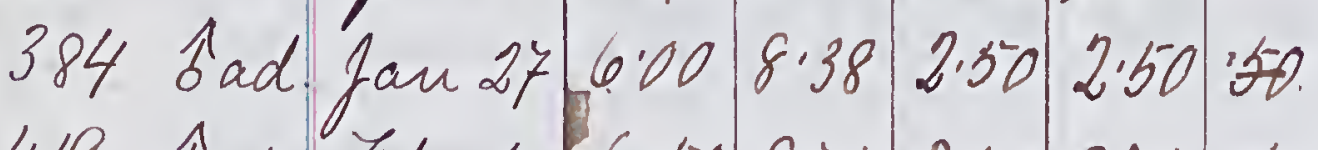

419 bad. Fct. I 6.50 8.752 .502 .75 .50

435 fad. Atct. 1. At

444 bad. Feb.16

510 fad. Mar. 17

512 Sad. Mar.15

520 fad. War20

333 qad Wrar. 30.

724 sju. July 12

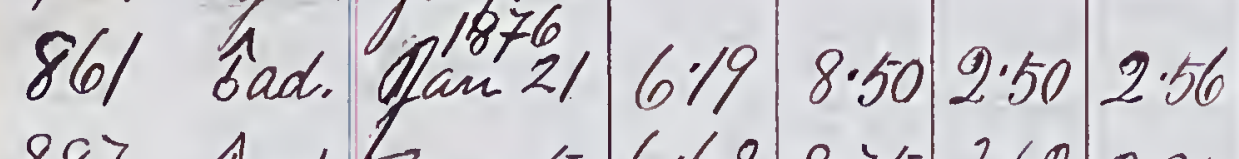

887 1.ad. Mas 5 6.628 .752 .622 .81

896 fad. nar $24 \quad 6.44 \quad 8.69 \quad 2.50 \quad 2.62$

906 dad. mar 31 $6.44 \quad 8.88 \quad 2.62$ 2.75

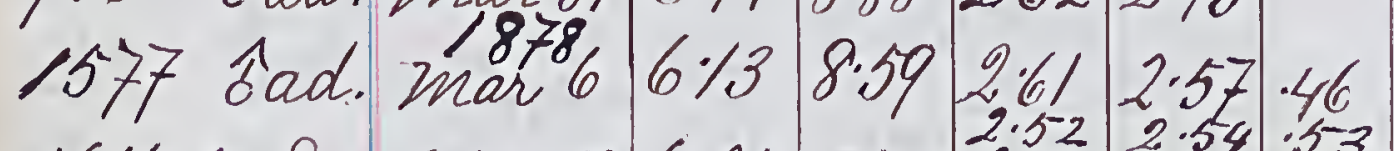

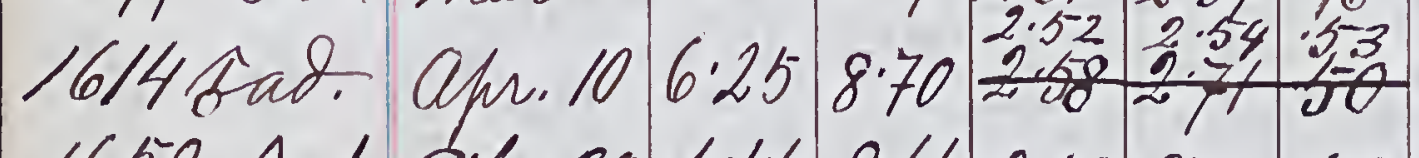

1652 sad. Afm.30 6.46 8.66 2.58 2.71 50

1654 qad. Aps $30 \quad 6.30 \quad 8.402 .42 \quad 2.60: 50$

1828 ad. Mar. $13.36 .40 \quad 8.50 \quad 2.50 \quad 2.75 \cdot 46$

1864 sad.apr.10 6.258 .70 


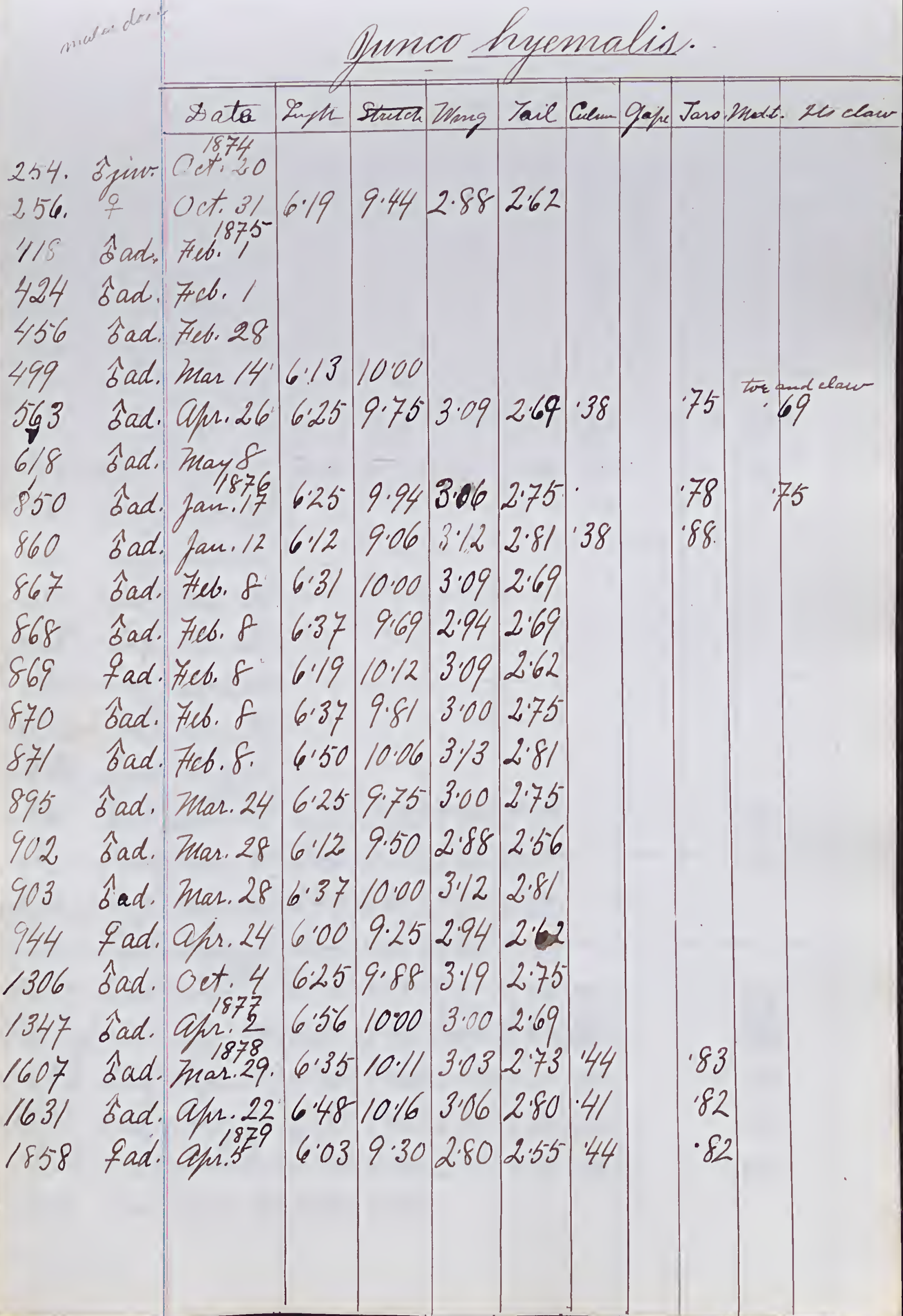


Spizella fusilla.

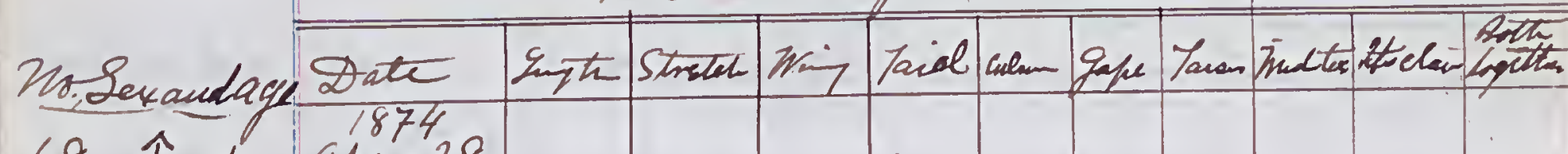
69 Sad. apr. 28

619 bad. $\operatorname{man}_{1876} 85.758 .19$

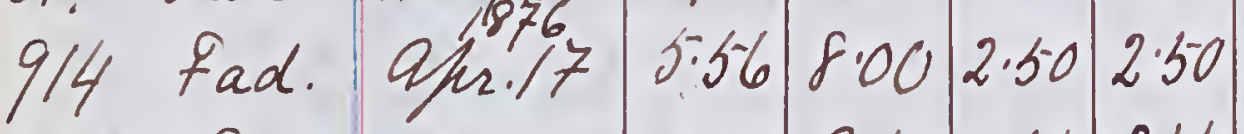

1116 fad. Heay 27 5.75 8.122 .442 .44

$1288 \hat{b} \quad$ Sp.29 $5: 69 \quad 8.12 \quad 2.562 .36$

SApelta srcialis.

$115 \mathrm{Fad}$. man; 3

584 bad. Op. 187505.448 .75

585 fad. Cpr.30 $5.19 \quad 8.4422 .632 .25$

617 Sad. Inay 8 5.50 8.56 2.69 2.25

$774 \div$ ? Sep. 23

941 isad ap, 22 5.25 8.882 .752 .37

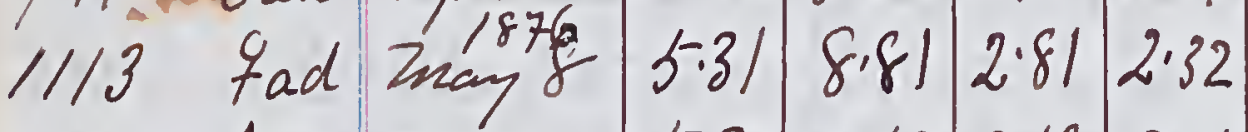

$1 / 18$ bad many $5.37 \quad 8.6222 .692 .25$

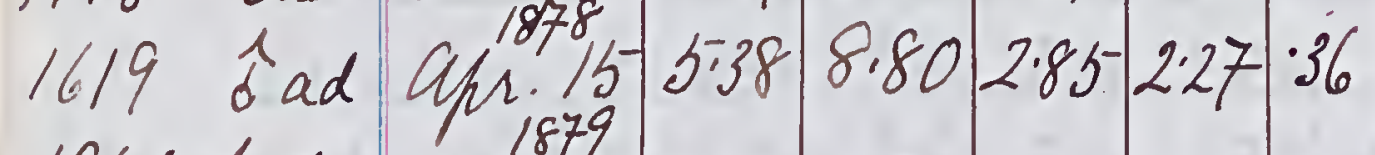

1960 fullus 2 ily 1979 - -

2003 Ejur. Oet. I 5.509 .00 
Spizella monticola, Smelin.

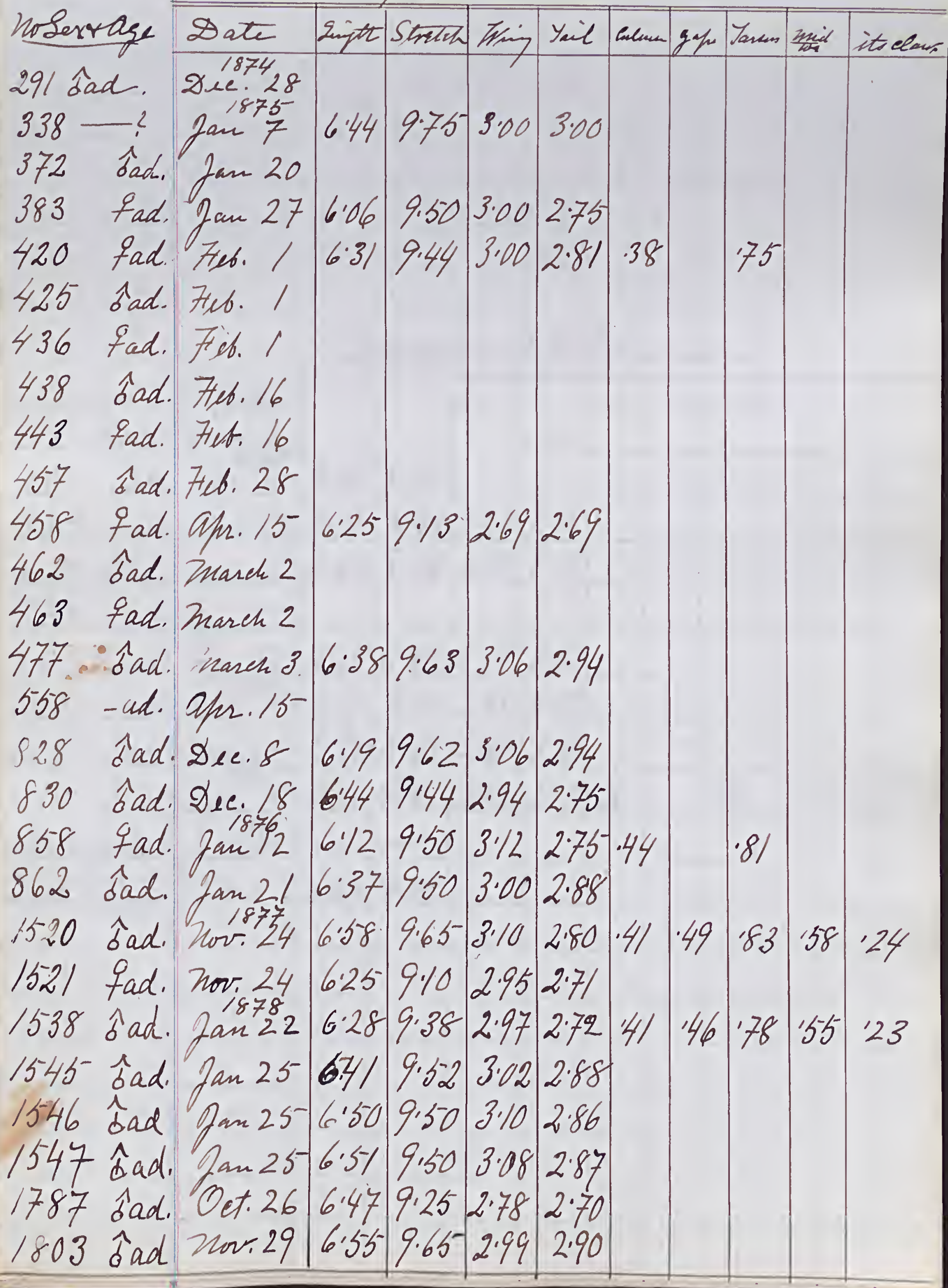


Pafeer domecticus, (Leiné).

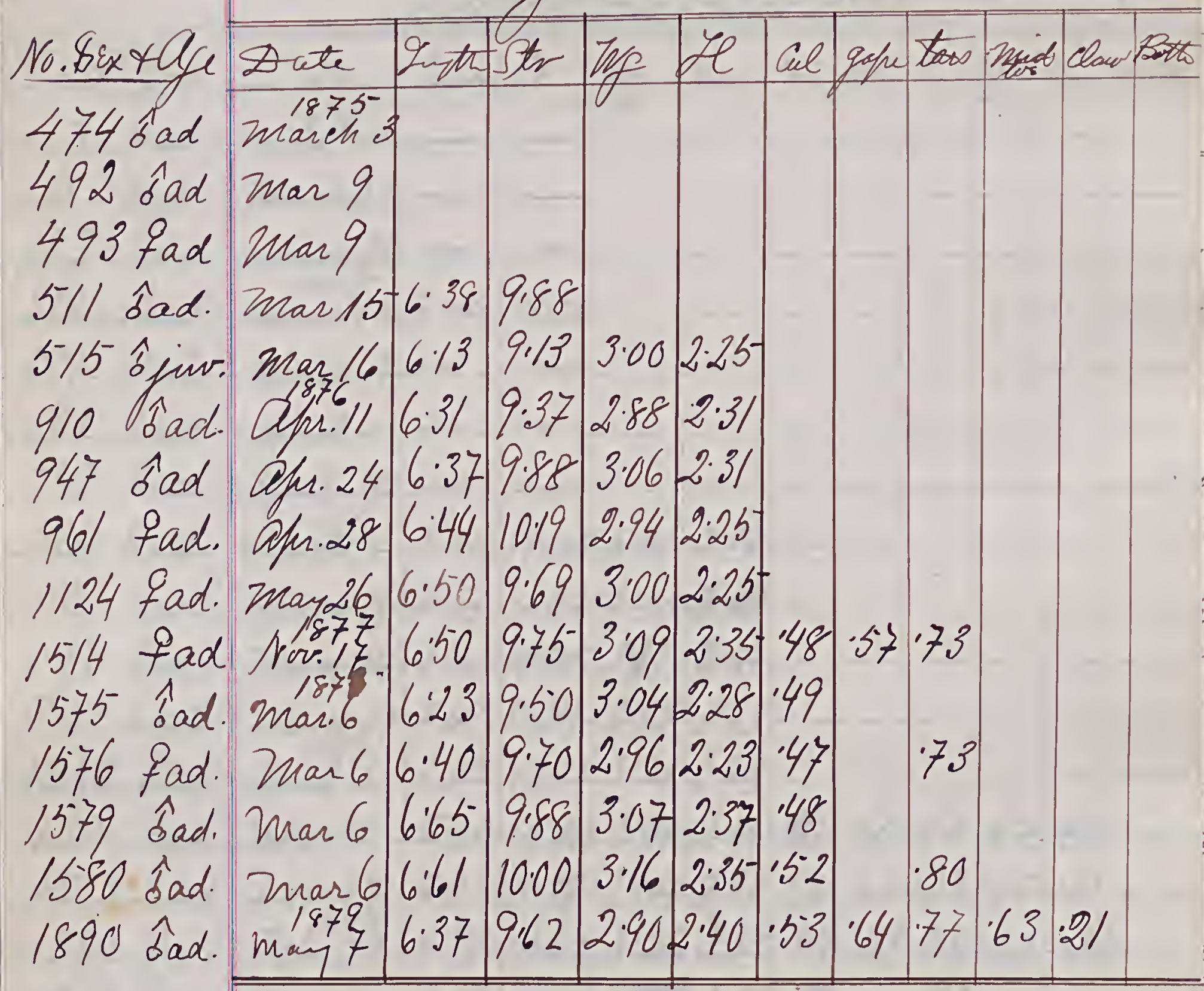


Pafserella iliaca, (Merrem).

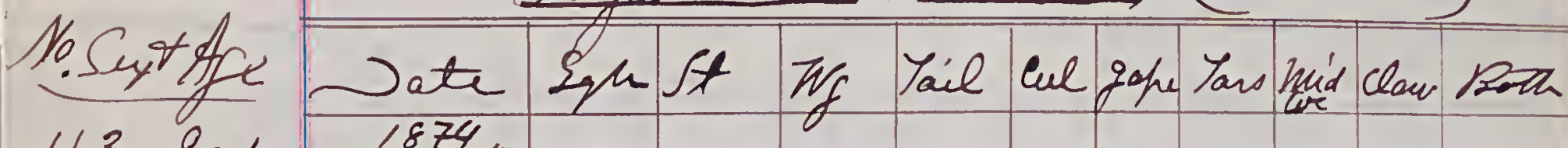

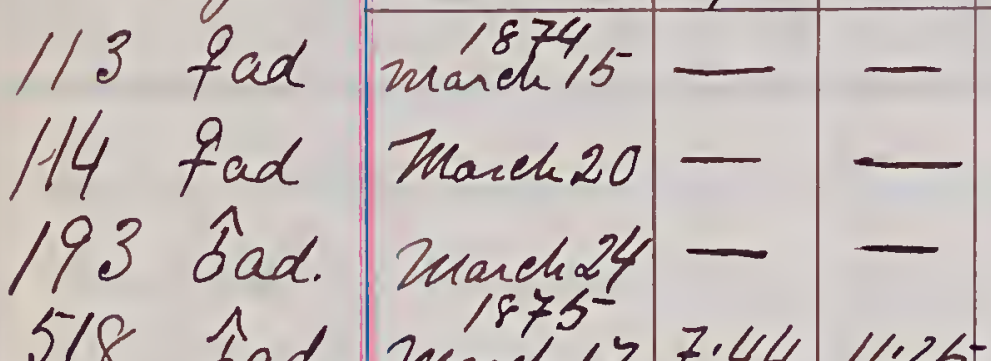

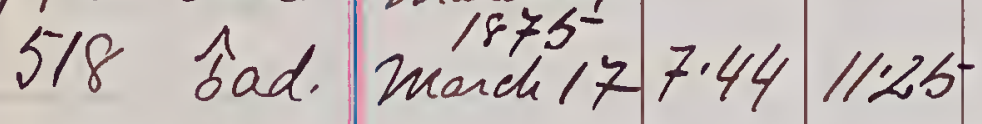

519 fad mand 17 - -

$541 \hat{b a d}$ aprill - -

$548 \mathrm{fad}$ april $15-$

886 fad merch 787.25111 .003 .412 .88

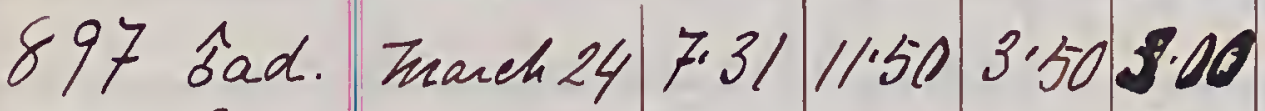

$898 \mathrm{fad}$ mench 247.0010 .753 .1992 .63

901 bad muest 7.69911 .883693 .13

$1348 \mathrm{Fad}$ afine $7: 2510.813 .312 .88$

$1507 \mathrm{Fad}$ now.9 7.0010 .803412 .665260 .976230

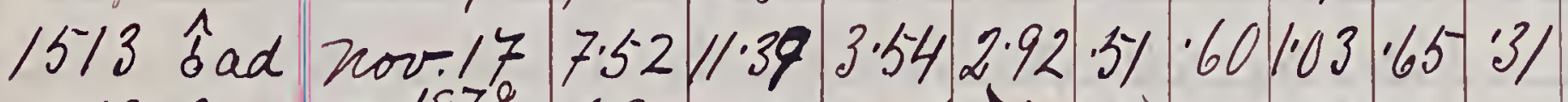

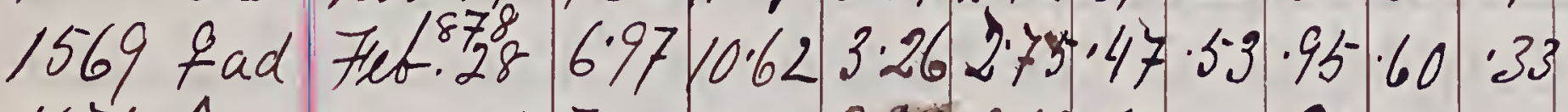

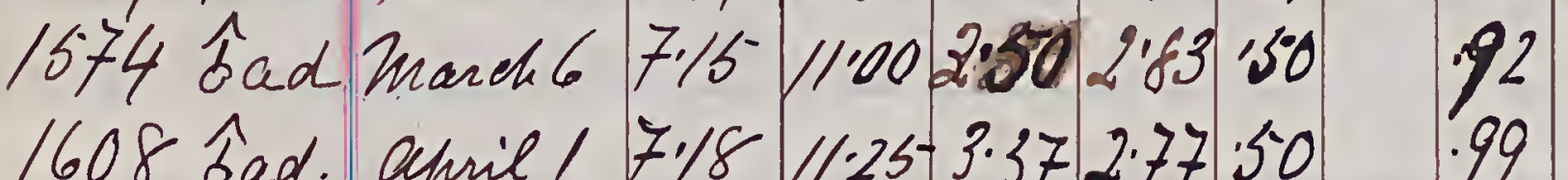

1608 bad. Qpinil 7.18 1/25-3.372.77.50 99

1612 îad. Aprie 4 7.65 1/78 3.56 3.03

1842 bad afriel 27.3510803 .252 .855 .50

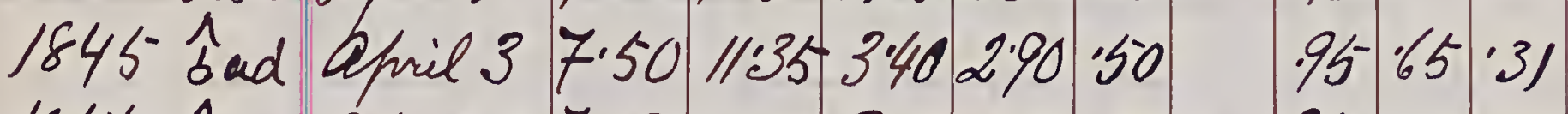

$1846 \mathrm{bad}$. Amil 37.08 11.05 33352.90.50 $94160: 30$

1863 fad. Apull $106.9010803 \cdot 15=2.60 \cdot 49 \cdot 3 \cdot 9 \cdot 95 \cdot 63 \cdot 28$ 
Soniafhea hedoviciana, (Limne').

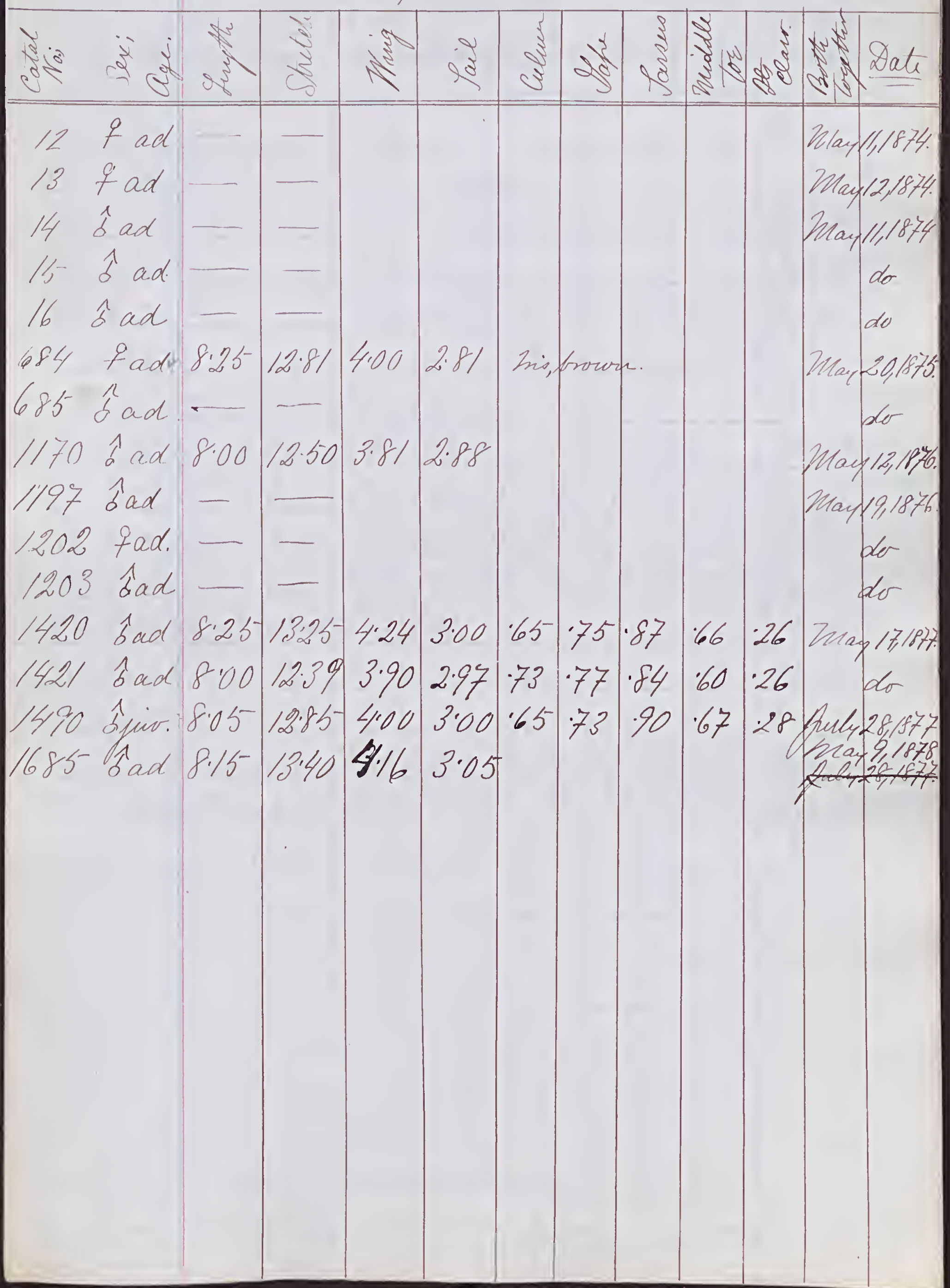


byanosfuza cyanea, (Ininé).

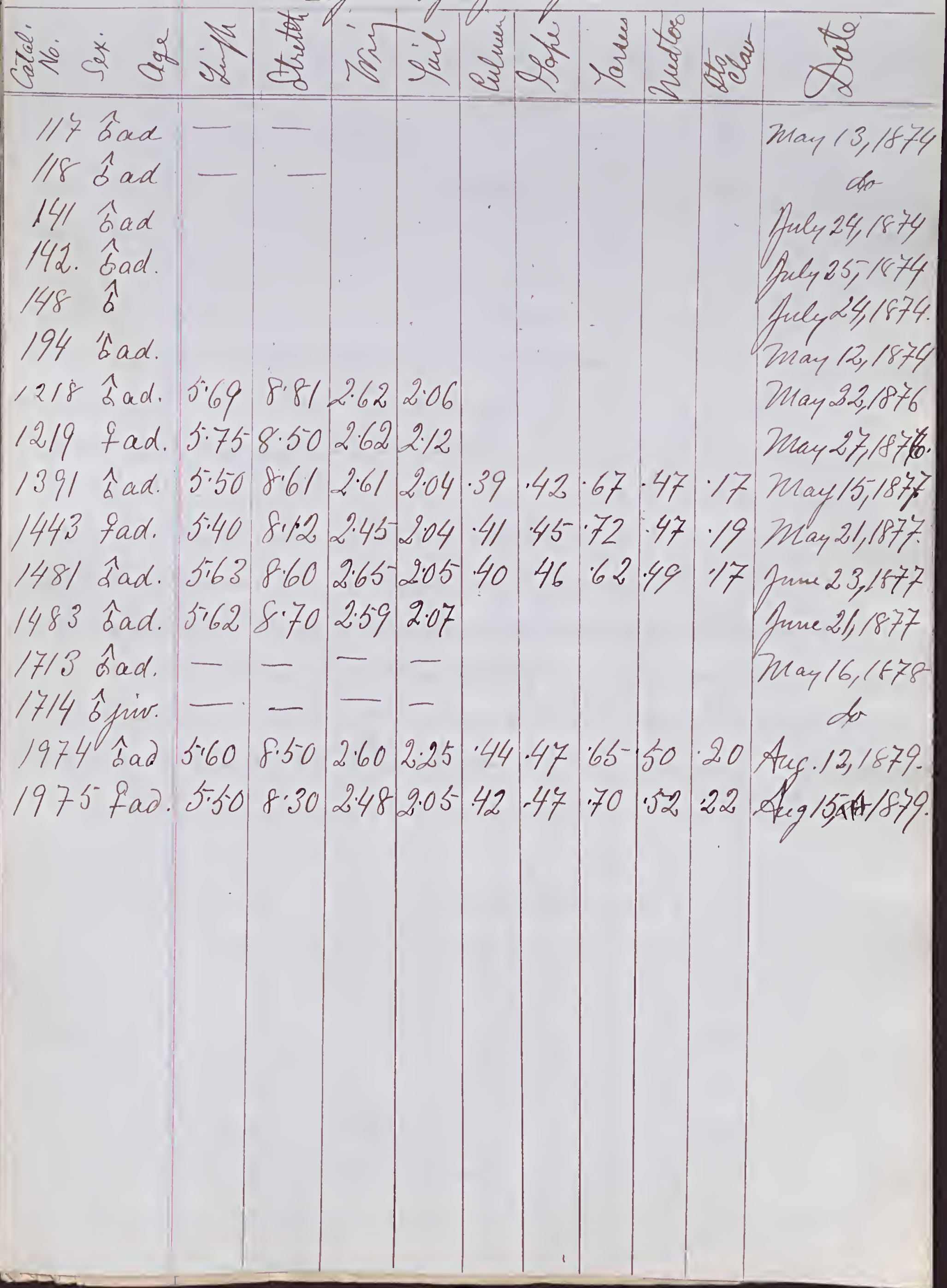




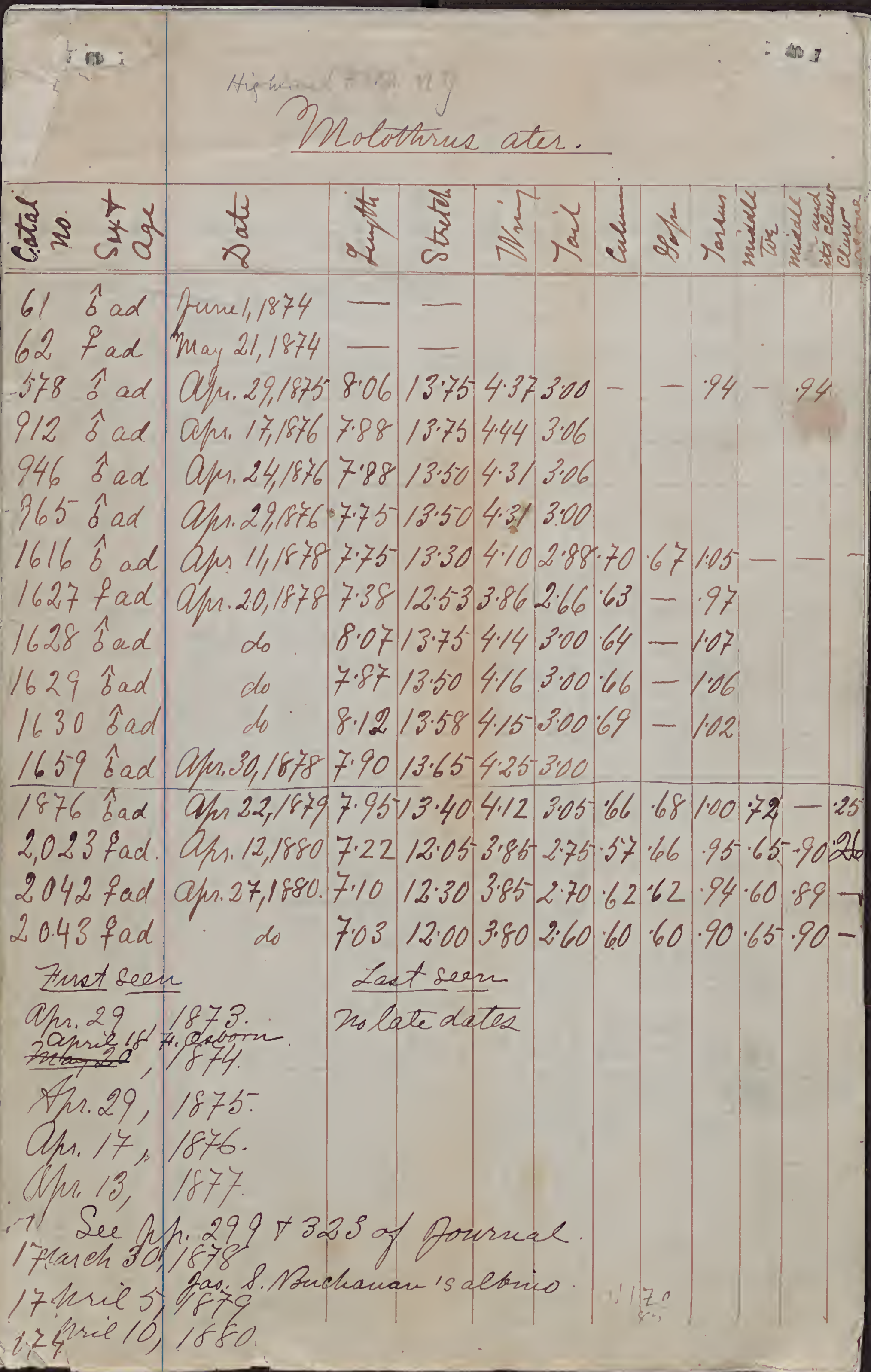


Ageläns phörnicens - Contisined.

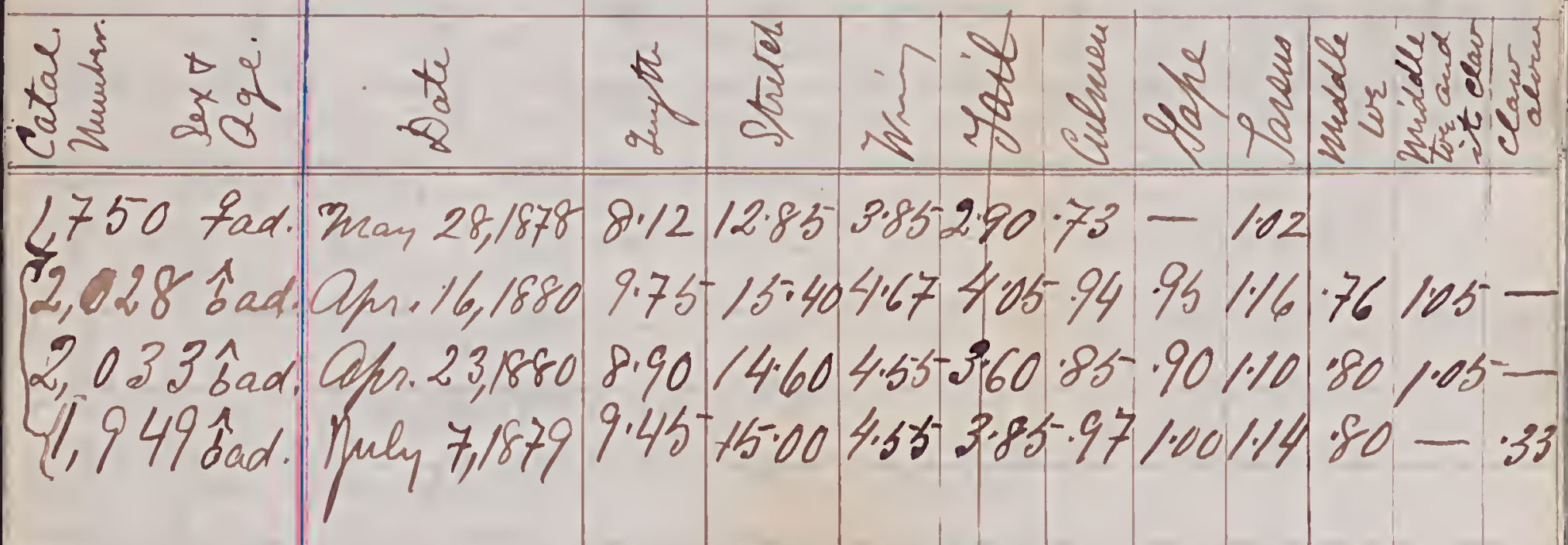

1345 sad. Apr. $7,187910.8216434 .8532 .551 .431 .501 .73-1.35-$

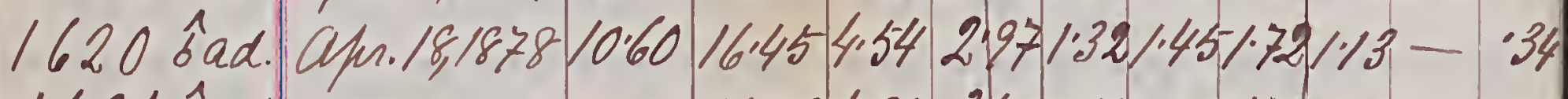

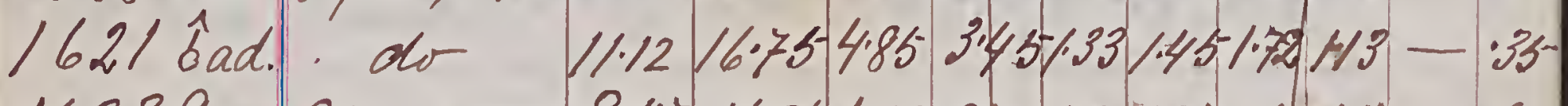

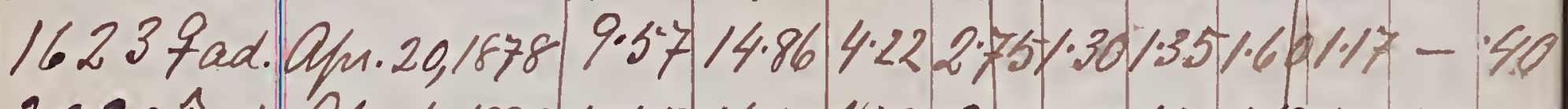
$2020 \hat{\mathrm{cad}}$. Opr.6,1880 1045 16.5044.78 3001.301.401.691.181.50- 


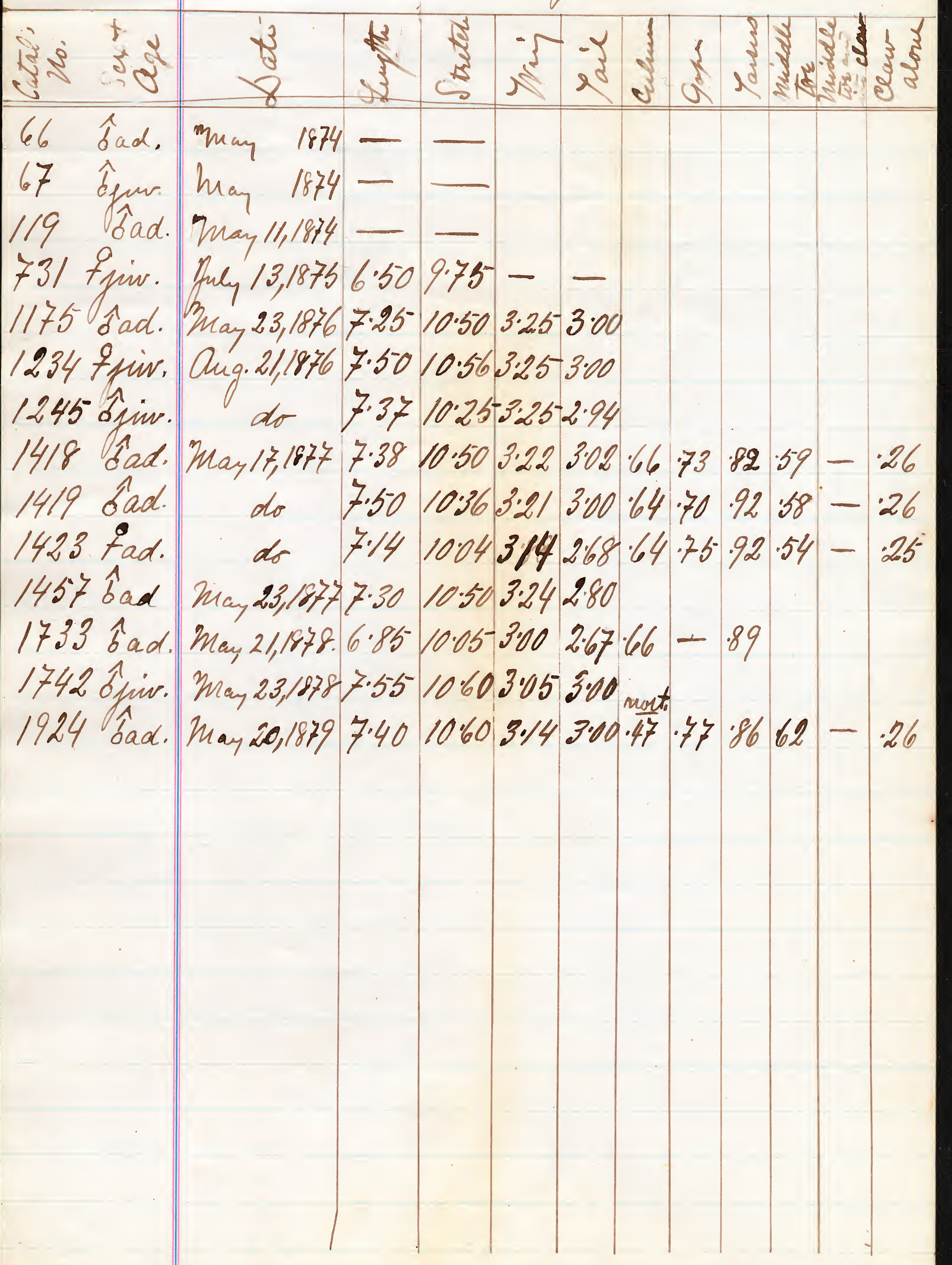


Deterus baltinore (- galvula),

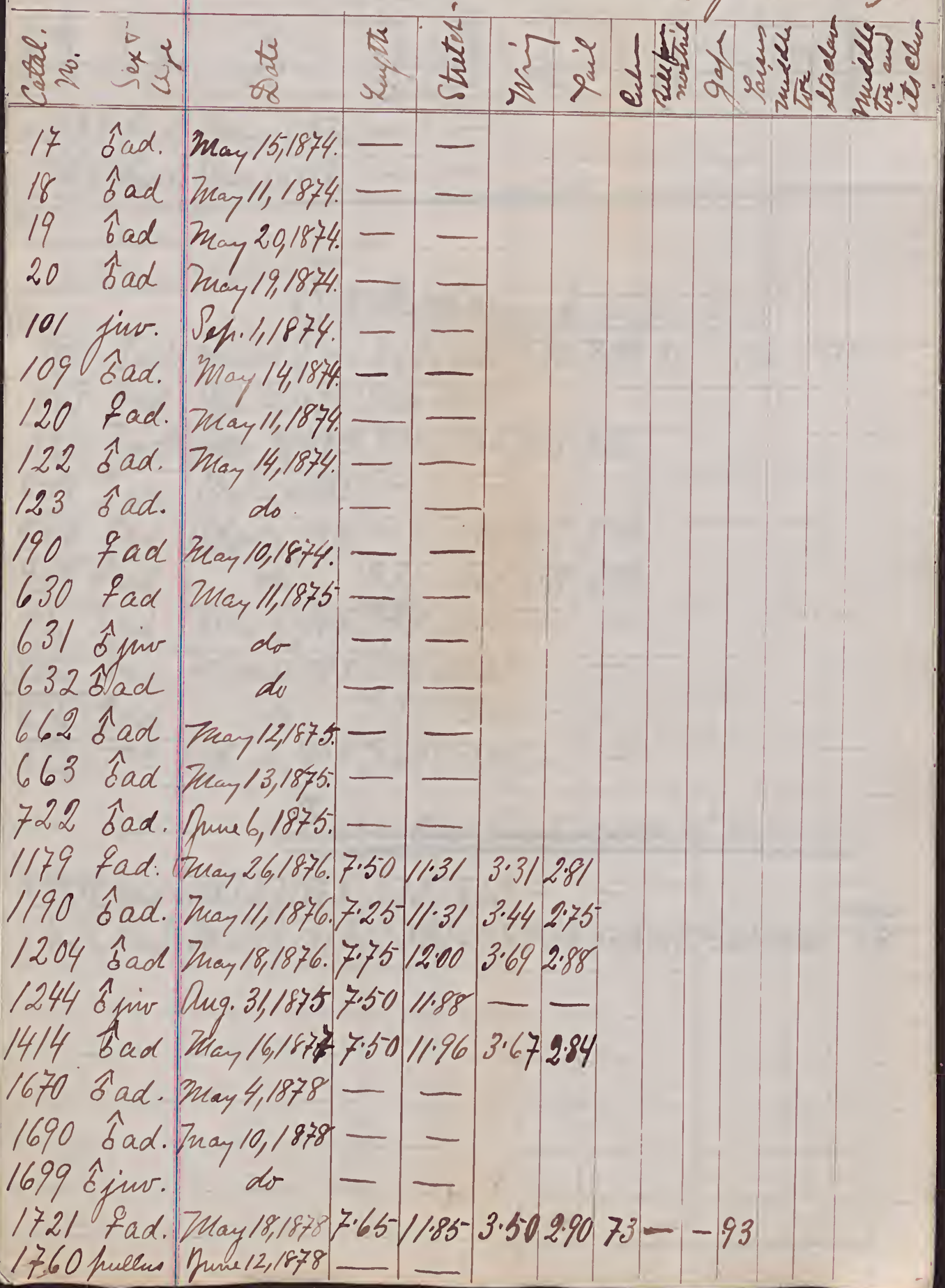


Corrus americanue.

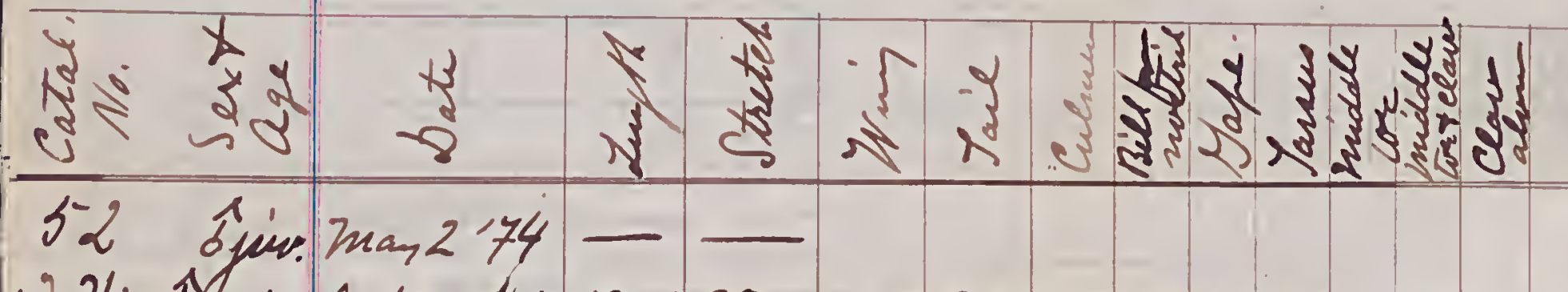

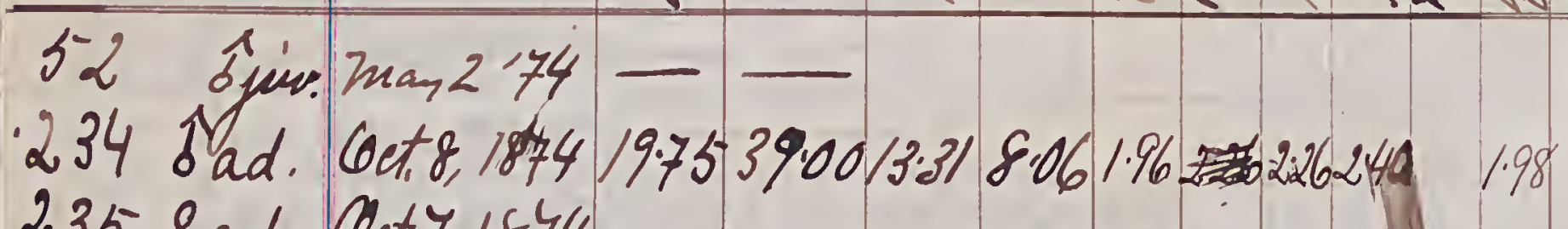

$235 \mathrm{fad}$. Qet.7.1844

$2.36 \mathrm{fad}$. 187.74

$237 \hat{b}$ ad. Spp29/187420.0037.19

$813 \hat{\delta} \quad N_{w_{1} 13,187518.75-30.0011 .567 .50}$

$878 \mathrm{fad}$. Mar $4 / 1876 / 9.0037 .50 / 2.447 .50$

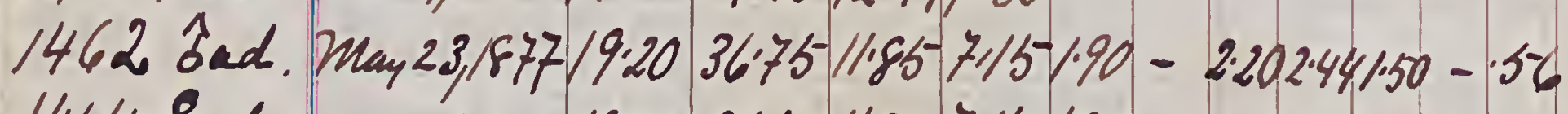

$1464 \mathrm{fad}$. do $18.85-36.7011 .807 .141 .80--2221.37-.58$

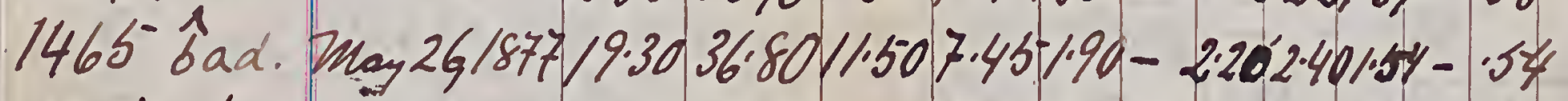

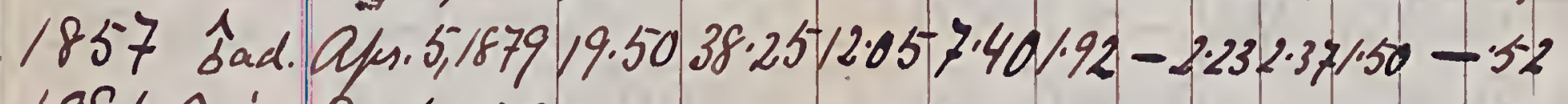

1981 ojum. Ssp.6,1879 - -

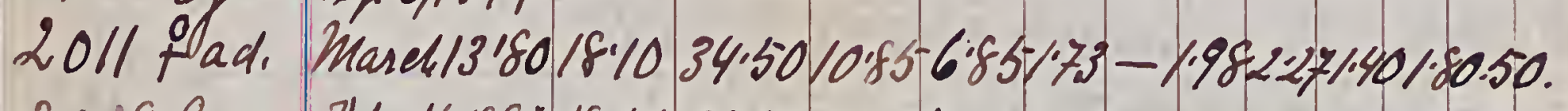

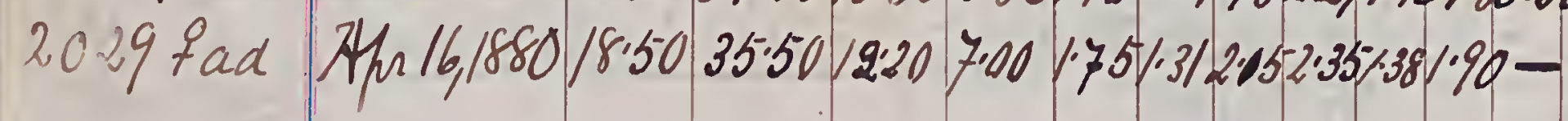

Comrus fsifragus.

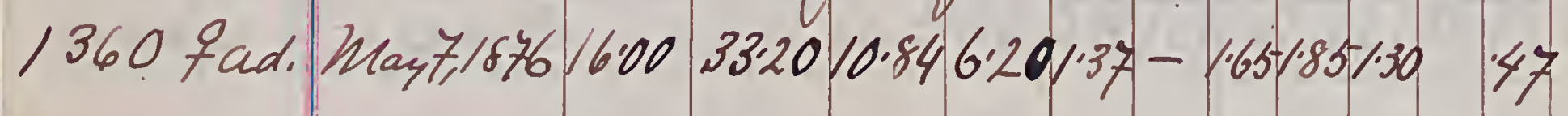


Cyamine cristatue.

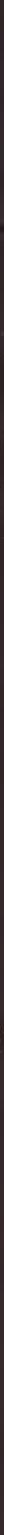

$2016 \mathrm{cad}$. Mar26,1850 12:201675 5i/953010841970.45 -

$109 \mathrm{y}^{120.71}$ dew

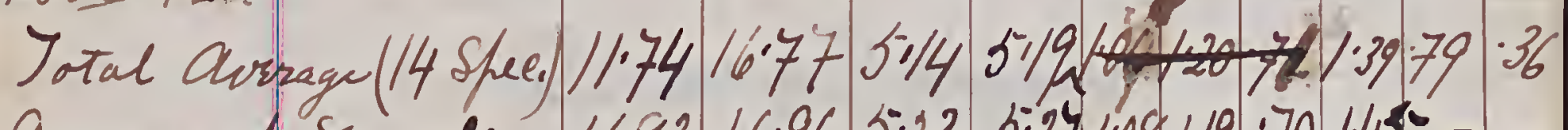

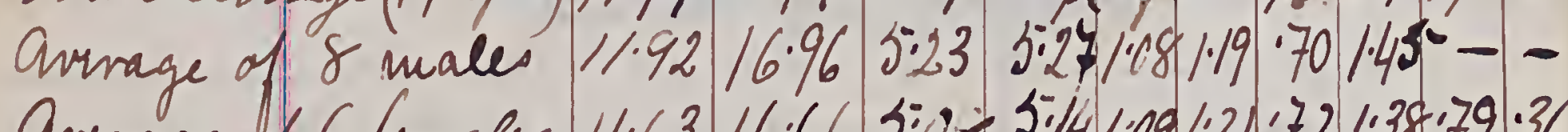

Average of 6 fencales 11.63 /6.66 5.0.75.1/4/.09/.21.72/.38.79.36 
Dypramus carolinemsis.

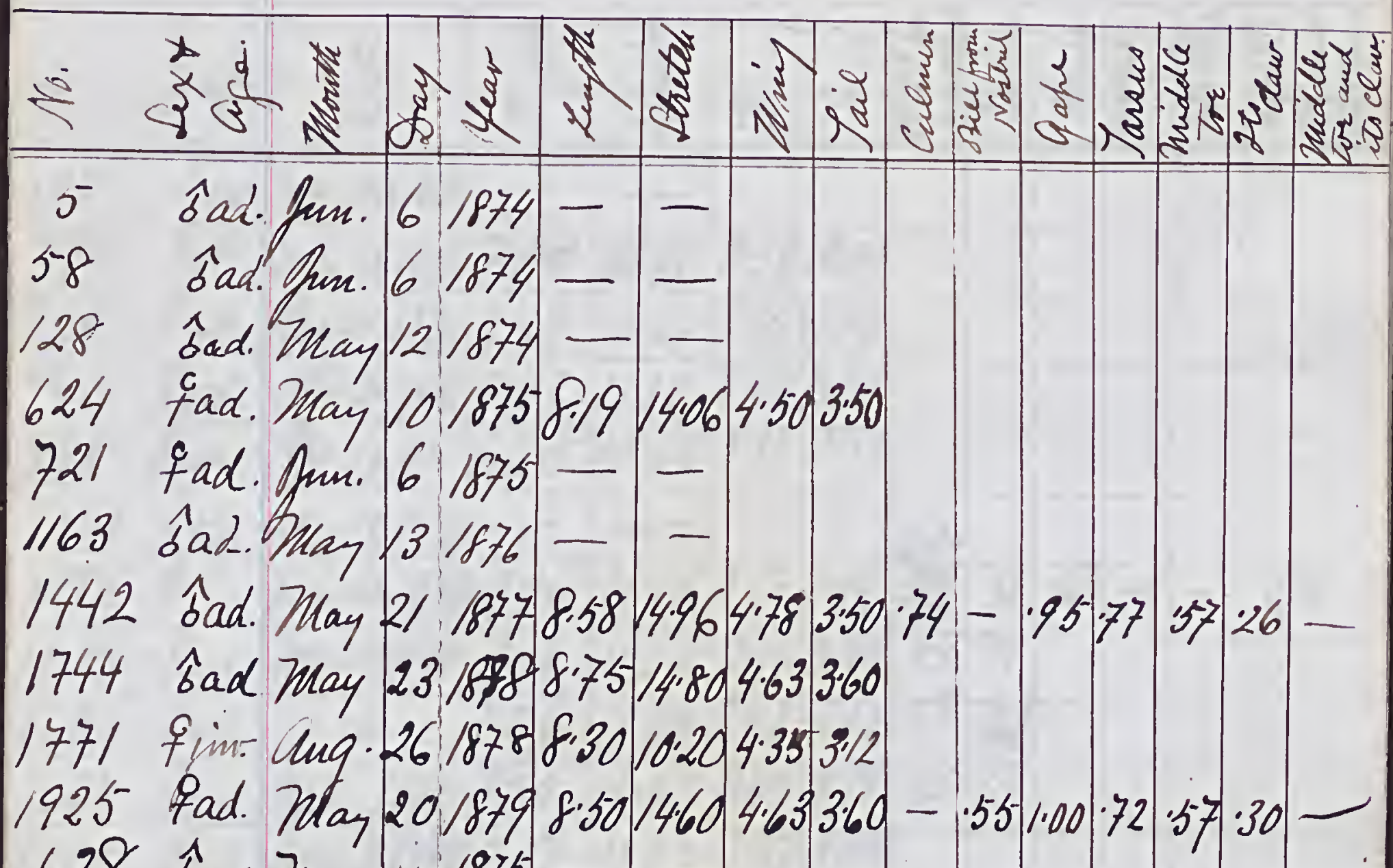
$628 \mathrm{cad}$ Tmay $101875-$ 
Saormis fusens.

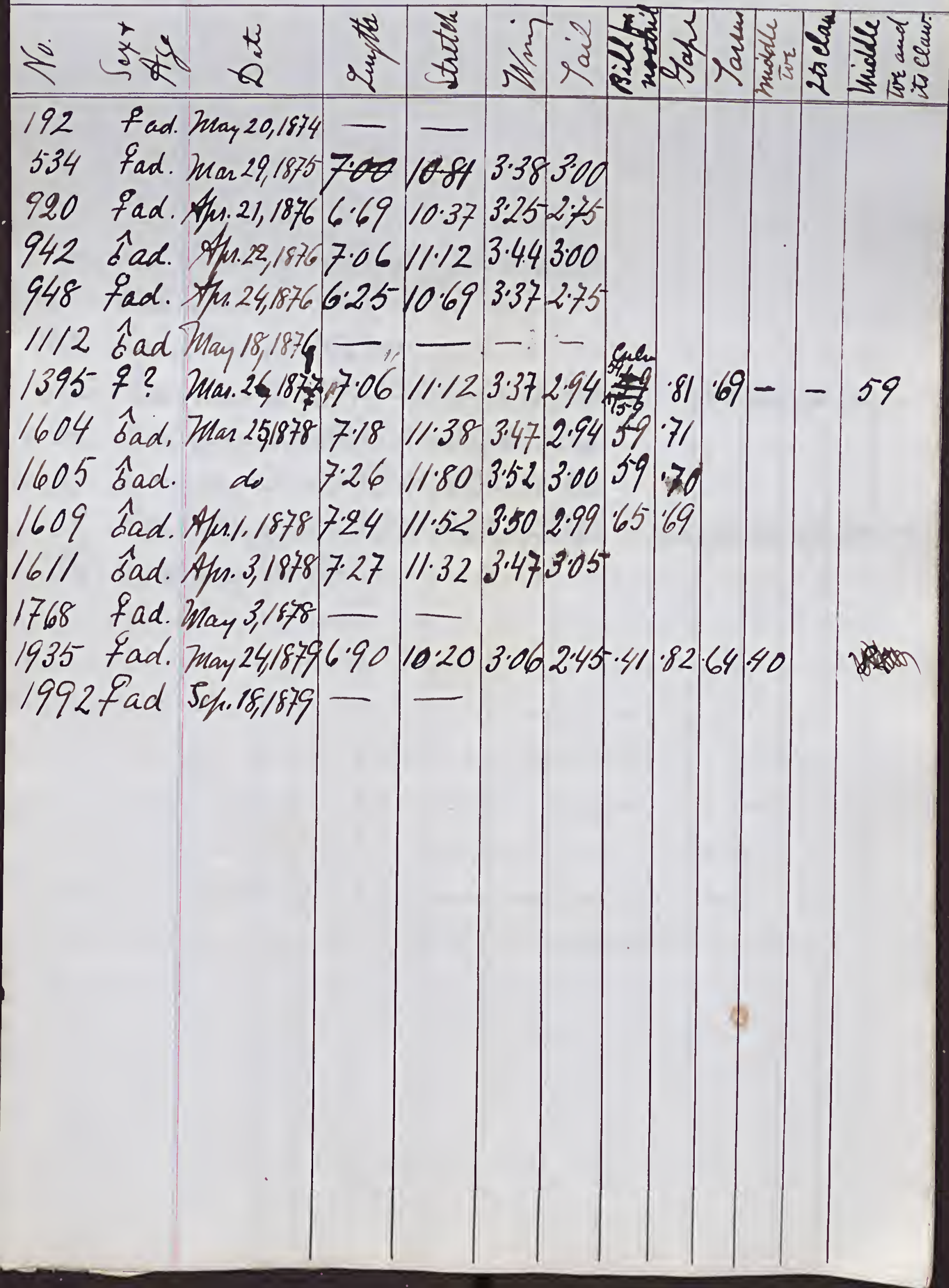


Contopus virins.

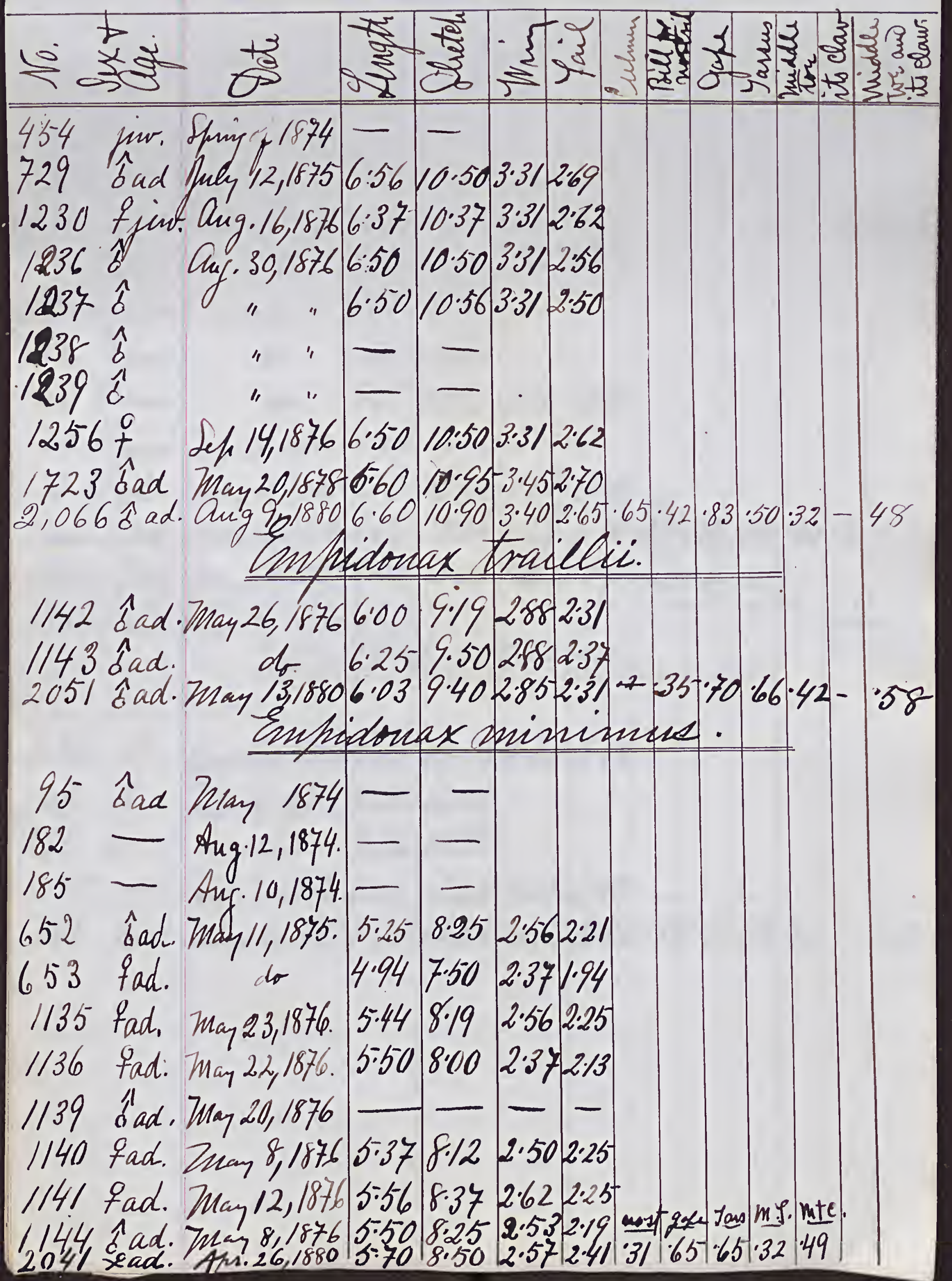




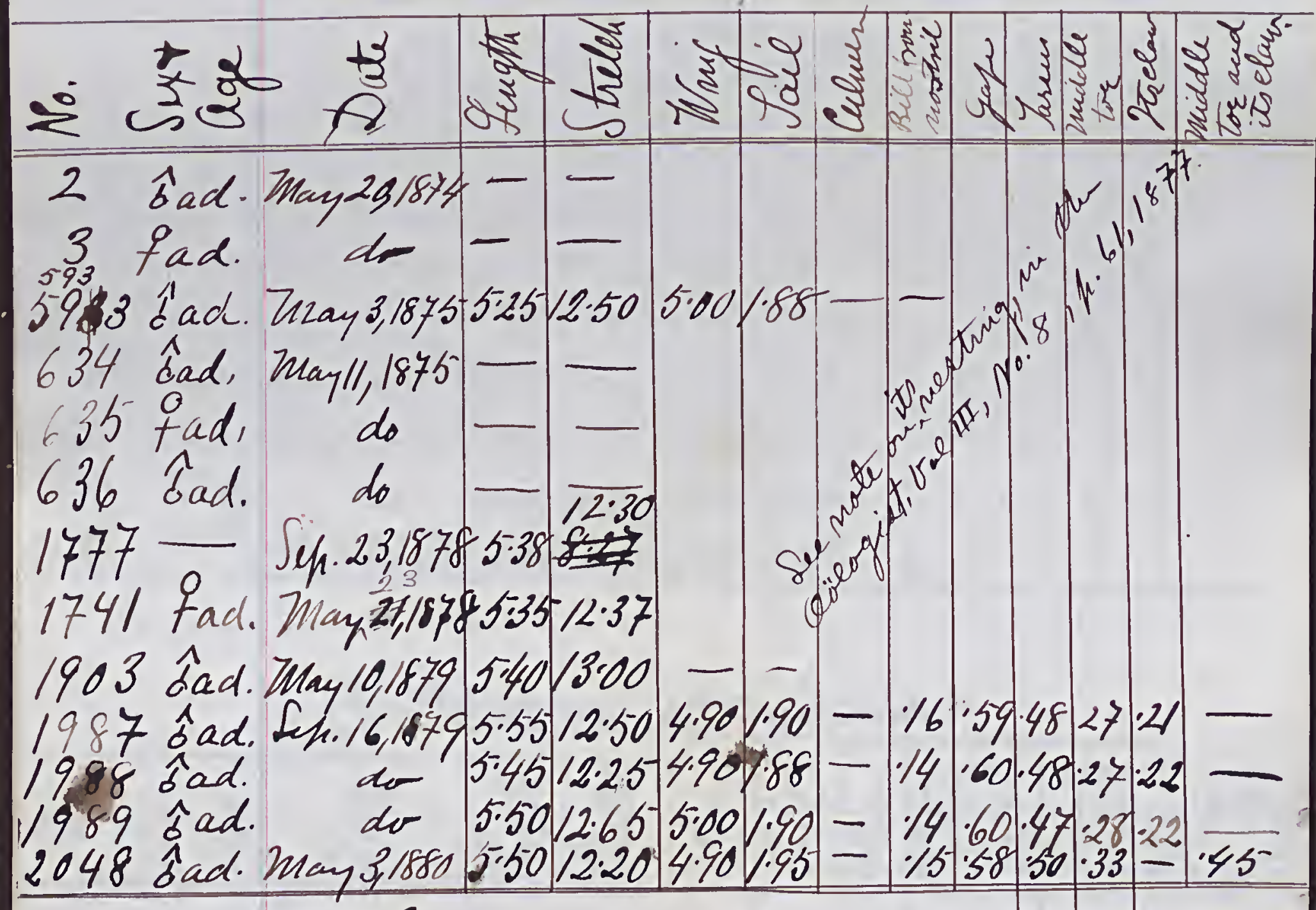

Orrotilus colubris.

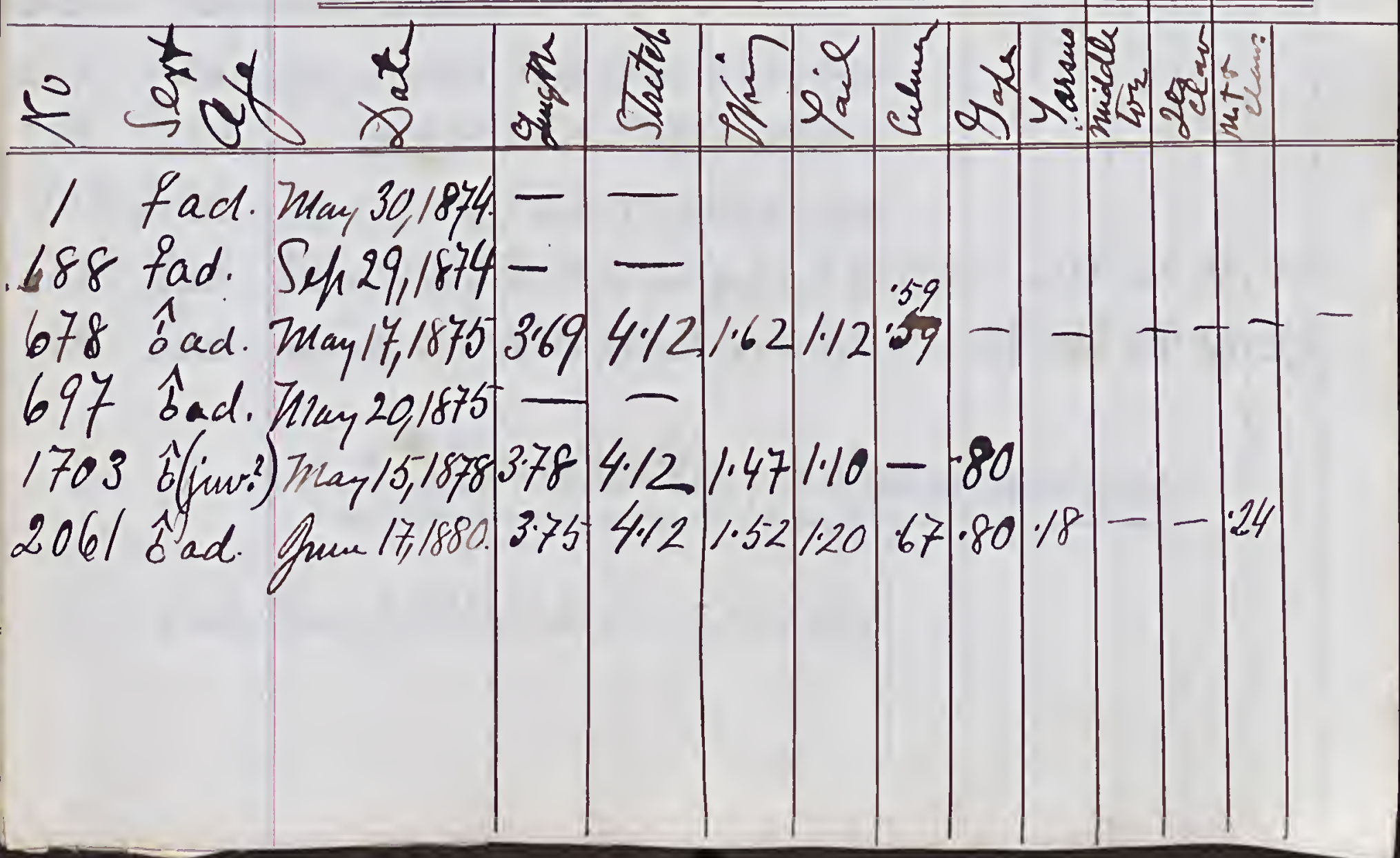




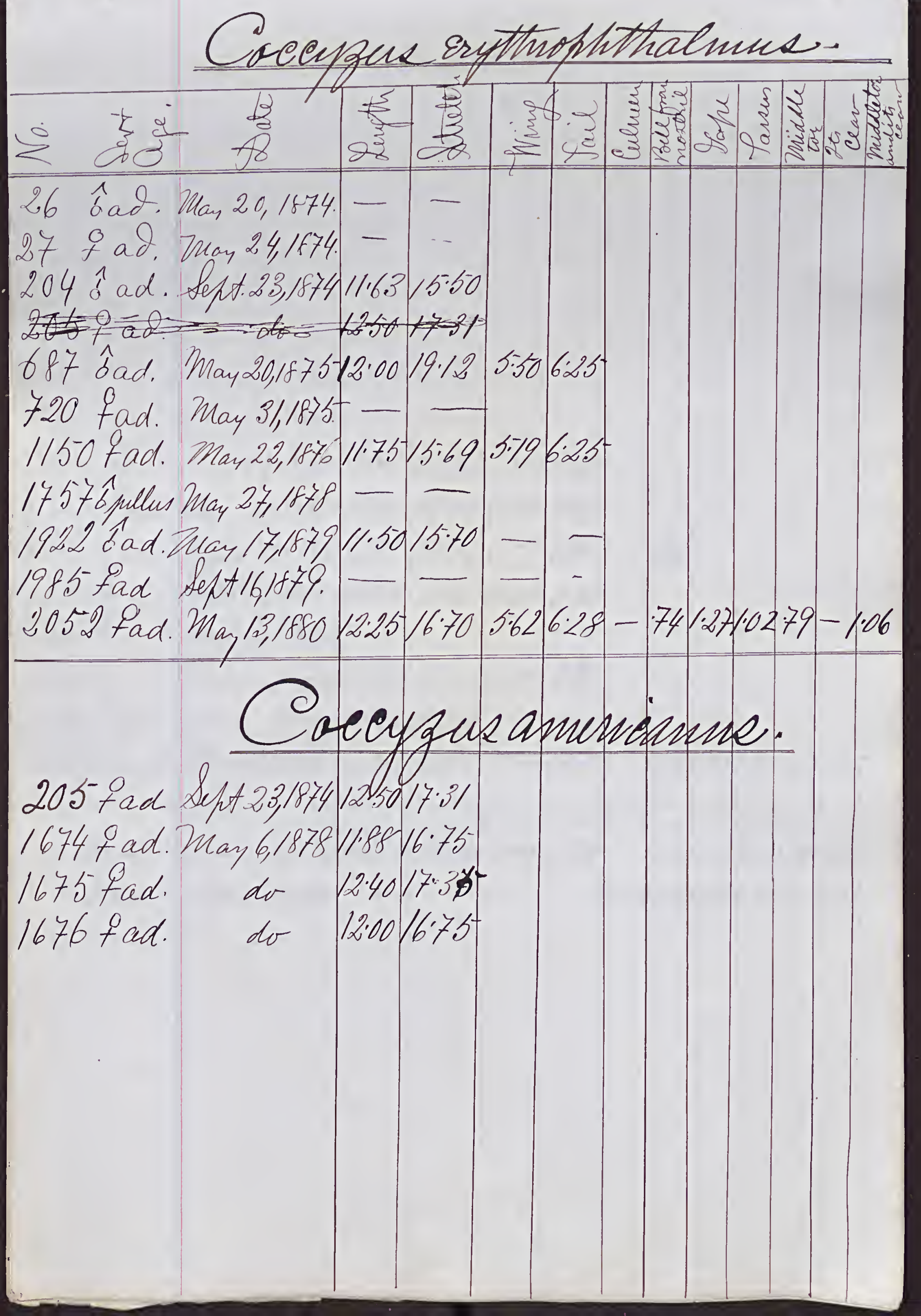


1

Prenr villosur.

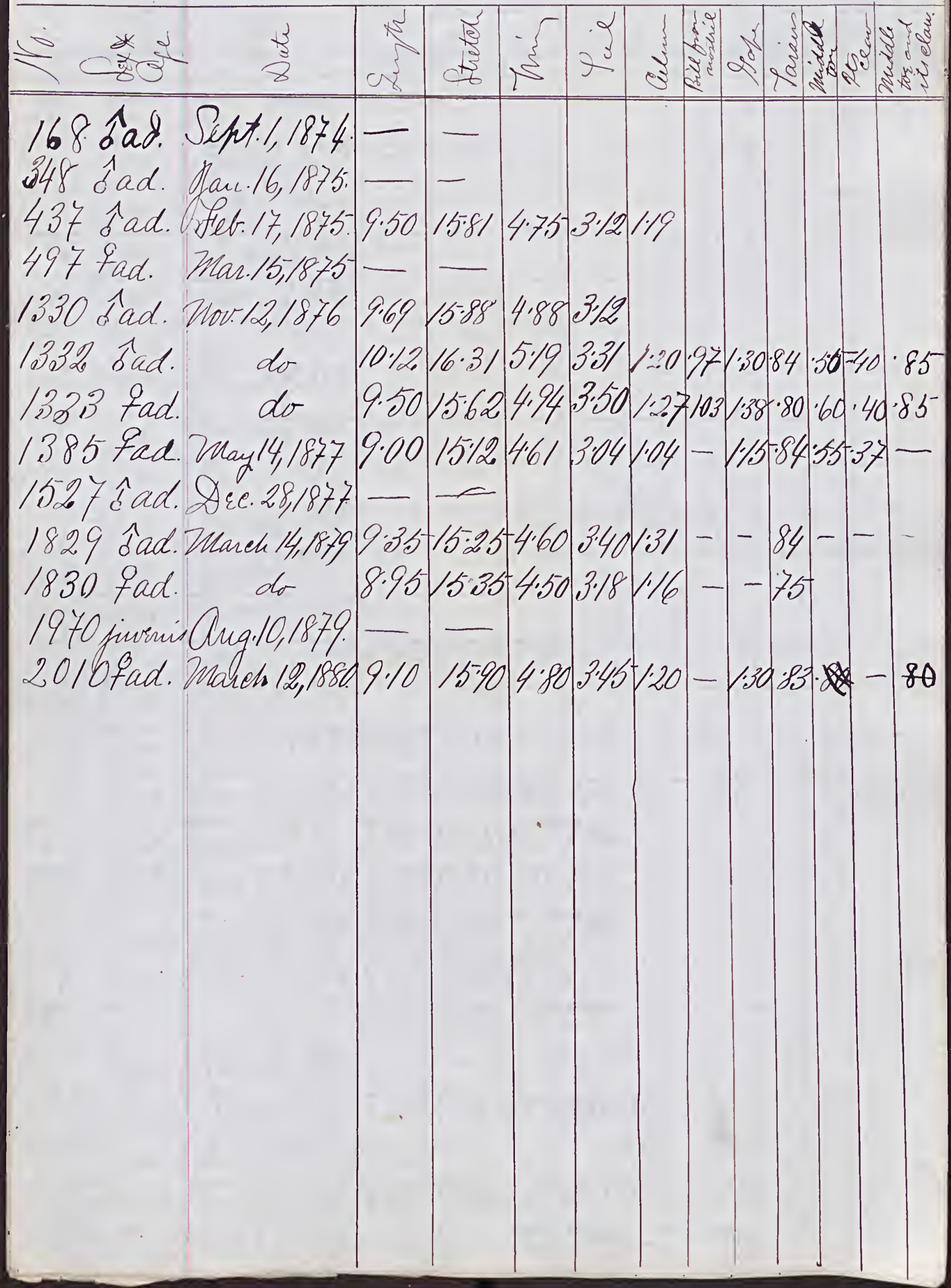




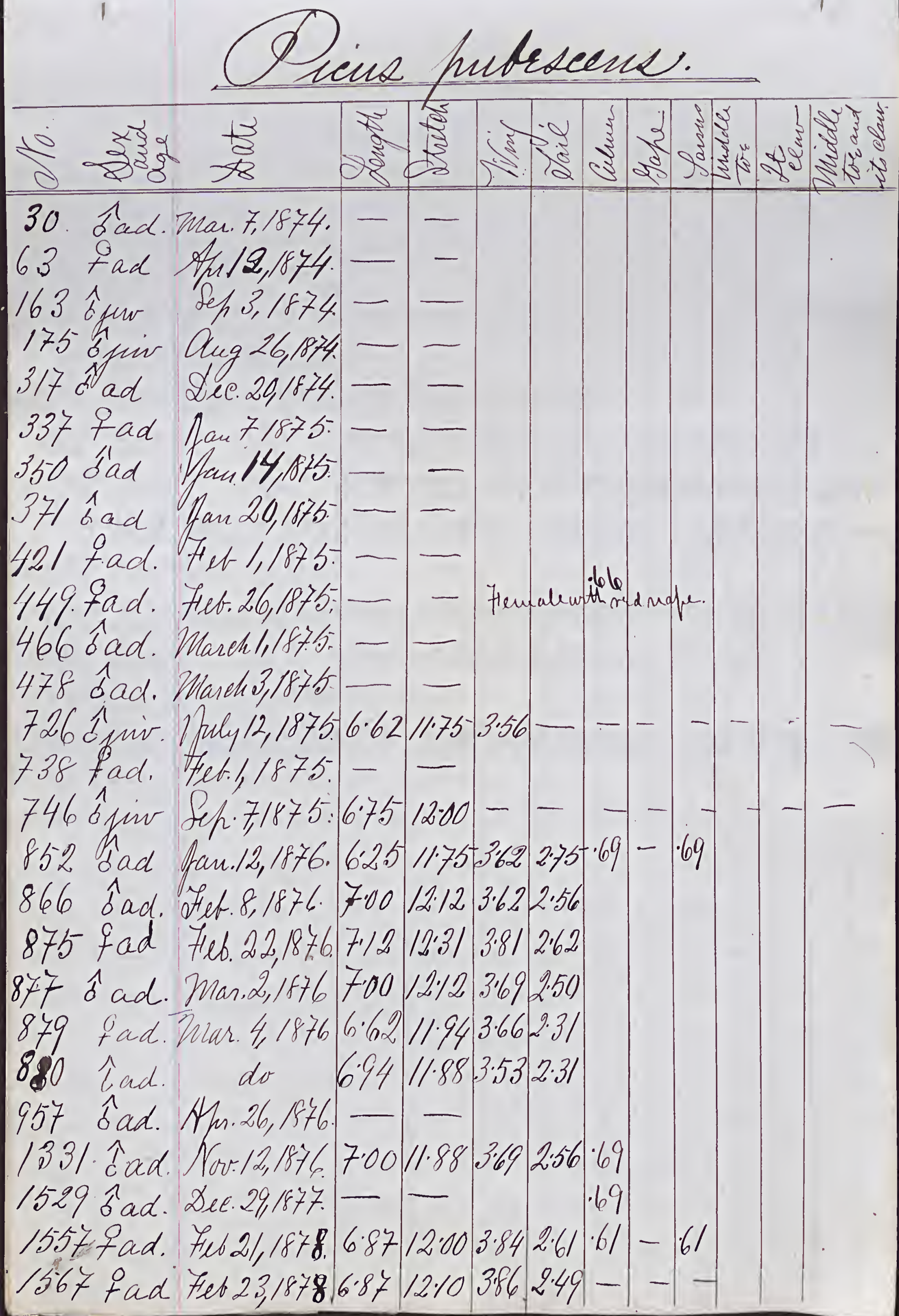


Preis putrsens - entinued.

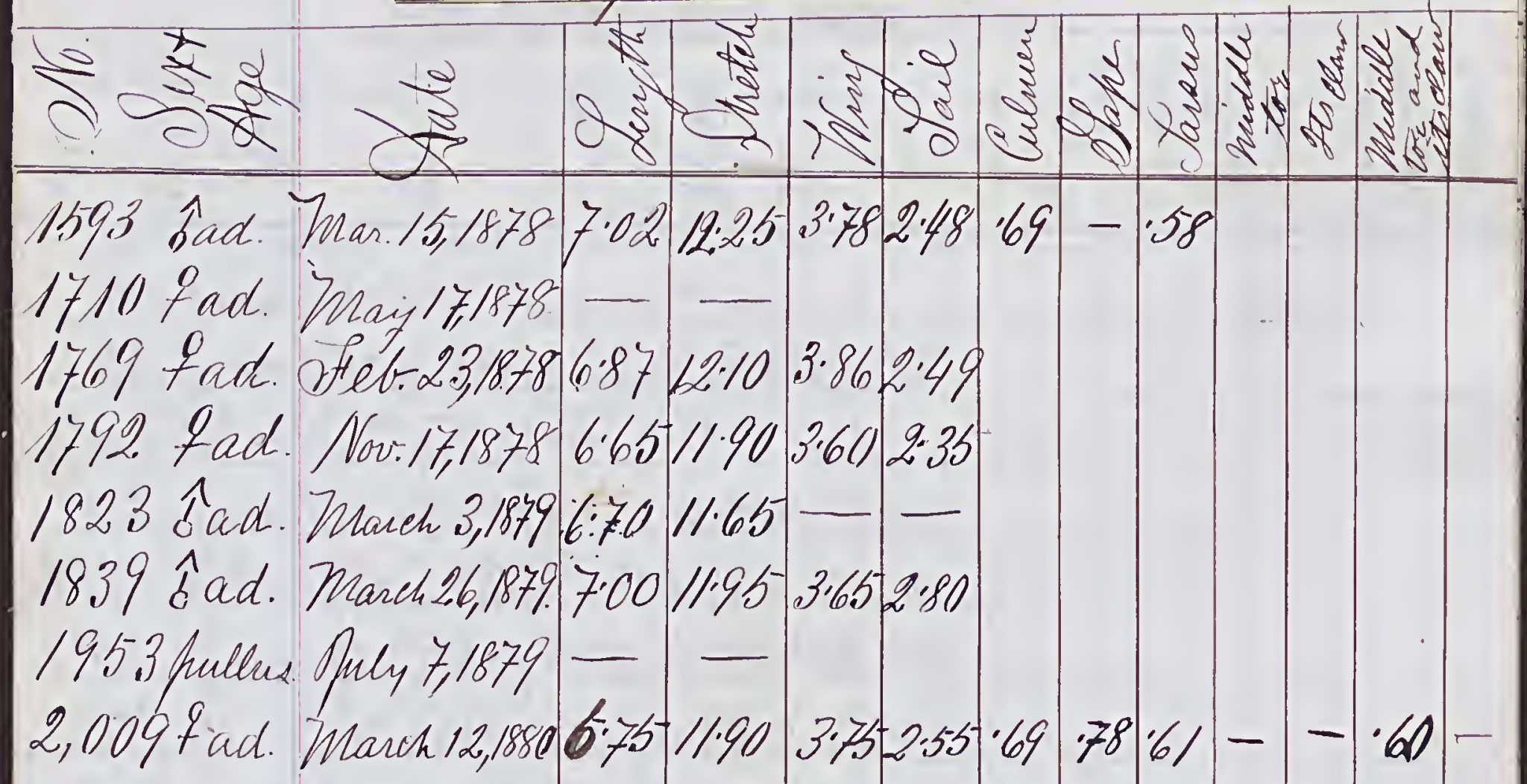

Mulanespes enjtureshalese.

1334 f juw. Now 1, $18769944 \times 7: 25$ 5:373:31 - -

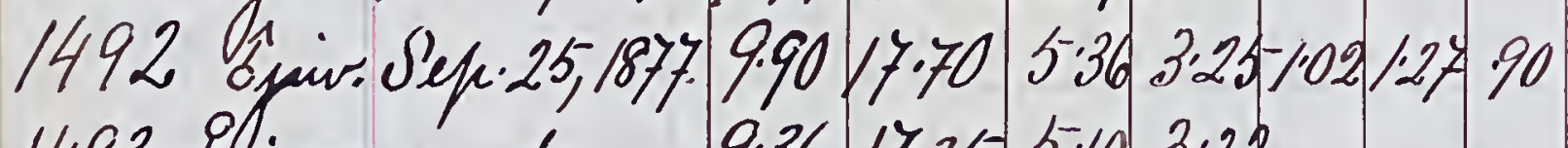

1493 fljur do $9.3617 \% 25-5 \% 10322$

1525 djuir. Dee 28,1879: - -

1528 d jiv. Oec. 29,1877 - -

1/526 13.ju Dec 28,1877. - -

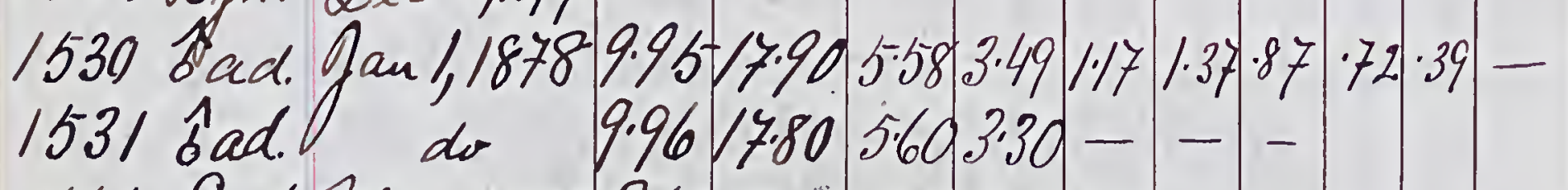
1661 fad. Way2,18789.6018.00 5.373.001.09- .80 
Ophypafuiue varuis.

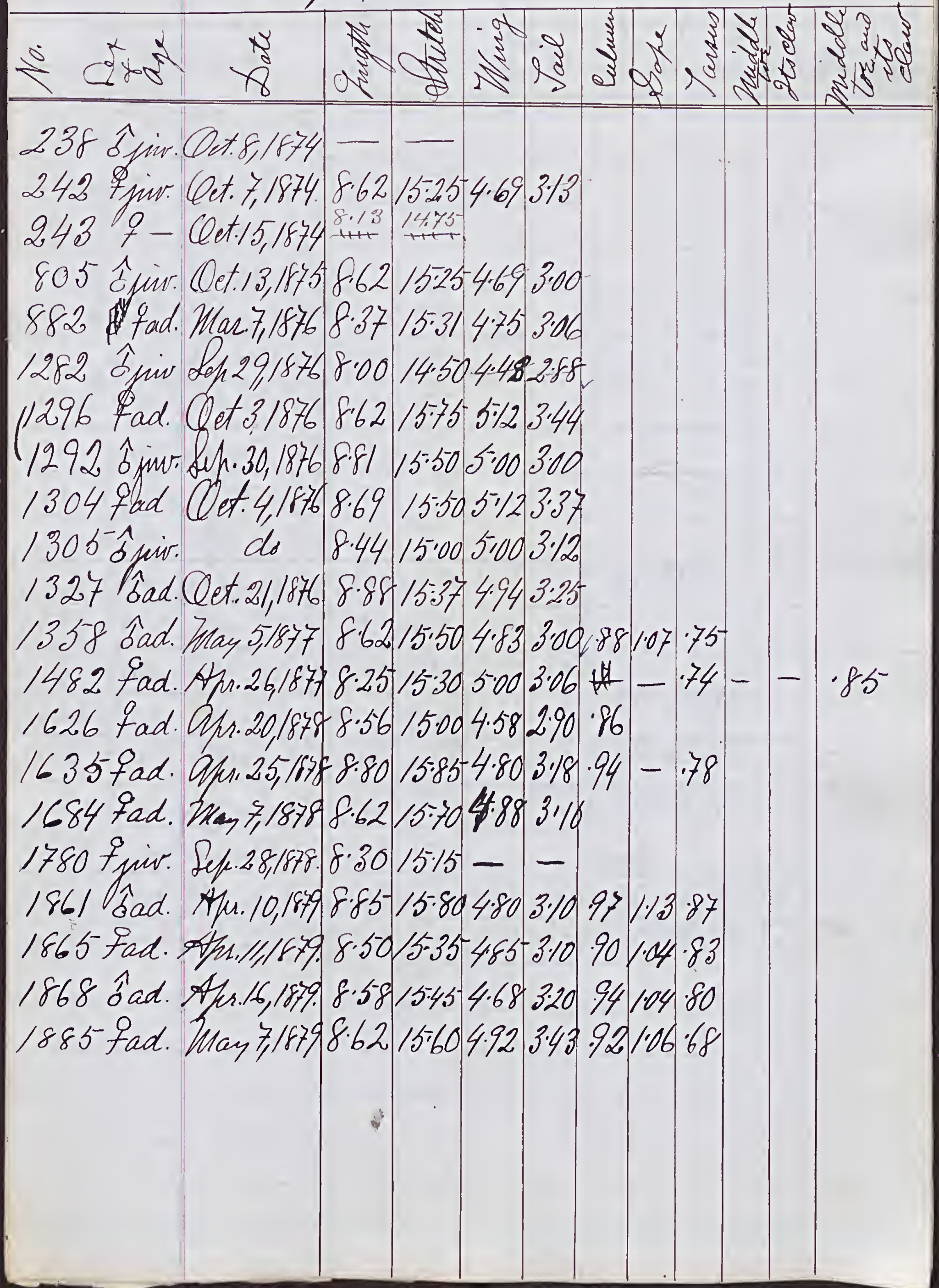




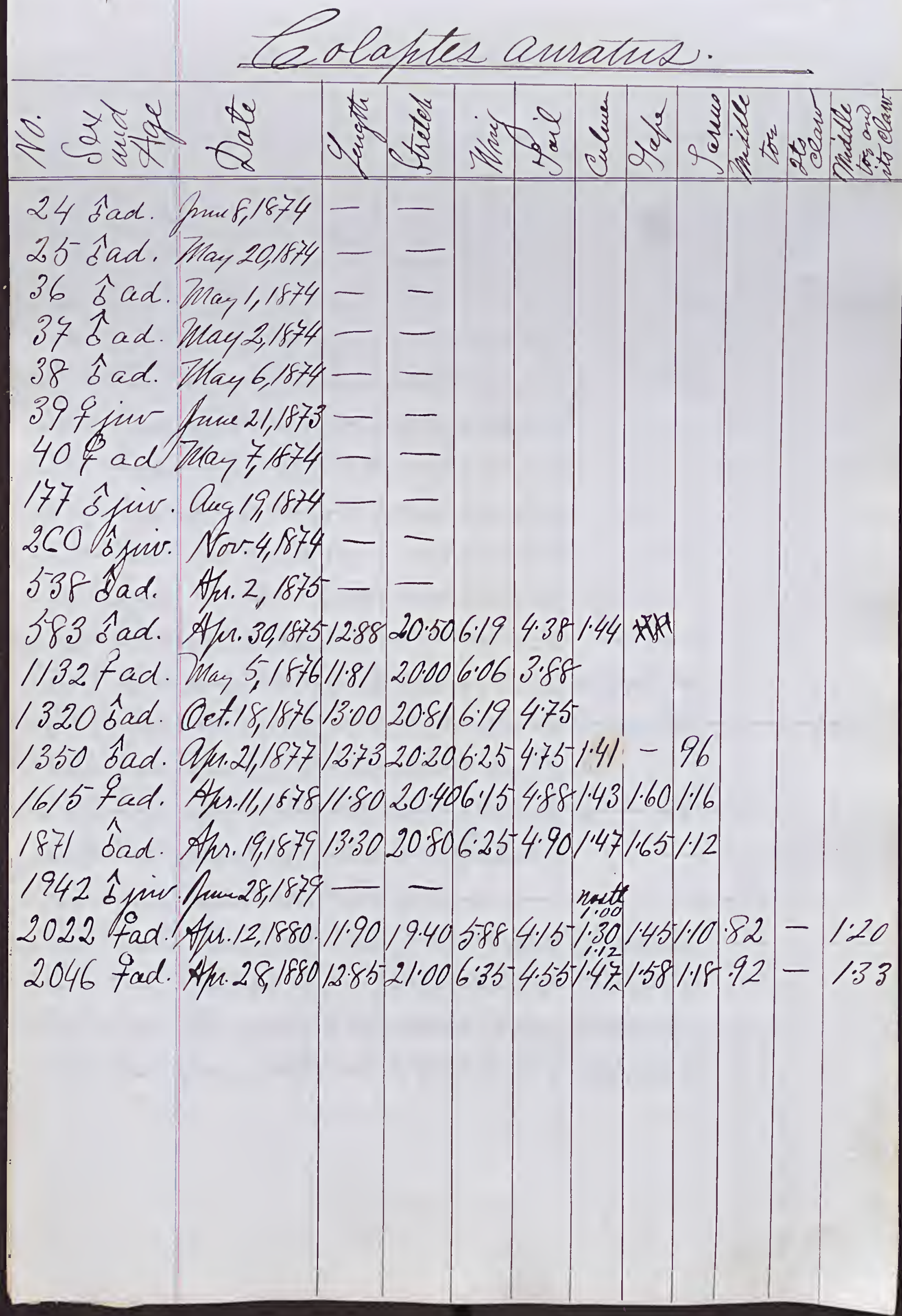




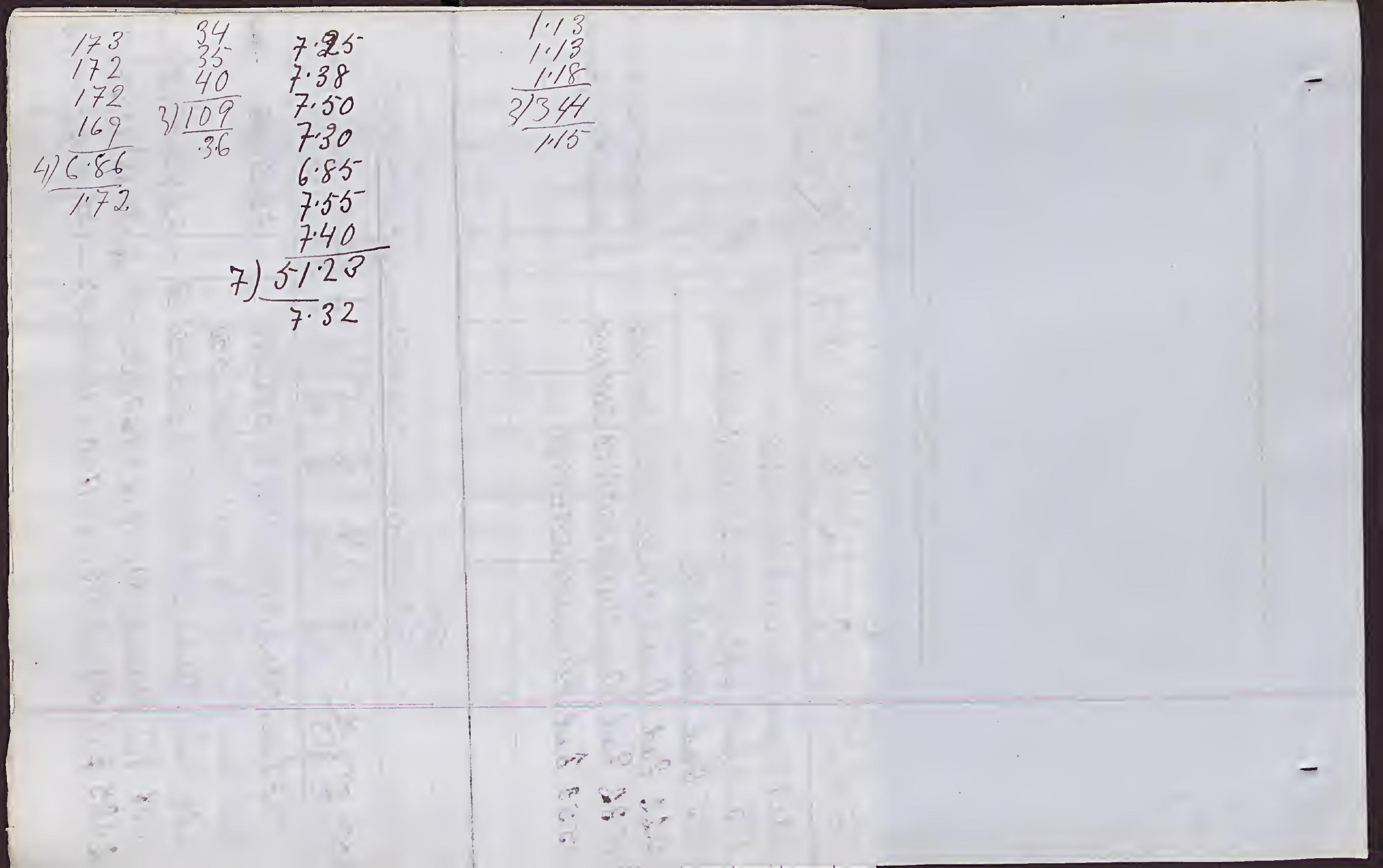




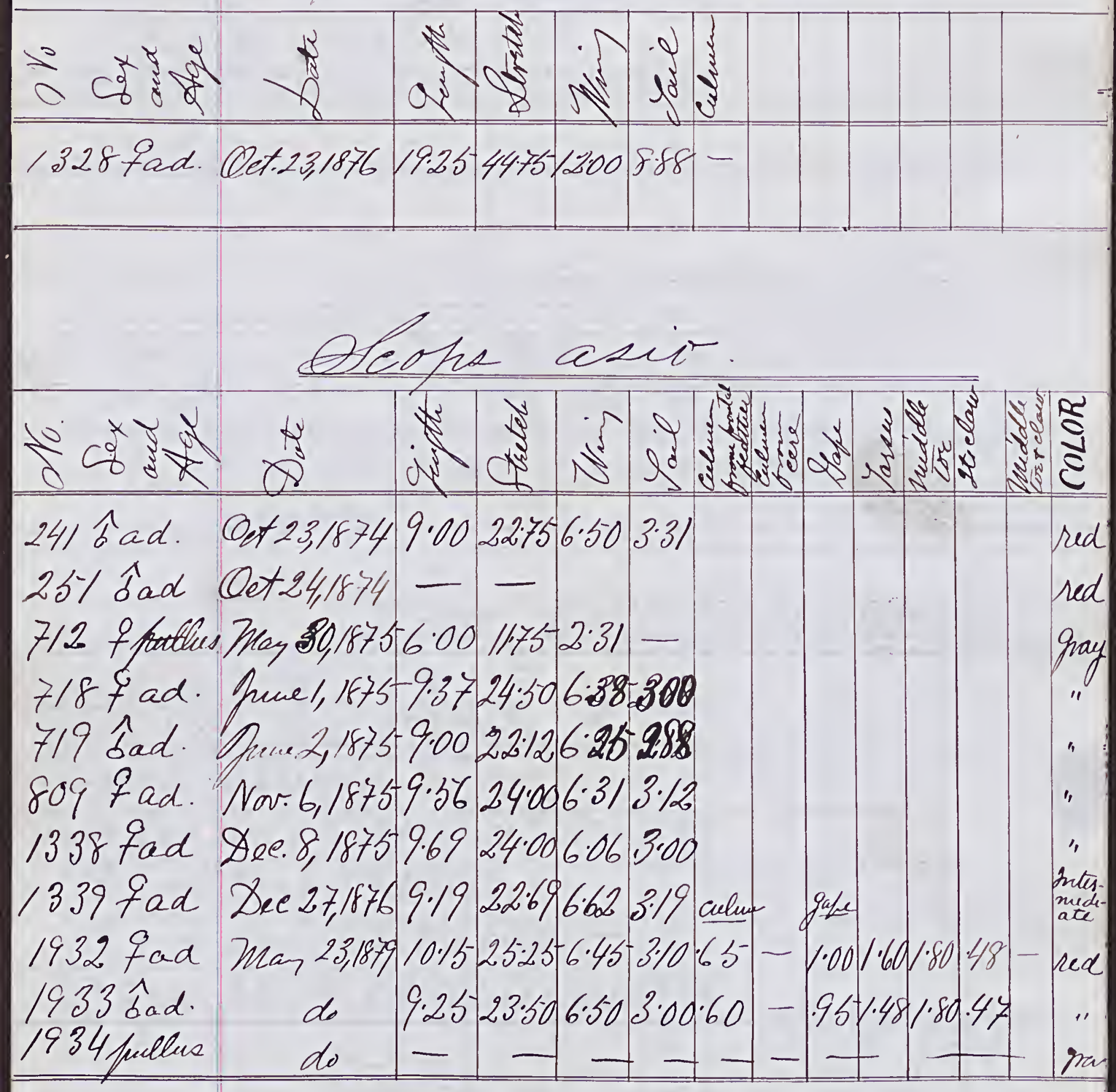

Qtus vulgaris wilsonianus.

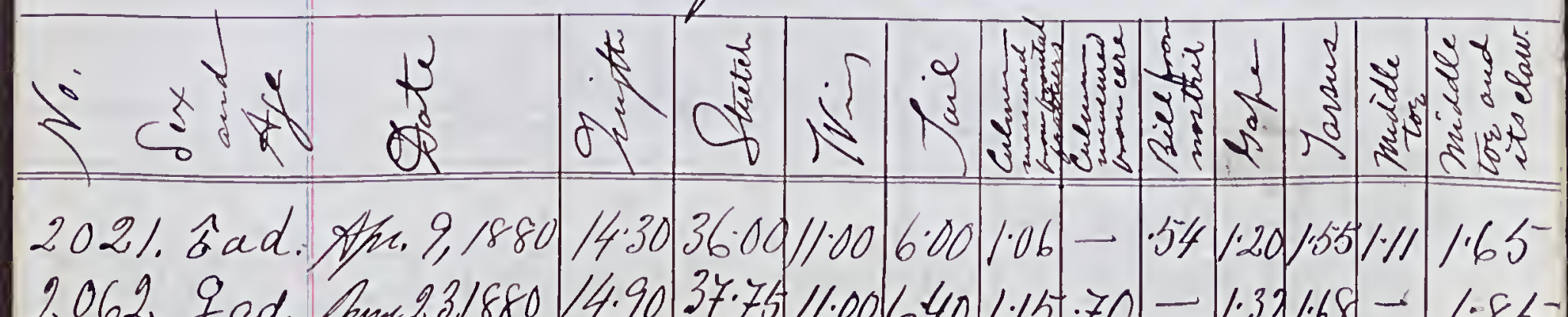

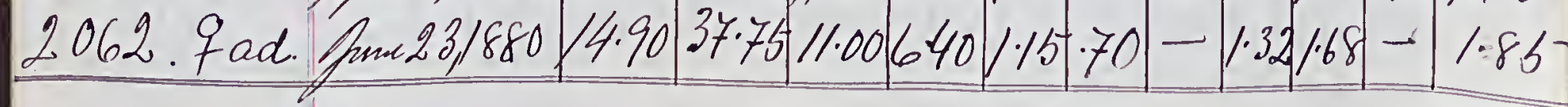


Subo virginamus, Bonafuete.

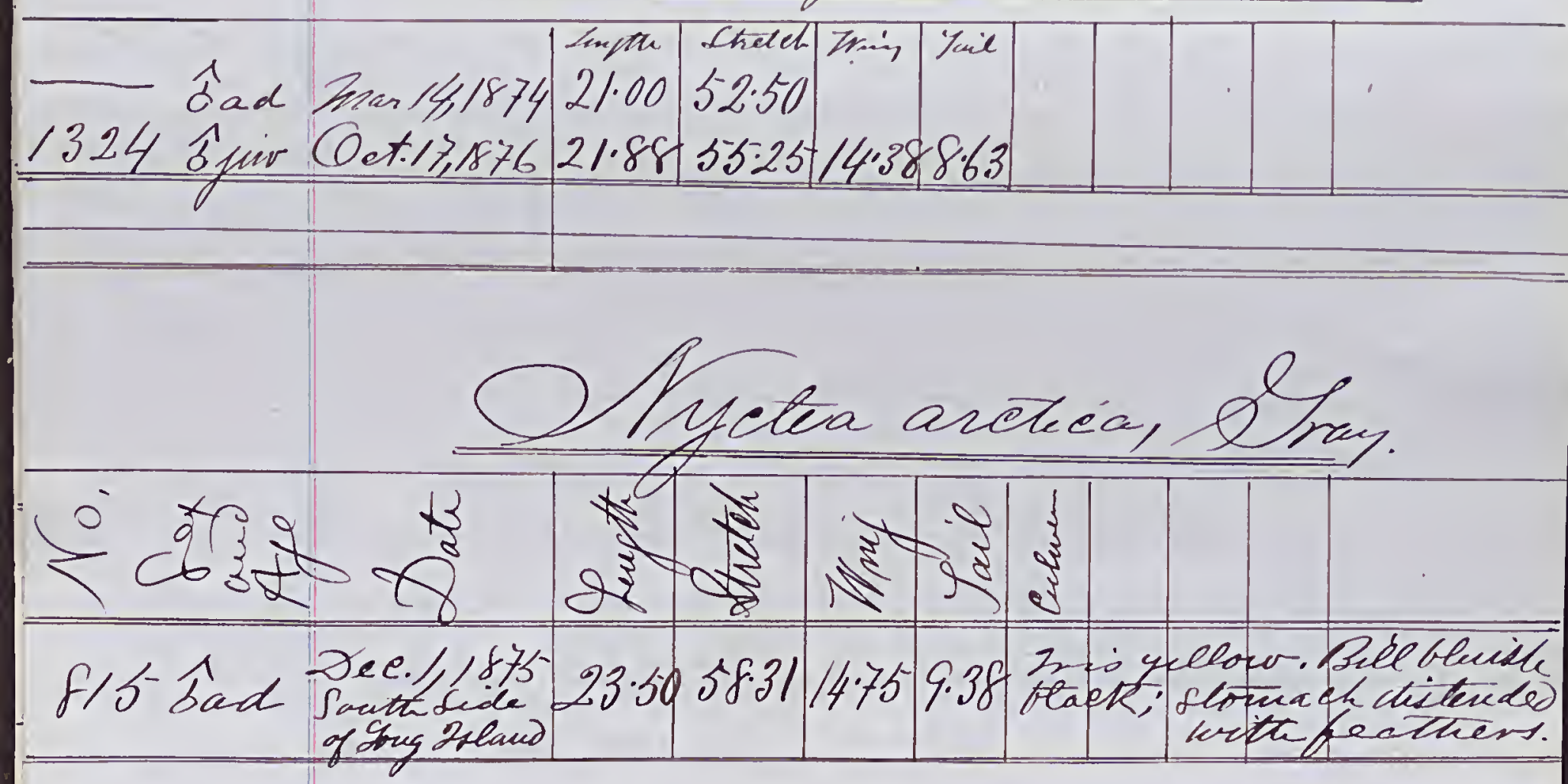

Tandion haliāectus cardinensit

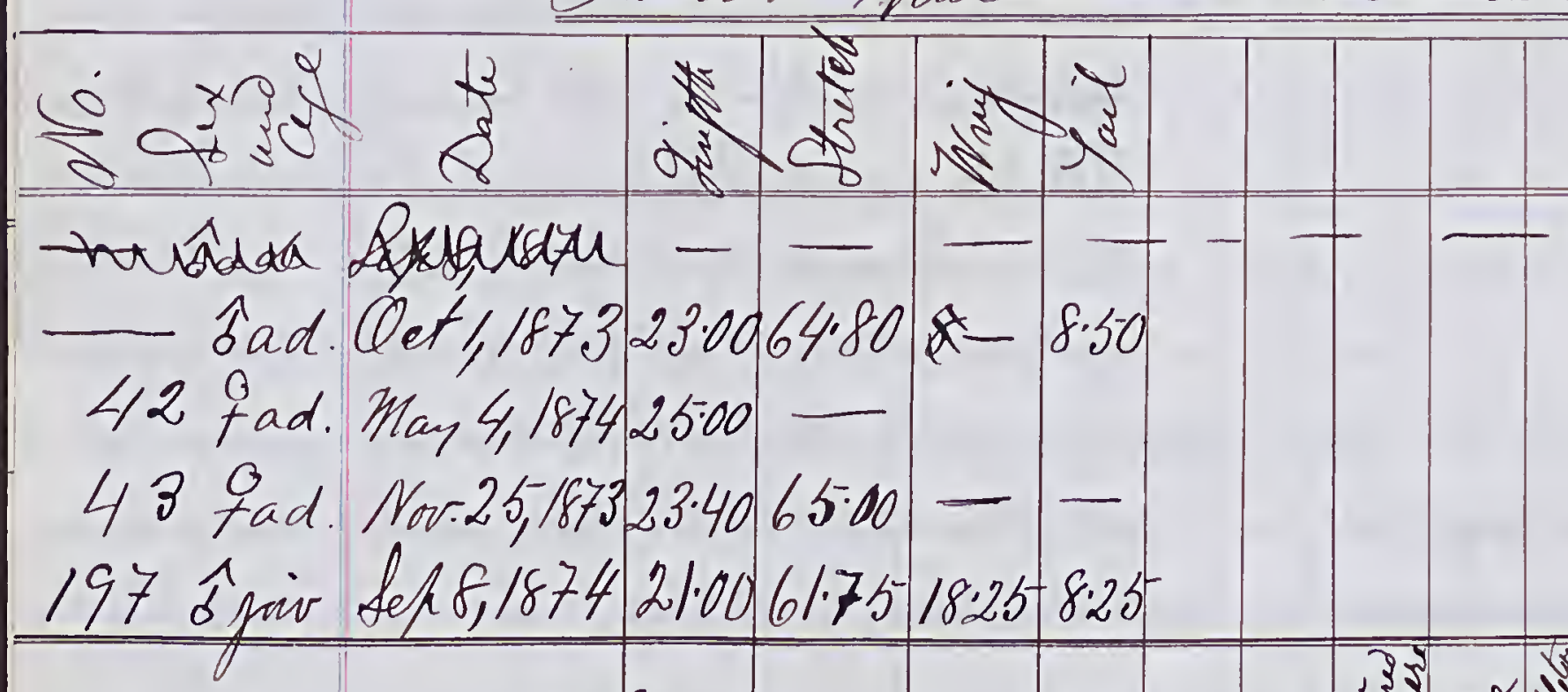

Saled Afawrruid.

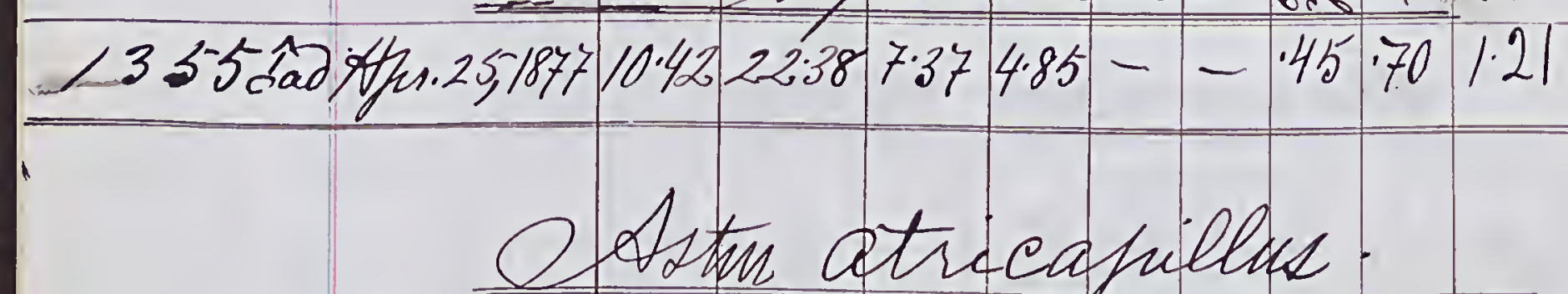

Astur atricafillus.

Cul gogatar. that claw

20057juir. Dee2,167923.75442:25-13.1011.00 9011402.881.81 77 
Dofcipiter cooperi.

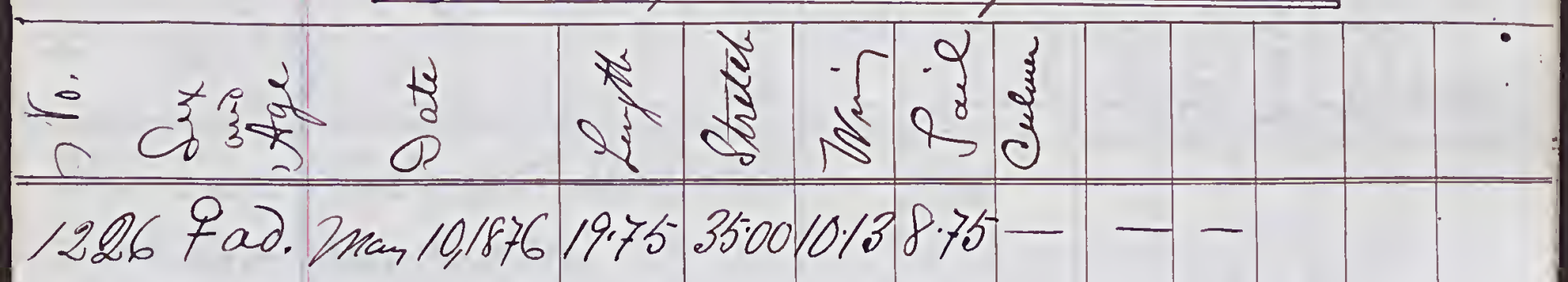

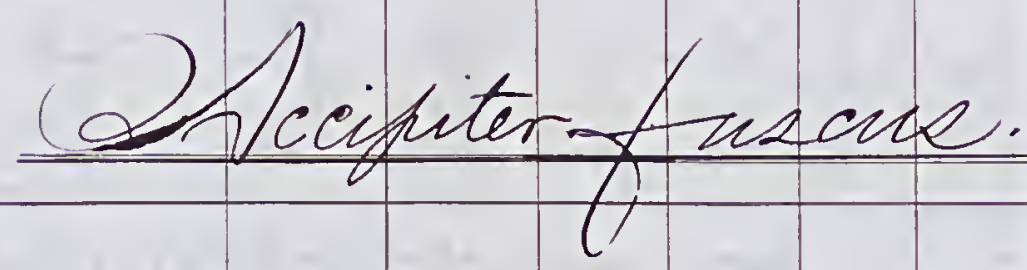

169 ôniv. Sep.4,187411.50 - -

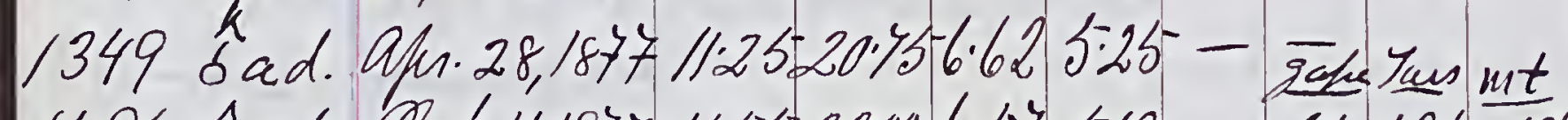

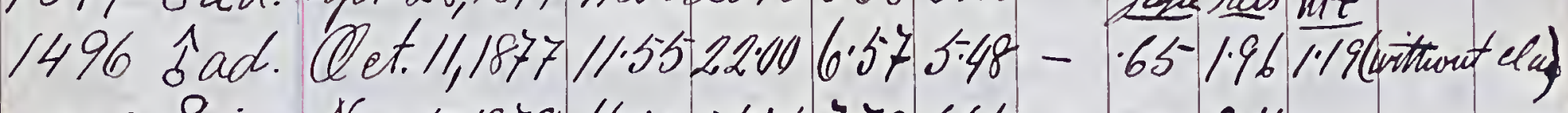

1802 fjur Nor.5,1878 14.0025,557,706.65 - 2.11

Buter pennsylianieus.

41 fad. Mar 4,1874. 14.88 37.3812.007.00

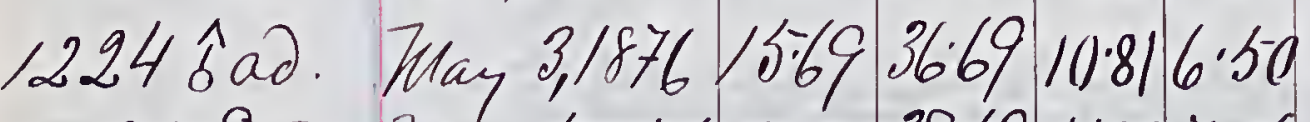

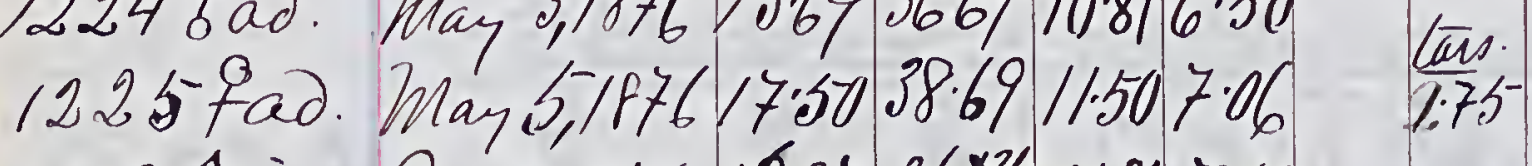

1229 ojuw. On. 17, 18761637367511.317 .011

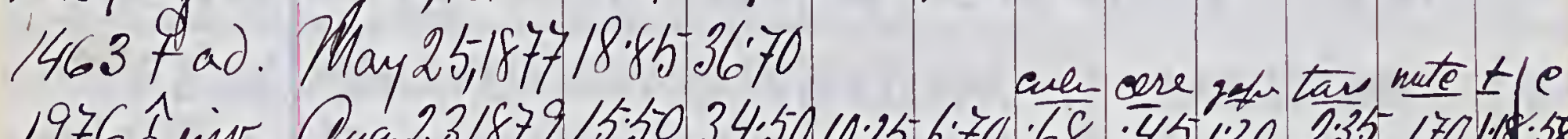

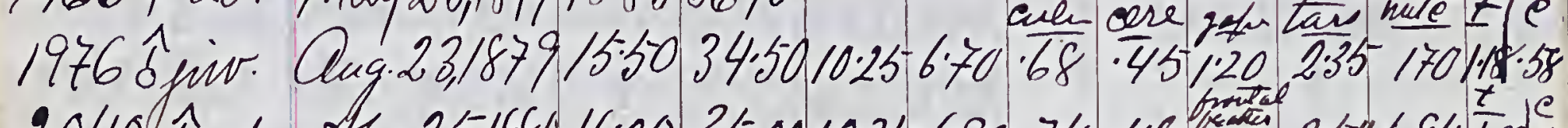

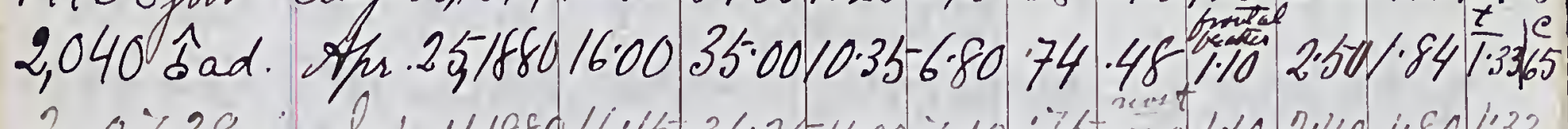

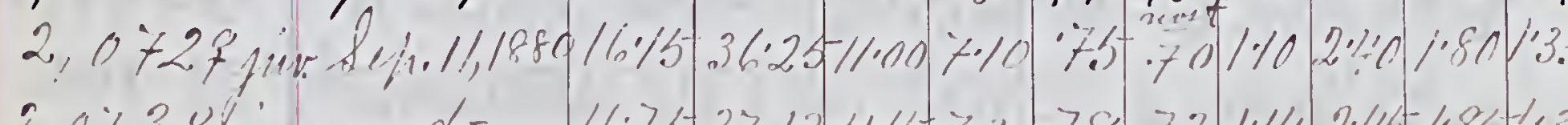

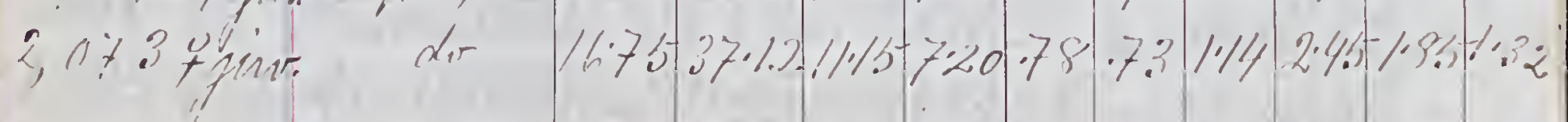


Ectoputes migratorins, Lu-

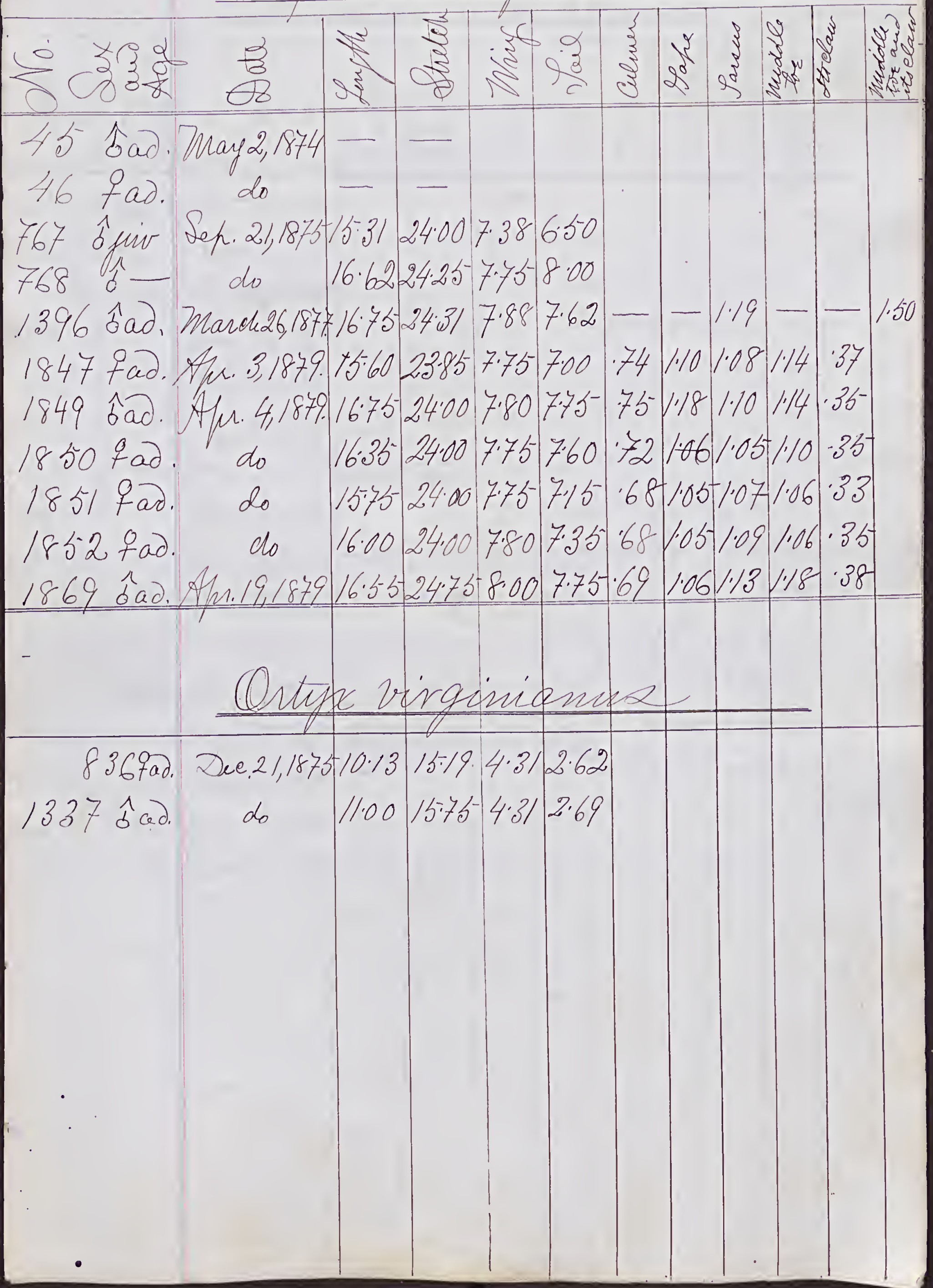


Conasa umbrelus.

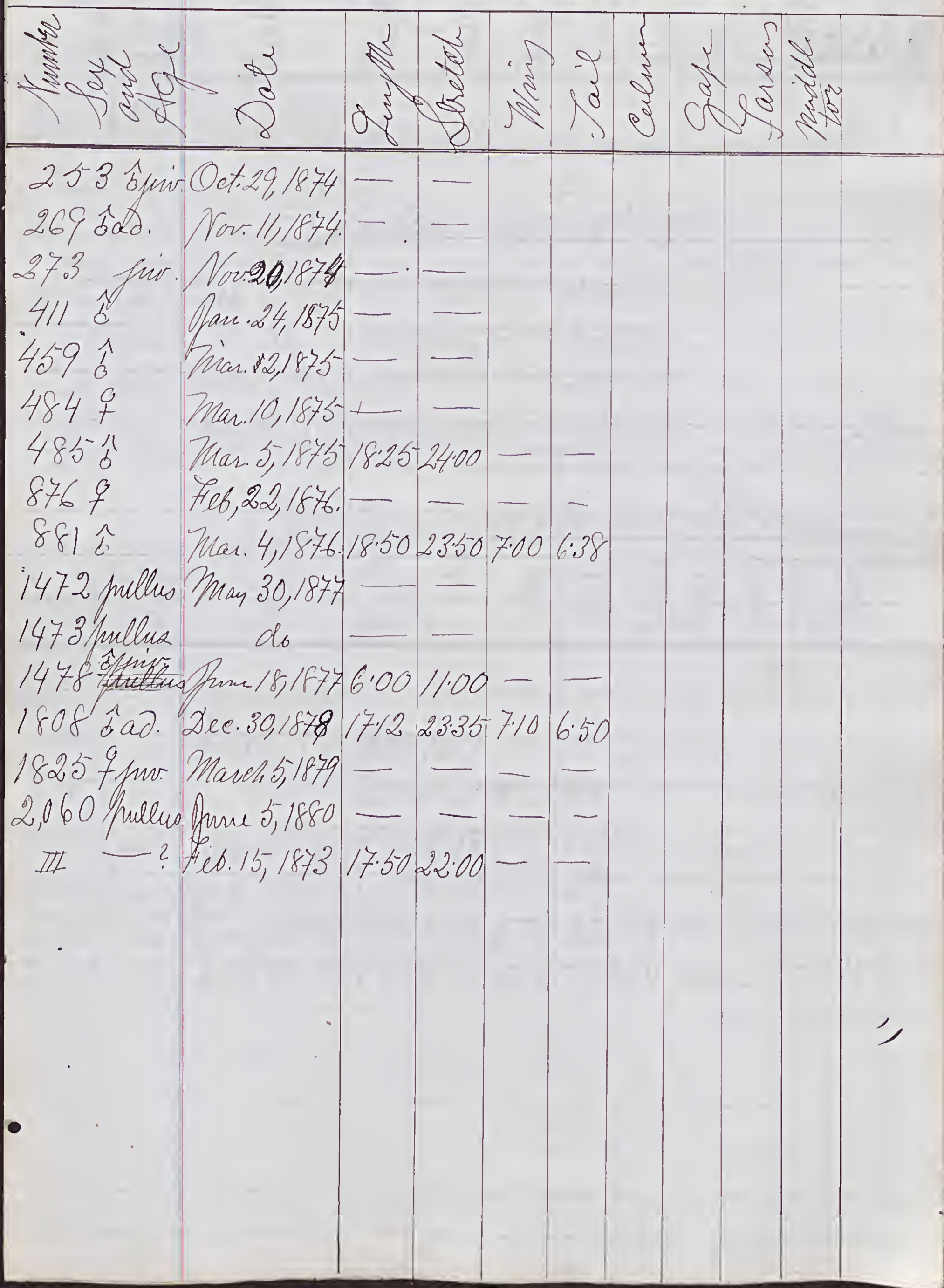


Pribhela mision:

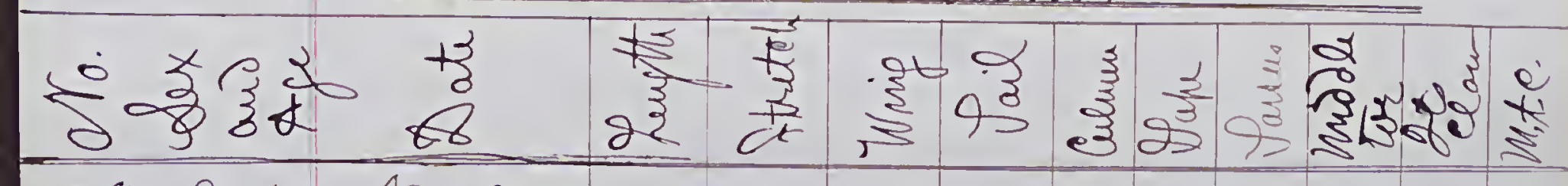

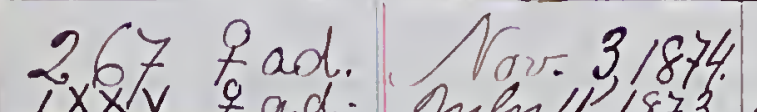

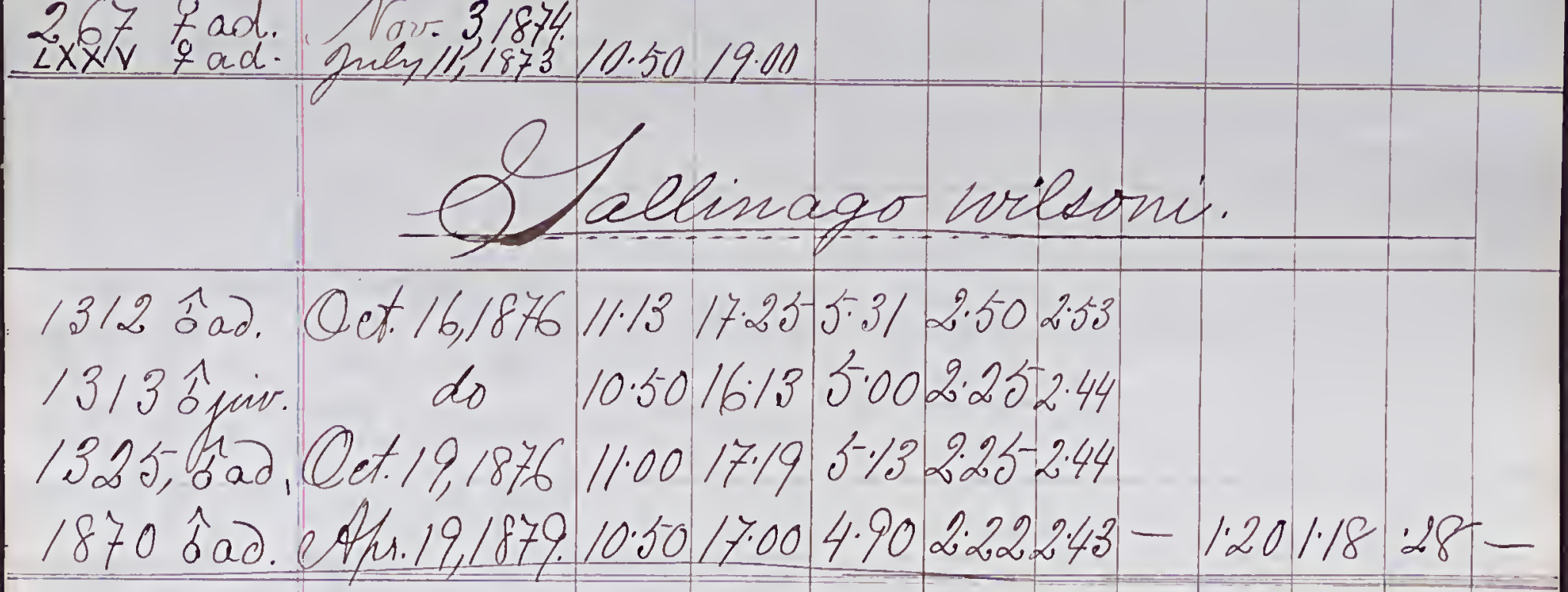

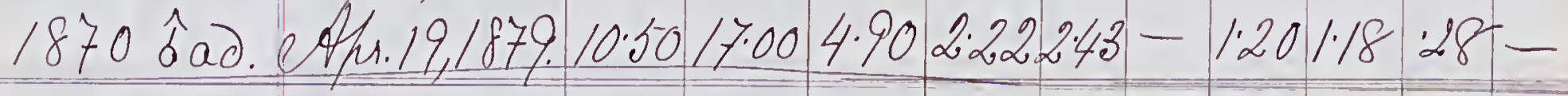

Botanus solitarims, Dileon.

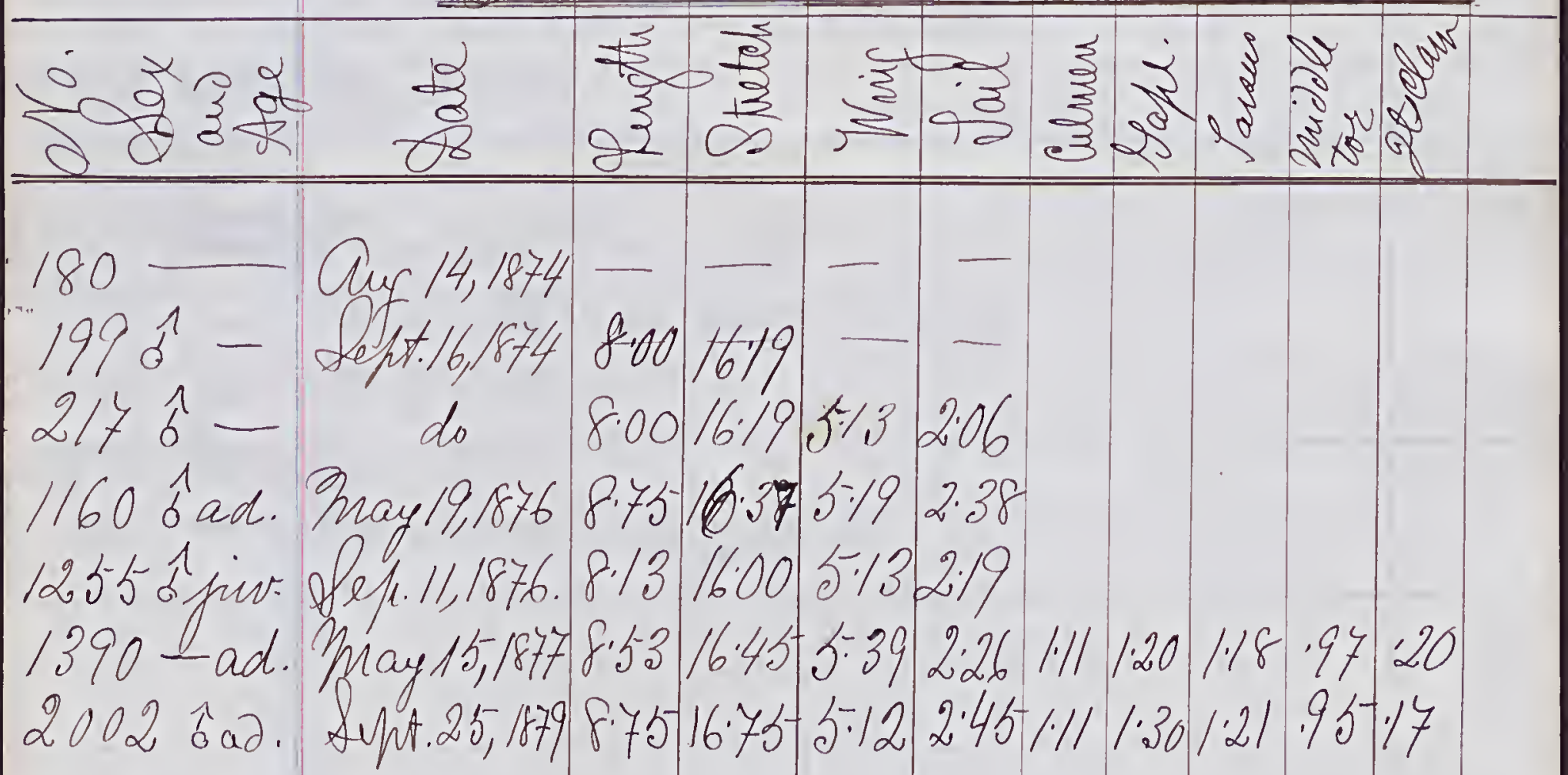



$\frac{\text { Dtrdea herodias }}{\text { D }}$

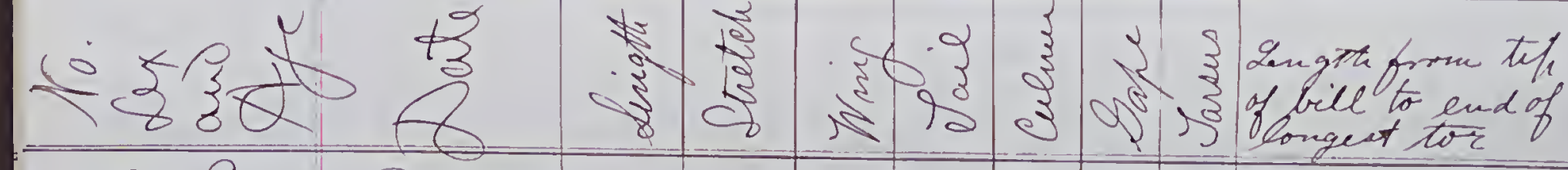

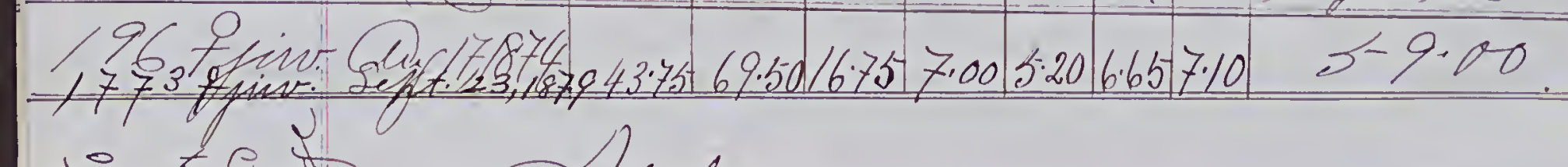

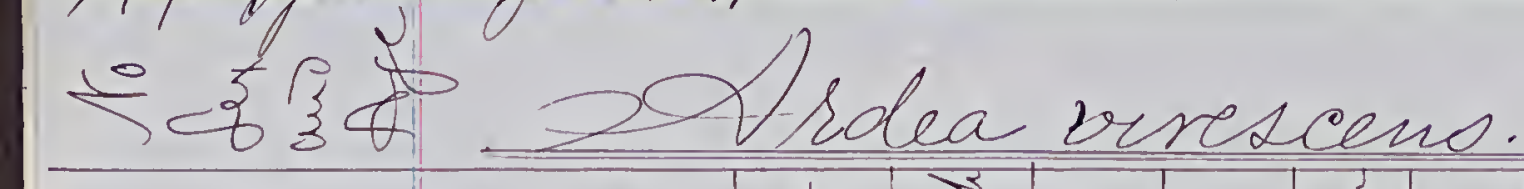

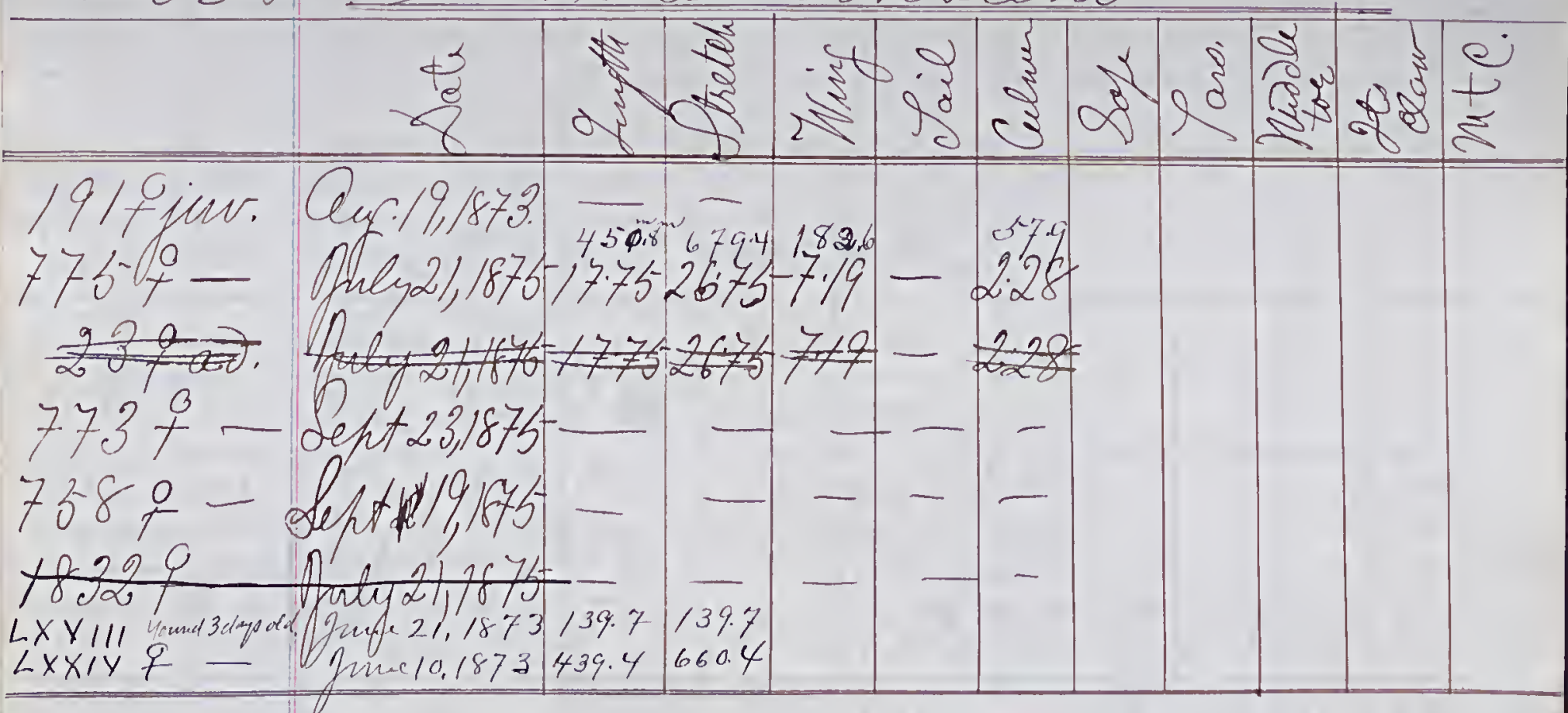


Poszana carolina.

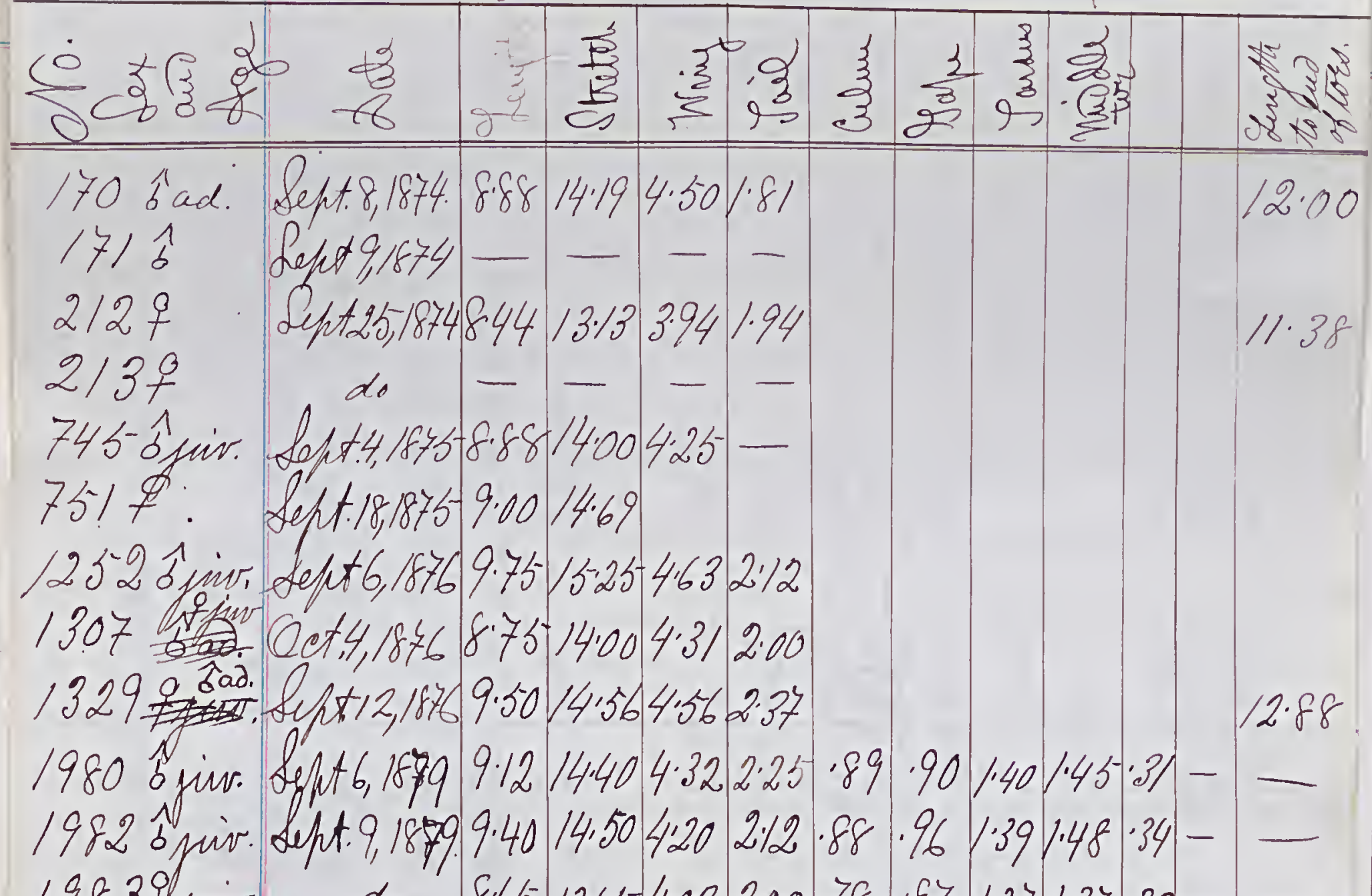

19839 jiv
83

800 îad. Qet.11,1875.14.50 26.007.19 1.94:2000

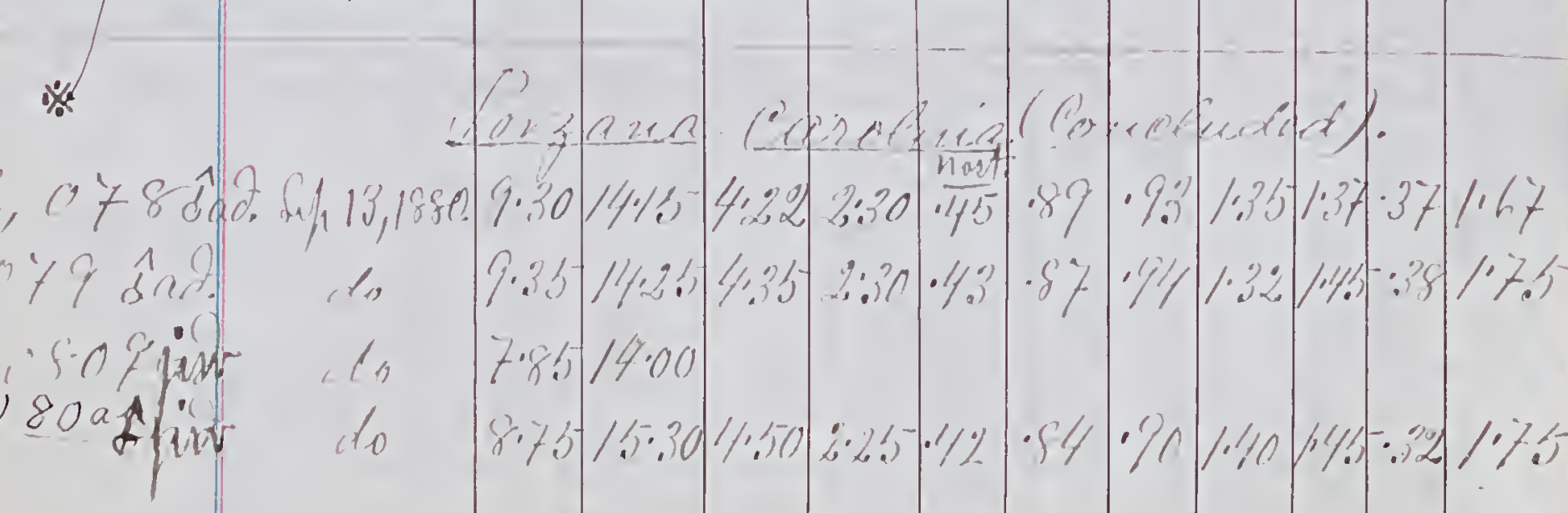




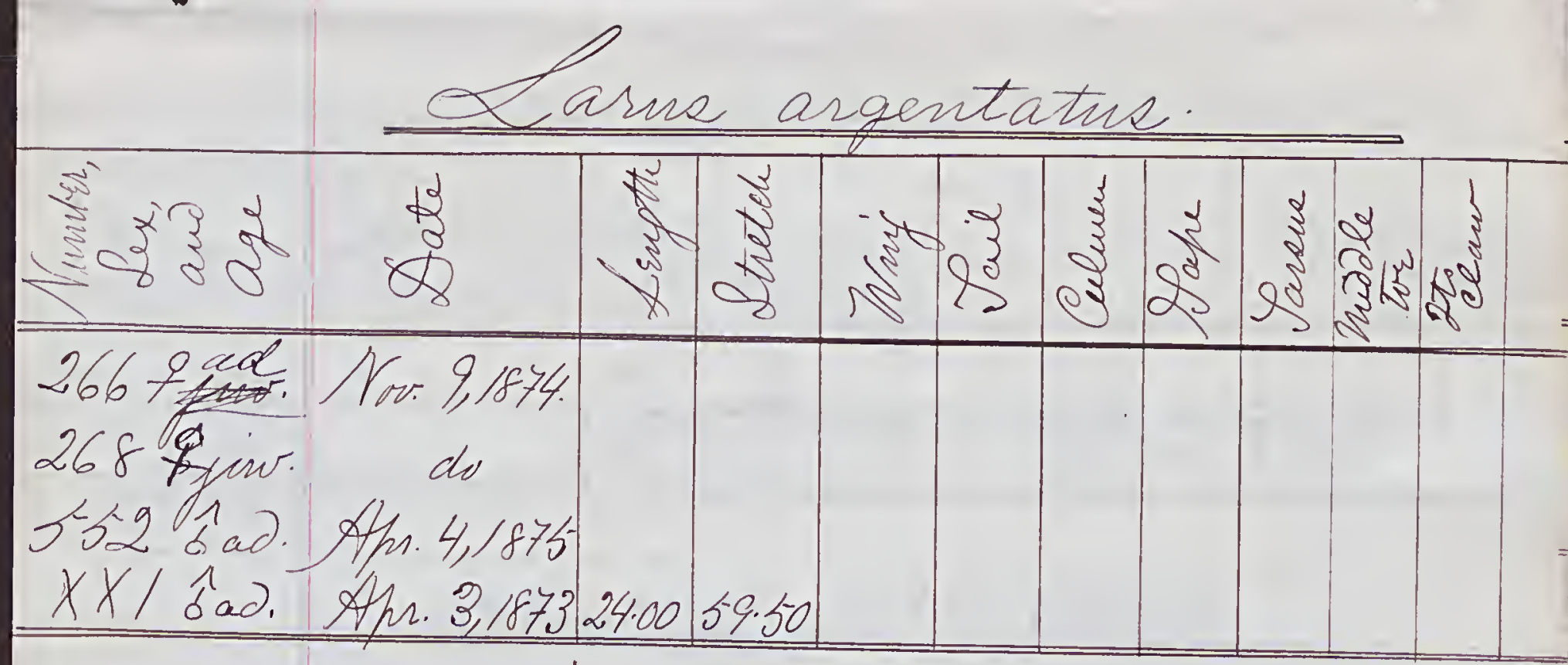

Lams hiladelphia.

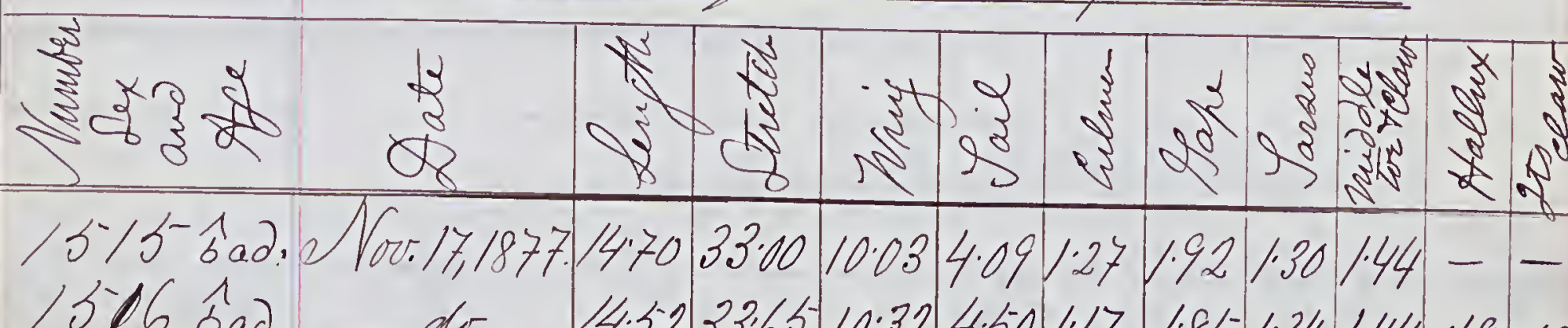

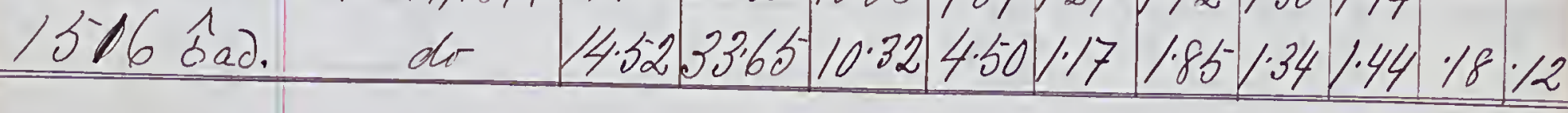

Sterna fuliqinota.

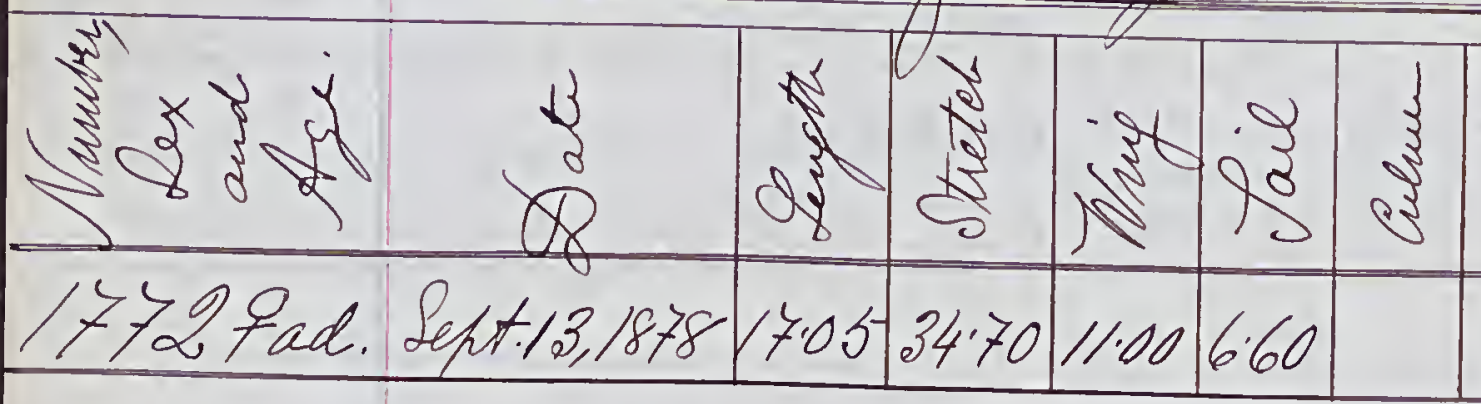

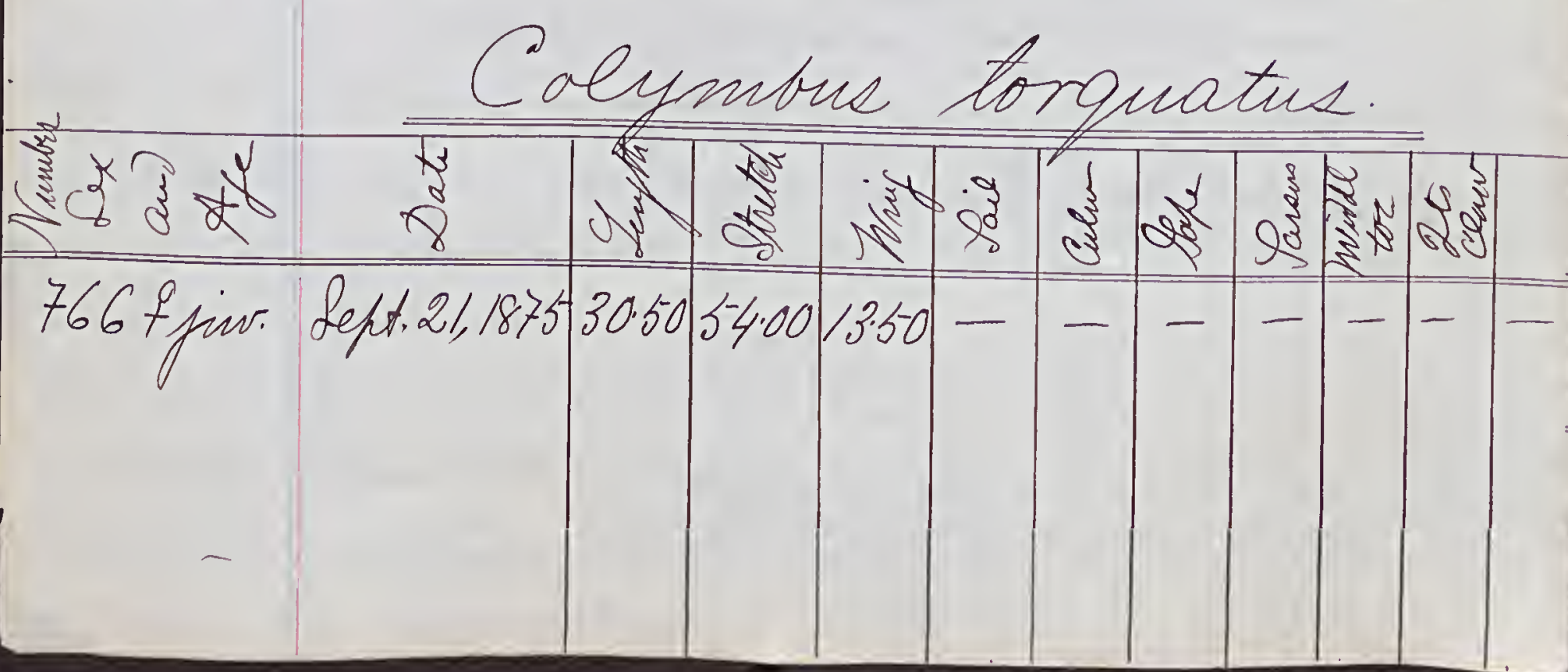


